\title{
Clinical and molecular genetic studies in hereditary cutaneous leiomyomatosis
}

Citation for published version (APA):

Badeloe, S. (2011). Clinical and molecular genetic studies in hereditary cutaneous leiomyomatosis. [Doctoral Thesis, Maastricht University]. Datawyse / Universitaire Pers Maastricht. https://doi.org/10.26481/dis.20110415sb

Document status and date:

Published: 01/01/2011

DOI:

10.26481/dis.20110415sb

Document Version:

Publisher's PDF, also known as Version of record

\section{Please check the document version of this publication:}

- A submitted manuscript is the version of the article upon submission and before peer-review. There can be important differences between the submitted version and the official published version of record.

People interested in the research are advised to contact the author for the final version of the publication, or visit the DOI to the publisher's website.

- The final author version and the galley proof are versions of the publication after peer review.

- The final published version features the final layout of the paper including the volume, issue and page numbers.

Link to publication

\footnotetext{
General rights rights.

- You may freely distribute the URL identifying the publication in the public portal. please follow below link for the End User Agreement:

www.umlib.nl/taverne-license

Take down policy

If you believe that this document breaches copyright please contact us at:

repository@maastrichtuniversity.nl

providing details and we will investigate your claim.
}

Copyright and moral rights for the publications made accessible in the public portal are retained by the authors and/or other copyright owners and it is a condition of accessing publications that users recognise and abide by the legal requirements associated with these

- Users may download and print one copy of any publication from the public portal for the purpose of private study or research.

- You may not further distribute the material or use it for any profit-making activity or commercial gain

If the publication is distributed under the terms of Article $25 \mathrm{fa}$ of the Dutch Copyright Act, indicated by the "Taverne" license above, 
Clinical and molecular genetic studies in hereditary cutaneous leiomyomatosis 
ISBN 9789461590398

(c) copyright Sadhanna Badeloe, Maastricht 2011

Cover design: Priya Badeloe

Printing: Datawyse / Universitaire Pers Maastricht 


\title{
Clinical and molecular genetic studies in hereditary cutaneous leiomyomatosis
}

\author{
PROEFSCHRIFT \\ ter verkrijging van de graad van doctor \\ aan de Universiteit Maastricht \\ op gezag van de Rector Magnificus Prof. mr. G.P.M.F. Mols \\ volgens het besluit van het College van Decanen, \\ in het openbaar te verdedigen \\ op vrijdag 15 april 2011 om 14.00 uur \\ door \\ Sadhanna Badeloe
}

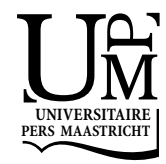




\section{Promotor}

Prof. dr. P.M. Steijlen

\section{Copromotoren}

Dr. J. Frank

Dr. M. van Geel

\section{Beoordelingscommissie}

Prof. dr. F.C.S. Ramaekers (voorzitter)

Dr. H.M. Hazelbag (MCH Den Haag)

Prof. dr. P.C.M. van de Kerkhof (UMC St. Radboud)

Prof. dr. J. G. Nijhuis

Prof. dr. C.T.R.M. Schrander-Stumpel

Financial support for printing this thesis was kindly provided by:

Abbott BV, Astellas Pharma BV, Bauerfeind, Beiersdorf NV, Galderma, Janssen-Cilag BV, La Roche-Posay, Leo Pharma BV, Meda Pharma BV, Medi Nederland BV, Merck Sharp \& Dohme BV, Pfizer BV, Vinger aan de Pols compressiekousen en bandages. 
Aan mijn ouders 



\section{Contents}

Chapter 2 Molecular basis of hereditary cutaneous leiomyomatosis

2.1 The spectrum of mutations in the fumarate hydratase gene in

diffuse and segmental variants of hereditary cutaneous

leiomyomatosis missense mutations in the fumarate hydratase gene

2.3 Absence of fumarate hydratase mutation in a family with cutaneous leiomyosarcoma and renal cancer

Chapter 3 Type 2 segmental manifestation in hereditary cutaneous leiomyomatosis

Chapter 4 Hereditary leiomyomatosis and renal cell cancer in the Netherlands: a nationwide study

Chapter 5 Wilms tumor in hereditary leiomyomatosis and renal cell cancer

\section{Chapter 6}

Discussion

Summary

Samenvatting

List of abbreviations

Curriculum vitae

List of publications

Dankwoord 



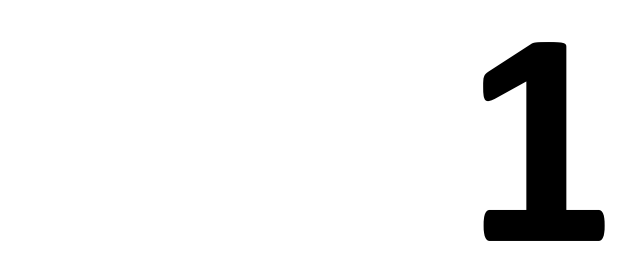

\section{General introduction}

S. Badeloe, Frank J. Clinical and molecular genetic aspects of hereditary multiple cutaneous leiomyomatosis. Eur J Dermatol. 2009 Nov-Dec;19(6):545-51 


\section{Introduction}

Leiomyomas of the skin were first described by Virchow in 1854 (1). Cutaneous leiomyomas are rare benign tumors arising from smooth muscle cells. According to their site of origin they can be classified into three types, i) those derived from the arrector pili muscle of hair follicles (piloleiomyomas); ii) those originating from the vascular smooth muscle (angioleiomyomas); and iii) those arising from the smooth muscle of genital skin (dartoic leiomyomas). Piloleiomyoma is the most common type among cutaneous leiomyomas $(1,2)$. In contrast to the mainly solitary angioleiomyomas and dartoic leiomyomas, piloleiomyomas predominantly manifest as multiple tumors, referred to as leiomyomatosis. In 1958 Kloepfer et al. described for the first time, in an Italian family with cutaneous leiomyomatosis, an autosomal dominant inheritance pattern with incomplete penetrance (3). Subsequently, different authors reported several families with autosomally dominant inherited cutaneous leiomyomatosis (4-6). Furthermore, in some of these families, affected female individuals also exhibited uterine leiomyoma $(4,6)$. In 1973, Reed et al. were the first to emphasize the association with leiomyoma of the uterus and, therefore, this syndrome was known as Reed's syndrome for many years (7). Currently this syndrome is referred to as multiple cutaneous and uterine leiomyomatosis syndrome (MCUL; OMIM 150800). In 2001, Launonen et al. reported that a small proportion of families with MCUL also cluster renal cell cancer (RCC) (8). The latter disease variant is referred to as hereditary leiomyomatosis and renal cell cancer (HLRCC; OMIM 605839). In 2002, Tomlinson et al. showed that germline mutations in the fumarate hydratase $(\mathrm{FH})$ gene underlie hereditary cutaneous leiomyomatosis and its associated features (9).

\section{Clinical features}

\section{Cutaneous leiomyomas and leiomyosarcoma}

Cutaneous leiomyomas typically present in the second to fourth decade of life as skin colored or brown-reddish grouped papules or nodules localized on the trunk and limbs (figure 1a). These benign tumors are characteristically painful in response to pressure or low temperature. While the exact pathophysiological origin of pain in leiomyomas has not yet been elucidated, different authors have proposed theories, including contraction of smooth muscle cells, compression or invasion of cutaneous nerve bundles, and an increased number of nerve elements within the tumors (2, 10-16). Leiomyomas gradually increase in size and number and the extent of the skin lesions is variable, even within one family. Some patients suffer from extensive disease, with multiple leiomyomas covering large areas of the body, whereas others 
only have a few inconspicuous papules. Interestingly, multiple cutaneous leiomyomas do not exclusively manifest in a diffuse and symmetric fashion (figure 1b). Rather frequently, a segmental or band-like manifestation pattern of these tumors can be observed, most likely reflecting mosaicism (17-39) (figure 1c).

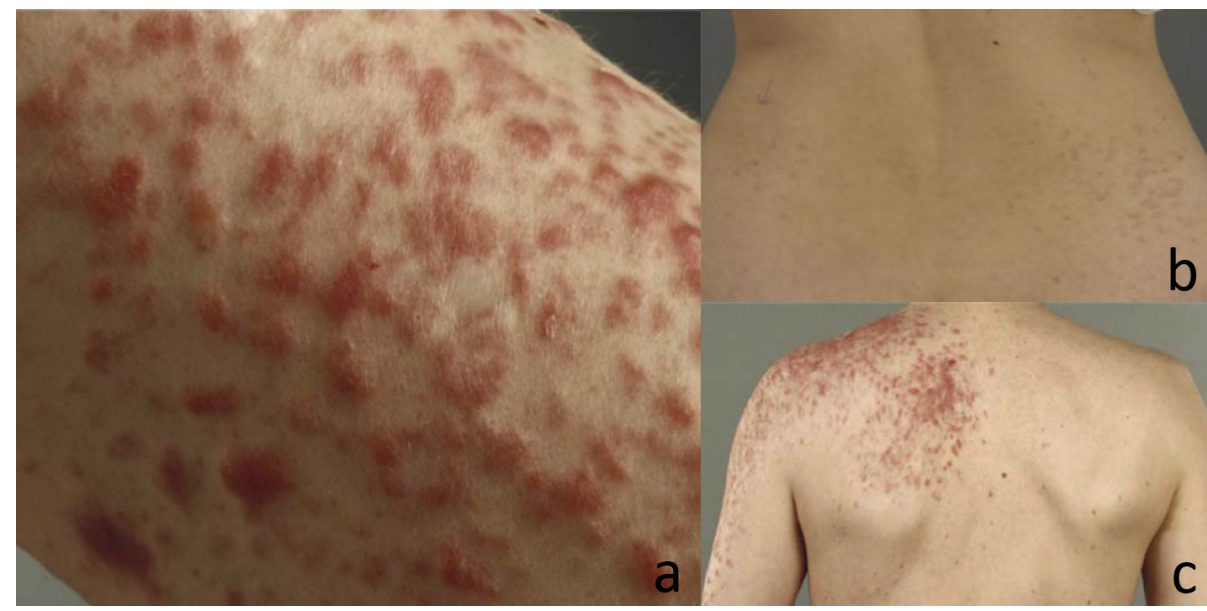

Figure 1a) Multiple cutaneous leiomyomas on the forearm; b) Multiple cutaneous leiomyomas diffuse and symmetric distribution on the lower back; c) Multiple cutaneous leiomyomas distributed in a segmental fashion on the back.

Already 12 years ago, Happle postulated a genetic concept for the segmental manifestation of dominantly inherited skin diseases (23). Whenever the segmental skin lesions reveal the same degree of severity as that found in the corresponding nonmosaic trait and a germline mutation is absent, a type 1 segmental involvement is present. Occasionally, however, the severity of cutaneous involvement observed in the segmentally affected skin areas is far more pronounced. Happle suggested that this phenomenon can be explained by loss of heterozygosity (LOH) at the same locus that caused the phenotypically less severe, diffuse involvement (23). Although the type 2 segmental manifestation is usually only rarely observed, he noted that in cutaneous leiomyomatosis the type 2 segmental manifestation occurs rather frequently. Recently, the hypothesis for the type 2 segmental manifestation of autosomal dominant skin disorders has been confirmed on the cellular and molecular level in Hailey-Hailey disease (40). In hereditary cutaneous leiomyomatosis though, this concept has not yet been demonstrated to be valid.

Malignant transformation of cutaneous leiomyoma is rare. However, two cases of cutaneous leiomyosarcoma in two different, apparently unrelated families with hereditary cutaneous leiomyomatosis and renal cell cancer (HLRCC) have been reported $(41,42)$. 


\section{Uterine leiomyomas and leiomyosarcoma}

Uterine leiomyomas occur in more than $90 \%$ of females with MCUL. These patients may have a medical history of menorrhagia and pelvic pressure or pain, frequently requiring a hysterectomy before the age of 30 years (43). A minority of patients with MCUL/HLRCC are predisposed to the development of highly aggressive uterine leiomyosarcoma before the age of 30 . Interestingly, this disease variant has only been observed in the Finnish population to date $(8,44,45)$.

\section{Renal cancer}

Type 2 papillary RCC is the predominant type of kidney cancer in HLRCC (46). These tumors tend to be very aggressive. Metastases are seen in more than $50 \%$ of affected individuals, even in those with relatively small primary tumors. Furthermore, sporadic cases of collecting duct carcinoma, oncocytoma, and clear cell carcinoma have been described (46). Recently, we described a patient with cutaneous and uterine leiomyoma carrying a heterozygous $F H$ mutation who also had a history of a metastasizing Wilms tumor (WT) at the age of 2 years (47). RCCs in HLRCC are typically solid and unilateral, although in exceptional cases bilateral renal tumors have been reported $(46,48)$.

\section{Other associated tumors}

Infrequently, a broad range of other benign and malignant tumors has also been observed in MCUL/HLRCC families, including breast carcinoma, prostate carcinoma, bladder carcinoma, testis Leydig cell tumors, cerebral cavernomas, ovarian and kidney cysts, and adrenal gland adenomas (48-53). Some of these tumors showed biallelic $\mathrm{FH}$ inactivation, indicating that they are associated with MUCL/HLRCC. However, the majority of tumors observed in these families most probably occurred by coincidence and, thus, it seems rather unlikely that they are pathogenetically associated with hereditary cutaneous leiomyomatosis.

\section{Histopathological findings}

\section{Cutaneous leiomyomas and leiomyosarcoma}

Piloleiomyomas are poorly circumscribed lesions consisting of interlacing bundles of smooth muscle fibers intermingled with varying amounts of collagen bundles (figure 2a). The neoplasms are located in the dermis and may encroach upon the subcutaneous tissue. The smooth muscle fibers usually show an eosinophilic cytoplasm with 
typical cigar shaped nuclei (figure $2 \mathrm{~b}$ ). Immunohistochemistry reveals positive staining with anti-desmin and anti- $\alpha$-smooth muscle actin (10) (figure $2 c$ ).

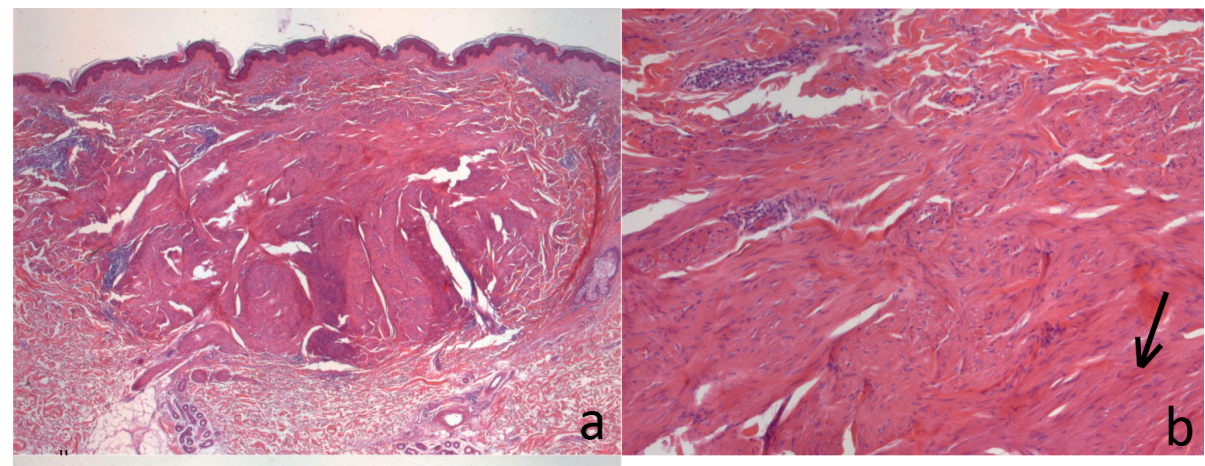

Figure 2. Histological picture of a cutaneous piloleiomyoma, consisting of interlacing bundles of smooth muscle fibers intermingled with varying amounts of collagen bundles (hematoxylin and eosin:) a) $\times 25$; b) $\times 100$ (cigar shaped nuclei are depicted with an arrow); (anti-smooth muscle antibodies) c) $\times 25$.

Similarly to cutaneous leiomyomas, cutaneous leiomyosarcoma show a poorly demarcated dermal tumor composed of proliferative bundles of spindle cells intermingled with collagen fibers with positive immunohistochemical staining for anti- $\alpha$ smooth muscle actin and desmin. Additionally, however, mitotic figures and atypical cells are present (10).

\section{Uterine leiomyomas and leiomyosarcoma}

Uterine leiomyomas are characterized by whirled bundles of elongated smoothmuscle cells that are closely packed so that the tumor appears to be more cellular. The nuclei of cells are elongated and uniform. Mitosis figures are absent or sparse (54). In contrast, uterine leiomyosarcoma show mitotic activity, nuclear atypia, and tumor necrosis (55). 


\section{Renal cancer}

Type 2 papillary RCC is characterized by a papillary growth pattern with thick, lengthened papillae. The cells lining the papillae are large with abundant cytoplasm and display a high Fuhrman nuclear grade ( 3 or 4) with large and prominent "owleye-like" nuclei $(8,46,56,57)$. Furthermore, tubulo-papillary, tubular, and cystic growth patterns can be found in HLRCC related kidney malignancies. Recently, Merino et al. reviewed 40 RCCs from HLRCC patients. According to their observations, the hallmark of these tumors is the presence of large eosinophilic nucleoli with a clear perinuclear halo, regardless of the prevailing histological pattern. Moreover, they state that this feature is not only seen in the majority of the tumor cells but is unique to HLRCC kidney tumors (46). Although a specific immunophenotype has not yet been established for HLRCC-associated renal tumors, absent expression of cytokeratin 7 (CK7) and Ulex europeaus agglutinin (UEA-1) may support the diagnosis (46). Utilization of FH antibodies could also contribute to the diagnosis of an HLRCCrelated malignant tumor.

\section{Diagnosis}

All patients with a tentative diagnosis of cutaneous leiomyomatosis should be examined by a dermatologist. To exclude the differential diagnoses of eruptive syringoma, neurofibroma, neurinoma or eccrine spiradenoma, a biopsy for histopathological examination must be obtained to confirm the diagnosis because the histological features of cutaneous leiomyomas are highly specific and will help to differentiate it from other tumors with similar clinical appearances. In a patient with histologically confirmed cutaneous leiomyomas, taking a detailed family history is mandatory to identify putative relatives at risk and arrange for genetic counseling and additional screening for uterine leiomyomas and kidney cancer. DNA mutation analysis of the $\mathrm{FH}$ gene is compulsory in order to confirm the diagnosis on the molecular genetic level and should nowadays be considered as a state-of-the-art diagnostic technique.

\section{Gene and function}

In 2001, Alam and colleagues reported linkage of MCUL to chromosome 1q42.3-q43 $(32,58)$. Subsequently, heterozygous germline mutations in the fumarate hydratase (FH) gene were detected in both MCUL and HLRCC, confirming that these disorders are allelic $(9,41)$. The $F H$ gene spans $22 \mathrm{~kb}$ and contains 10 exons. To date, approximately 73 different mutations distributed throughout the $\mathrm{FH}$ gene have been 
reported in cutaneous leiomyomatosis $(9,19,20,26,31,41,42,45,48-53,59-73)$. These sequence deviations include missense, nonsense, frameshift, and splice-site mutations as well as whole gene and exonic deletions and, together, demonstrate the molecular heterogeneity associated with disorders caused by $F H$ mutations (figure 3).

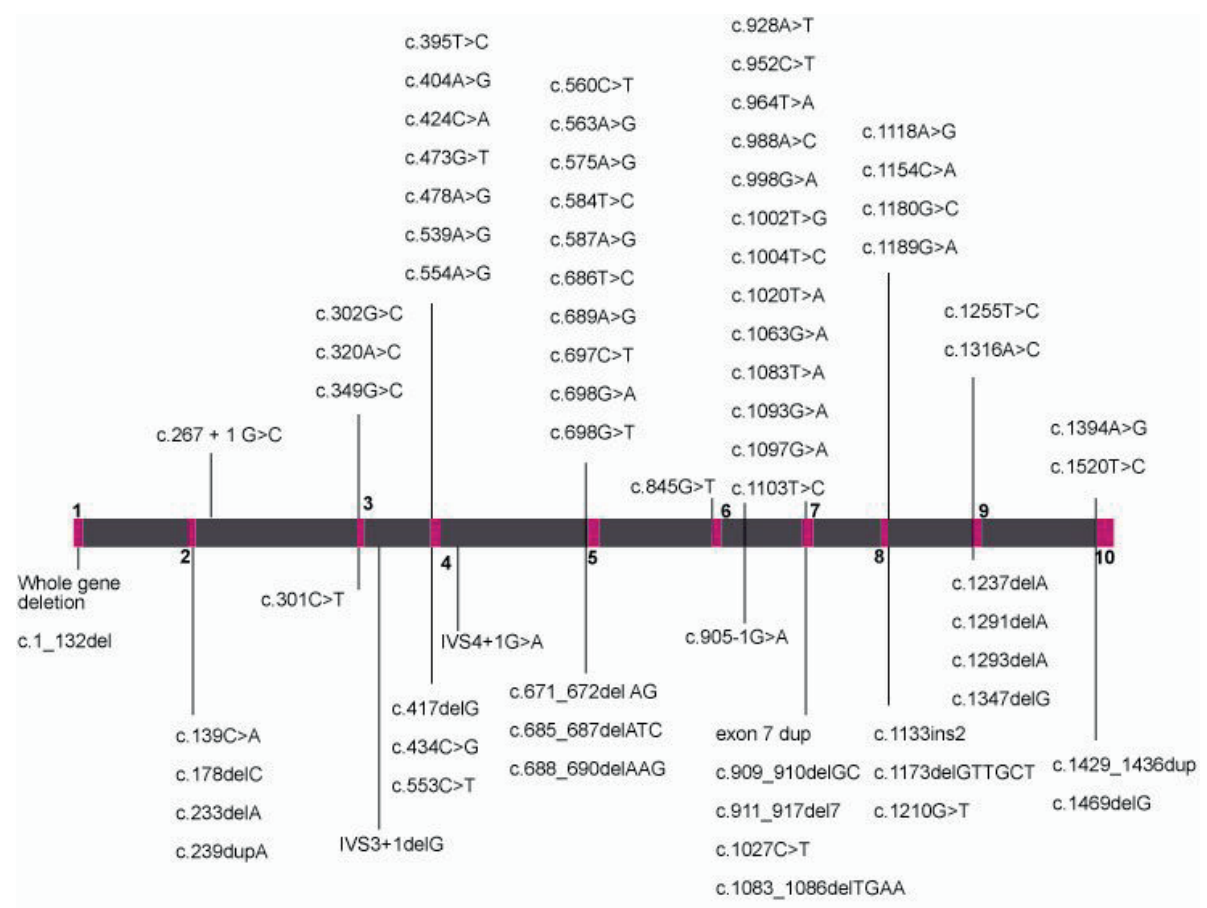

Figure 3. Germline fumarate hydratase gene mutations reported in cutaneous leiomyomatosis to date.

Currently, there is no strong evidence for a putative genotype-phenotype correlation in cutaneous leiomyomatosis. Previous reports suggested that $F H$ mutations occurring at $5^{\prime}$ of codon 250 of $F H$ could be associated with an increased risk of developing renal cell cancer (9). However, a subsequent study from Toro et al. showed that only $55 \%$ of $F H$ mutations in HLRCC were indeed located at 5 ' of codon 250 , a notion that was confirmed by Wei et al. who reported on $F H$ mutations distributed over the entire gene in HLRCC families. Of these mutations, only a few were located upstream of codon 250 of $F H(41,42)$. In addition, there are no reports on families in which more than one individual developed kidney cancer. Therefore, a heterozygous germline mutation alone is most likely not sufficient to give rise to renal cancer, suggesting an important role of additional genetic inactivation by, e.g. $\mathrm{LOH}$ or a second hit mutation in the development of kidney cancer. 
Homozygous or compound heterozygous $\mathrm{FH}$ germline mutations cause autosomal recessive fumarate hydratase deficiency (FHD) (OMIM 136850), a severe metabolic disease characterized by neurological impairment and encephalopathy (74). To date, neither the occurrence of leiomyomas nor renal cancer has been reported in individuals affected with FHD. This may be due to the fact that most individuals suffering from FHD only live a few months and do not reach early adulthood (74).

$\mathrm{FH}$ encodes for the enzyme fumarate hydratase $(\mathrm{FH})$ that catalyzes the conversion of fumarate to malate in the Krebs cycle (9). FH is thought to act as tumor suppressor since loss of the wild-type allele has been found in cutaneous, uterine, and renal tumors of patients with MCUL and $\operatorname{HLRCC}(9,41)$. Furthermore, enzymatic FH activity was low or absent in tumors from affected individuals (75).

The exact mechanism by which improper FH function leads to tumor formation has not yet been defined. However, recent studies suggest a pseudohypoxic drive in the pathogenesis of tumors in $\operatorname{HLRCC}(76,77)$. Considering the position of the enzyme in the Krebs cycle, loss of mitochondrial $\mathrm{FH}$ leads to an intracellular accumulation of fumarate. Elevated intracellular levels of fumarate have been shown to stabilize the transcription factors hypoxia-inducible factor (HIF-1 $\alpha$ and HIF-2 $\alpha$ ) (77). HIF proteins are key regulators of oxygen homeostasis and act via transcriptional regulation of anti-apoptotic and proliferative genes, such as vascular endothelial growth factor (VEGF), platelet derived growth factor (PDGF), endothelial growth factor receptor (EGFR), glucose transporter protein 1 (Glut-1), and transforming growth factor- $\alpha$ (TGF- $\alpha$ ). Overexpression of these gene products is associated with improved vascularity, autocrine stimulation, uncontrolled growth, and survival of the cell $(76,78$, 79). This phenomenon has been described as the "pseudohypoxia" and shows remarkable similarities with von Hippel Lindau (VHL) syndrome (80-82). Increased expression of HIF-1 $\alpha$, HIF- $2 \alpha$ and Glut- 1 was recently detected in kidney tumors from patients with HLRCC (77). Additional studies on leiomyomas occurring in the context of HLRCC revealed an enhanced expression of VEGF, further supporting the role of a pseudohypoxic drive as the link between mitochondrial $\mathrm{FH}$ dysfunction and tumor formation in HLRCC (76).

\section{Multidisciplinary management}

Genetic counseling of patients and their relatives should be self-evident. Once the diagnosis of hereditary cutaneous leiomyomatosis is made, affected individuals must be considered at risk for the occurrence of other tumors. Women with MCUL/HLRCC have a high chance of developing uterus leiomyomas at young age, often necessitating hysterectomy. Further, they have a slightly increased risk for the occurrence of highly aggressive uterine leiomyosarcoma. Therefore, referral of all female patients for gynecologic evaluation seems justified in our eyes. Additionally, 
adequate counseling for family planning is advisable, considering that in these patients uterine leiomyomas usually develop early.

The precise risk for the development of renal cancer in HLRCC is not known. The overall frequency of malignant kidney tumors in familial cutaneous leiomyoma is variable, ranging from $1-14 \%$ when looking at different studies $(41,60,62)$. Likewise, age of onset varies from 16 to 90 years $(41,46,60,62)$. Renal malignancies in HLRCC are associated with a poor prognosis and frequently metastasize to regional lymph nodes. Of note though, there are no specific screening guidelines for HLRCC, most likely due to the rareness of the disease. We suggest that annual abdominal computational tomography could serve as a screening procedure for both the detection of kidney tumors and uterine changes. Magnetic resonance imaging and ultrasound could serve as alternative techniques if contrast-enhanced computational tomography cannot be performed. However, ultrasound alone cannot be considered an adequate screening technique since lesions may be isoechoic and therefore, may be missed. Magnetic resonance imaging of the uterus is particularly helpful in detecting and characterizing uterine leiomyomas and leiomyosarcoma (83).

\section{Therapy}

\section{Cutaneous leiomyoma and leiomyosarcoma}

On the one hand, cutaneous leiomyomas may cause cosmetic discomfort. Moreover, recurrent pain arising in these tumors can cause serious complaints and disturb daily activities, sometimes even leading to suicidal thoughts. While solitary leiomyomas can be easily treated by surgical excision, multiple leiomyomas covering large surfaces of the body are difficult to manage. Several different treatment modalities have been hitherto described for symptomatic pain relief or tumor destruction in cutaneous leiomyomatosis, including pharmacological agents such as nifedipine, gabapentine, doxasozine, phenoxybenzamine, hyoscine, hydrobromide, and nitroglycerine or invasive therapy consisting of extensive surgical excision, $\mathrm{CO} 2$ laser ablation and cryotherapy, all with variable success $(2,7,11,12,14,37,84-93)$. Unfortunately, some patients with severe complaints do not respond to any of these treatment modalities. Hence, there is a need for additional therapeutic strategies, particularly for patients suffering from extensive painful leiomyomas.

Most of the current therapeutic recommendations for cutaneous leiomyosarcoma include a wide surgical excision. Routine lymph node excision is not indicated unless lymph node invasion is evident. Radiotherapy could be an option if surgery is unfeasible. However, recurrence rates are very high $(10,94)$. 


\section{Uterine leiomyoma and leiomyosarcoma}

Different surgical approaches, including myomectomy, hysterectomy or abdominal uterus extirpation can be considered. Prior to recommending a specific therapy the patient's individual concerns should always be respected though, in particular the specific symptoms and their effect on quality of life and the possible request to preserve fertility $(95,96)$.

As a general rule, hysterectomy is the treatment of choice for patients with uterine malignancies. Peritoneal washing and omentectomy are indicated if the diagnosis of leiomyosarcoma is sure. The role of prophylactic lymphadenectomy is limited since a high percentage of patients without lymph node metastases will still experience a recurrence. Myomectomy may be considered in patients with low stage leiomyosarcoma who strongly desire future fertility (97).

\section{Renal cancer}

Only little is known about the treatment of kidney malignancies in HLRCC but since these tumors behave aggressively, total nephrectomy at early stage is indicated. Recent advances in the understanding of the molecular pathways involved in the etiopathogenesis of RCC have led to the early development of promising targeted therapies in hereditary malignant kidney tumors $(98,99)$.

\section{Acknowledgements}

JF is a board member of the Dutch working group on hereditary leiomyomatosis and member of the Network for Ichthyoses and Related Keratinization Disorders (NIRK) that is supported by the German Federal Ministry of Education and Research (BMBF). We thank Dr. A. van Marion, MD, for providing the histological pictures. Financial support: none. Conflict of interest: none. 


\section{Aims of this thesis}

The general aim of this thesis was to gain deeper insights into the clinical and molecular genetic aspects of hereditary cutaneous leiomyomatosis.

Hereditary cutaneous leiomyomatosis is caused by heterozygous mutations in the $\mathrm{FH}$ gene and previous studies from different countries indicated both clinical and molecular heterogeneity in this disease. Therefore, we studied both clinically and genetically several patients and families from the Netherlands and other European countries with the clinical characteristics of hereditary leiomyomatosis and tackled the following aspects of the disease:

a. Elucidation of the underlying $F H$ gene defect in our families.

b. Identification of novel clinical symptoms of the disease.

c. Confirmation of the molecular heterogeneity reported by others or identification of common/recurrent $F H$ mutations, which might indicate mutational hotspots or founder effects.

d. Elaboration of putative genotype-phenotype correlations in hereditary cutaneous leiomyomatosis.

e. Challenging the theory of the type 2 segmental manifestation of cutaneous leiomyomatosis on the genetic level.

f. Elaboration of a proposal for diagnostic criteria and management guidelines. 


\section{References}

1. Virchow R. Über Makroglossie und pathologische Neubildung quergestreifter Muskelfasern. Virchows Arch Pathol Anat 1854; 7: 126-38.

2. Fischer Z, Helwig E. Leiomyomas of the skin. Arch Dermatol 1963; 88: 510-20.

3. Kloepfer HW, Krafchuk J, Derbes V, Burks J. Hereditary multiple leiomyoma of the skin. Am J Hum Genet 1958; 10: 48-52.

4. Guillet G, Grau P, Sassolas B, Zagnoli A, Leroy JP, Labouche F. Leiomyomes cutanes multiples et fibromes uterins: a propos d'une observation d'un cas non familial. Semin Hop Paris 1987; 63: 65-7.

5. Mezzadra G. Multiple hereditary cutaneous leiomyoma. Study of a systemic case in a male subject related to a family with cutaneous leiomyomatosis and uterine fibromyomatosis. Minerva Dermatol 1965; 40: 388-93.

6. Rudner EJ, Schwartz OD, Greekin JN. Multiple cutaneous leiomyoma in identical twins. Arch Derm 1972; 104: 81-2.

7. Reed WB, Walker R, Horowitz R. Cutaneous leiomyomata with uterine leiomyomata. Acta Derm Venereol 1973; 53: 409-16.

8. Launonen V, Vierimaa $\mathrm{O}$, Kiuru $\mathrm{M}$, et al. Inherited susceptibility to uterine leiomyomas and renal cell cancer. Proc Natl Acad Sci U S A 2001; 98: 3387-92.

9. Tomlinson IP, Alam NA, Rowan AJ, et al. Germline mutations in FH predispose to dominantly inherited uterine fibroids, skin leiomyomata and papillary renal cell cancer. Nat Genet 2002; 30: 406-10.

10. Holst VA, Junkins-Hopkins JM, Elenitsas R. Cutaneous smooth muscle neoplasms: clinical features, histologic findings, and treatment options. J Am Acad Dermatol 2002; 46: 477-90.

11. Archer CB, Greaves MW. Assessment of treatment for painful cutaneous leiomyomas. J Am Acad Dermatol 1987; 17: 141-2.

12. Archer CB, Whittaker S, Greaves MW. Pharmacological modulation of cold-induced pain in cutaneous leiomyomata. Br J Dermatol 1988; 118: 255-60.

13. Montgomery H, Winkelmann RK. Smooth-muscle tumors of the skin. AMA Arch Derm 1959; 79: 3240; discussion 40-31.

14. Thyresson HN, Su WP. Familial cutaneous leiomyomatosis. J Am Acad Dermatol 1981; 4: 430-4.

15. Mann PR. Leiomyoma cutis: an electron microscope study. Br J Dermatol 1970; 82: 463-9.

16. Raj S, Calonje E, Kraus M, Kavanagh G, Newman PL, Fletcher CD. Cutaneous pilar leiomyoma: clinicopathologic analysis of 53 lesions in 45 patients. Am J Dermatopathol 1997; 19: 2-9.

17. Agarwalla A, Thakur A, Jacob M, Joshi A, Garg VK, Agrawal S. Zosteriform and disseminated lesions in cutaneous leiomyoma. Acta Derm Venereol 2000; 80: 446.

18. Fleta Ası́n B, Berzal Rosende M, Carrillo Gijo'n R, Ferna'ndez- Guarino M, Jae'n Ola'solo P. Type 2 segmental cutaneous leiomyomatosis: an example of mosaicism. Eur J Dermatol 2009; 19: 183-4.

19. Badeloe S, Bladergroen RS, Jonkman MF, et al. Hereditary multiple cutaneous leiomyoma resulting from novel mutations in the fumarate hydratase gene. J Dermatol Sci 2008; 51: 139-43.

20. Badeloe S, van Geel M, van Steensel MA, et al. Diffuse and segmental variants of cutaneous leiomyomatosis: novel mutations in the fumarate hydratase gene and review of the literature. Exp Dermatol 2006; 15: 735-41.

21. Badeloe S, van Geel M, van Steensel MA, Steijlen PM, Poblete- Gutierrez P, Frank JA. From gene to disease; cutaneous leiomyomatosis. Ned Tijdschr Geneeskd 2007; 151: 300-4.

22. Berendes U, Kuhner A, Schnyder UW. Segmentary and disseminated lesions in multiple hereditary cutaneous leiomyoma. Humangenetik 1971; 13: 81-2.

23. Happle R. Segmental forms of autosomal dominant skin disorders: different types of severity reflect different states of zygosity. Am J Med Genet 1996; 66: 241-2.

24. Happle R. Segmental type 2 manifestation of autosome dominant skin diseases. Development of a new formal genetic concept. Hautarzt 2001; 52: 283-7.

25. Happle R. Dohi Memorial Lecture. New aspects of cutaneous mosaicism. J Dermatol 2002; 29: 68192. 
26. Huter E, Wortham NC, Hartschuh W, Enk A, Jappe U. Single base mutation in the fumarate hydratase gene leading to segmental cutaneous leiomyomatosis. Acta Derm Venereol 2008; 88: 63-5.

27. Konig A. Segmental leiomyomatosis: from haplotype to type Happle. J Dtsch Dermatol Ges 2005; 3: 671-2.

28. Konig A, Happle R. Two cases of type 2 segmental manifestation in a family with cutaneous leiomyomatosis. Eur J Dermatol 2000; 10: 590-2.

29. Konig A, Happle R. Type 2 segmental cutaneous leiomyomatosis. Acta Derm Venereol 2001; 81: 383.

30. Lang K, Reifenberger J, Ruzicka T, Megahed M. Type 1 segmental cutaneous leiomyomatosis. Clin Exp Dermatol 2002; 27: 649-50.

31. Martinez-Mir A, Glaser B, Chuang GS, et al. Germline fumarate hydratase mutations in families with multiple cutaneous and uterine leiomyomata. J Invest Dermatol 2003; 121: 741-4.

32. Martinez-Mir A, Gordon D, Horev L, et al. Multiple cutaneous and uterine leiomyomas: refinement of the genetic locus for multiple cutaneous and uterine leiomyomas on chromosome 1q42.3-43. J Invest Dermatol 2002; 118: 876-80.

33. Renner R, Sticherling M. Familial occurrence of a type 2 segmental manifestation of cutaneous leiomyomatosis. J Dtsch Dermatol Ges 2005; 3: 695-9.

34. Richter G. Primary segmental localization of multiple leiomyomas. Hautarzt 1965; 16: 177-9.

35. Ritzmann S, Hanneken S, Neumann NJ, Ruzicka T, Kruse R. Type 2 segmental manifestation of cutaneous leiomyomatosis in four unrelated women with additional uterine leiomyomas (Reed's Syndrome). Dermatology 2006; 212: 84-7.

36. Sada A, Misago N, Inoue T, Narisawa Y. Segmental multiple cutaneous piloleiomyoma with an overlying epidermal proliferation. J Dermatol 2007; 34: 665-7.

37. Smith CG, Glaser DA, Leonardi C. Zosteriform multiple leiomyomas. J Am Acad Dermatol 1998; 38: 272-3.

38. Suwattee $P$, Dakin C. Bilateral segmental leiomyomas: a case report and review of the literature. Cutis 2008; 82: 33-6.

39. Tsoitis G, Kanitakis J, Papadimitriou C, Hatzibougias Y, Asvesti K, Happle R. Cutaneous leiomyomatosis with type 2 segmental involvement. J Dermatol 2001; 28: 251-5.

40. Poblete-Gutierrez $P$, Wiederholt $T$, Konig A, et al. Allelic loss underlies type 2 segmental Hailey-Hailey disease, providing molecular confirmation of a novel genetic concept. J Clin Invest 2004; 114:146774.

41. Toro JR, Nickerson ML, Wei MH, et al. Mutations in the fumarate hydratase gene cause hereditary leiomyomatosis and renal cell cancer in families in North America. Am J Hum Genet 2003; 73: 95106.

42. Wei MH, Toure O, Glenn GM, et al. Novel mutations in FH and expansion of the spectrum of phenotypes expressed in families with hereditary leiomyomatosis and renal cell cancer. J Med Genet 2006; 43: 18-27.

43. Stewart EA. Uterine fibroids. Lancet 2001; 357: 293-8.

44. Kim G. Multiple cutaneous and uterine leiomyomatosis (Reed's syndrome). Dermatol Online J 2005; 11: 21.

45. Ylisaukko-oja SK, Kiuru M, Lehtonen HJ, et al. Analysis of fumarate hydratase mutations in a population-based series of early onset uterine leiomyosarcoma patients. Int J Cancer 2006; 119: 283-7.

46. Merino MJ, Torres-Cabala C, Pinto $\mathrm{P}$, Linehan WM. The morphologic spectrum of kidney tumors in hereditary leiomyomatosis and renal cell carcinoma (HLRCC) syndrome. Am J Surg Pathol 2007; 31: 1578-85.

47. Badeloe S, van Spaendonck-Zwarts KY, van Steensel MA, et al. Wilms tumour as a possible early manifestation of hereditary leiomyomatosis and renal cell cancer? Br J Dermatol 2009; 160: 707-9.

48. Lehtonen HJ, Kiuru M, Ylisaukko-Oja SK, et al. Increased risk of cancer in patients with fumarate hydratase germline mutation. J Med Genet 2006; 43: 523-6.

49. Kiuru M, Launonen V. Hereditary leiomyomatosis and renal cell cancer (HLRCC). Curr Mol Med 2004; 4: 869-75. 
50. Lehtonen HJ, Blanco I, Piulats JM, Herva R, Launonen V, Aaltonen LA. Conventional renal cancer in a patient with fumarate hydratase mutation. Human pathology 2007; 38: 793-6.

51. Varol A, Stapleton K, Roscioli T. The syndrome of hereditary leiomyomatosis and renal cell cancer (HLRCC): The clinical features of an individual with a fumarate hydratase gene mutation. Australas J Dermatol 2006; 47: 274-6.

52. Campione E, Terrinoni A, Orlandi A, et al. Cerebral cavernomas in a family with multiple cutaneous and uterine leiomyomas associated with a new mutation in the fumarate hydratase gene. J Invest Dermatol 2007; 127: 2271-3.

53. Carvajal-Carmona LG, Alam NA, Pollard PJ, et al. Adult leydig cell tumors of the testis caused by germline fumarate hydratase mutations. J Clin Endocrinol Metab 2006; 91: 3071-5.

54. Robboy SJ, Bentley RC, Butnor K, Anderson MC. Pathology and pathophysiology of uterine smoothmuscle tumors. Environ Health Perspect 2000; 108 (Suppl 5): 779-84.

55. Toledo G, Oliva E. Smooth muscle tumors of the uterus: a practical approach. Arch Pathol Lab Med 2008; 132: 595-605.

56. Delahunt B, Eble JN. Papillary renal cell carcinoma: a clinicopathologic and immunohistochemical study of 105 tumors. Mod Pathol 1997; 10: 537-44.

57. Delahunt B, Eble JN, McCredie MR, Bethwaite PB, Stewart JH, Bilous AM. Morphologic typing of papillary renal cell carcinoma: comparison of growth kinetics and patient survival in 66 cases. Human pathology 2001; 32: 590-5.

58. Alam NA, Bevan S, Churchman M, et al. Localization of a gene (MCUL1) for multiple cutaneous leiomyomata and uterine fibroids to chromosome 1q42.3-q43. Am J Hum Genet 2001; 68: 1264-9.

59. Alam NA, Barclay E, Rowan AJ, et al. Clinical features of multiple cutaneous and uterine leiomyomatosis: an underdiagnosed tumor syndrome. Arch Dermatol 2005; 141: 199-206.

60. Alam NA, Olpin S, Leigh IM. Fumarate hydratase mutations and predisposition to cutaneous leiomyomas, uterine leiomyomas and renal cancer. Br J Dermatol 2005; 153: 11-7.

61. Alam NA, Olpin S, Rowan A, et al. Missense mutations in fumarate hydratase in multiple cutaneous and uterine leiomyomatosis and renal cell cancer. J Mol Diagn 2005; 7: 437-43.

62. Alam NA, Rowan AJ, Wortham NC, et al. Genetic and functional analyses of FH mutations in multiple cutaneous and uterine leiomyomatosis, hereditary leiomyomatosis and renal cancer, and fumarate hydratase deficiency. Human molecular genetics 2003; 12: 1241-52.

63. Bayley JP, Launonen V, Tomlinson IP. The FH mutation database: an online database of fumarate hydratase mutations involved in the MCUL (HLRCC) tumor syndrome and congenital fumarase deficiency. BMC Med Genet 2008; 9: 20.

64. Chan I, Wong T, Martinez-Mir A, Christiano AM, McGrath JA. Familial multiple cutaneous and uterine leiomyomas associated with papillary renal cell cancer. Clin Exp Dermatol 2005; 30: 75-8.

65. Chuang GS, Martinez-Mir A, Engler DE, Gmyrek RF, Zlotogorski A, Christiano AM. Multiple cutaneous and uterine leiomyomata resulting from missense mutations in the fumarate hydratase gene. Clin Exp Dermatol 2006; 31: 118-21.

66. Dereure O. Mutations in fumarate hydratase during cutaneous and uterine leiomyomatosis associated with renal cancer. Ann Dermatol Venereol 2005; 132: 300.

67. Heinritz W, Paasch U, Sticherling $M$, et al. Evidence for a founder effect of the germline fumarate hydratase gene mutation R58P causing hereditary leiomyomatosis and renal cell cancer (HLRCC). Ann Hum Genet 2008; 72: 35-40.

68. Kiuru M, Lehtonen R, Arola J, et al. Few FH mutations in sporadic counterparts of tumor types observed in hereditary leiomyomatosis and renal cell cancer families. Cancer Res 2002; 62: 4554-7.

69. Lehtonen R, Kiuru M, Vanharanta S, et al. Biallelic inactivation of fumarate hydratase (FH) occurs in nonsyndromic uterine leiomyomas but is rare in other tumors. Am J Pathol 2004; 164: 17-22.

70. Makino T, Nagasaki A, Furuichi M, et al. Novel mutation in a fumalate hydratase gene of a Japanese patient with multiple cutaneous and uterine leiomyomatosis. J Dermatol Sci 2007; 48: 151-3. 
71. Chuang GS, Martinez-Mir A, Geyer A, et al. Germline fumarate hydratase mutations and evidence for a founder mutation underlying multiple cutaneous and uterine leiomyomata. J Am Acad Dermatol 2005; 52: 410-6.

72. Ahvenainen $\mathrm{T}$, Lehtonen $\mathrm{HJ}$, Lehtonen $\mathrm{R}$, et al. Mutation screening of fumarate hydratase by multiplex ligation-dependent probe amplification: detection of exonic deletion in a patient with leiomyomatosis and renal cell cancer. Cancer Genet Cytogenet 2008; 183: 83-8.

73. Ylisaukko-oja SK, Cybulski C, Lehtonen R, et al. Germline fumarate hydratase mutations in patients with ovarian mucinous cystadenoma. Eur J Hum Genet 2006; 14: 880-3.

74. Gellera C, Uziel G, Rimoldi M, et al. Fumarase deficiency is an autosomal recessive encephalopathy affecting both the mitochondrial and the cytosolic enzymes. Neurology 1990; 40: 495-9.

75. Pithukpakorn $\mathrm{M}$, Wei $\mathrm{MH}$, Toure $\mathrm{O}$, et al. Fumarate hydratase enzyme activity in lymphoblastoid cells and fibroblasts of individuals in families with hereditary leiomyomatosis and renal cell cancer. J Med Genet 2006; 43: 755-62.

76. Bratslavsky G, Sudarshan S, Neckers L, Linehan WM. Pseudohypoxic pathways in renal cell carcinoma. Clin Cancer Res 2007; 13: 4667-71.

77. Isaacs JS, Jung YJ, Mole DR, et al. HIF overexpression correlates with biallelic loss of fumarate hydratase in renal cancer: novel role of fumarate in regulation of HIF stability. Cancer Cell 2005; 8: 143-53.

78. Linehan WM, Vasselli J, Srinivasan R, et al. Genetic basis of cancer of the kidney: disease-specific approaches to therapy. Clin Cancer Res 2004; 10: 6282S-6289S.

79. Linehan WM, Walther MM, Zbar B. The genetic basis of cancer of the kidney. J Urol 2003; 170: 216372.

80. Ivan M, Kondo K, Yang H, et al. HIFalpha targeted for VHLmediated destruction by proline hydroxylation: implications for $\mathrm{O} 2$ sensing. Science 2001; 292: 464-8.

81. Kondo K, Kaelin Jr WG. The von Hippel-Lindau tumor suppressor gene. Exp Cell Res 2001; 264: 11725.

82. Kondo K, KIco J, Nakamura E, Lechpammer M, Kaelin Jr WG. Inhibition of HIF is necessary for tumor suppression by the von Hippel-Lindau protein. Cancer Cell 2002; 1: 237-46.

83. Choyke PL. Imaging of hereditary renal cancer. Radiol Clin North Am 2003; 41: 1037-51.

84. Abraham Z, Cohen A, Haim S. Muscle relaxing agent in cutaneous leiomyoma. Dermatologica 1983; 166: 255-6.

85. Alam M, Rabinowitz AD, Engler DE. Gabapentin treatment of multiple piloleiomyoma-related pain. J Am Acad Dermatol 2002; 46 (2 Suppl Case Reports): S27-9.

86. Batchelor RJ, Lyon CC, Highet AS. Successful treatment of pain in two patients with cutaneous leiomyomata with the oral alpha-1 adrenoceptor antagonist, doxazosin. Br J Dermatol 2004; 150: 775-6.

87. Christenson LJ, Smith K, Arpey CJ. Treatment of multiple cutaneous leiomyomas with $\mathrm{CO} 2$ laser ablation. Dermatol Surg 2000; 26: 319-22.

88. Engelke H, Christophers E. Leiomyomatosis cutis et uteri. Acta Derm Venereol Suppl (Stockh) 1979; 59: 51-4.

89. George S, Pulimood S, Jacob M, Chandi SM. Pain in multiple leiomyomas alleviated by nifedipine. Pain 1997; 73: 101-2.

90. Thompson Jr JA. Therapy for painful cutaneous leiomyomas. J Am Acad Dermatol 1985; 13: 865-7.

91. Tiffee JC, Budnick SD. Multiple cutaneous leiomyomas. Report of a case. Oral Surg Oral Med Oral Pathol 1993; 76: 716-7.

92. Venencie PY, Puissant A, Boffa GA, Sohier J, Duperrat B. Multiple cutaneous leiomyomata and erythrocytosis with demonstration of erythropoietic activity in the cutaneous leiomyomata. Br J Dermatol 1982; 107: 483-6.

93. Yaghoobi R, Mossavi Z. Mohammad poor M. Multiple popular and nodular lesions on the extremities and trunk. Arch Dermatol 1999; 135: 343-6.

94. Porter CJ, Januszkiewicz JS. Cutaneous leiomyosarcoma. Plast Reconstr Surg 2002; 109: 964-7.

95. Wallach EE, Vlahos NF. Uterine myomas: an overview of development, clinical features, and management. Obstet Gynecol 2004; 104: 393-406. 
96. Wallach EE, Vu KK. Myomata uteri and infertility. Obstet Gynecol Clin North Am 1995; 22: 791-9.

97. Reed NS. The management of uterine sarcomas. Clin Oncol (R Coll Radiol) 2008; 20: 470-8.

98. Brugarolas J. Renal-cell carcinoma--molecular pathways and therapies. N Engl J Med 2007; 356: 1857.

99. Refae MA, Wong N, Patenaude F, Begin LR, Foulkes WD. Hereditary leiomyomatosis and renal cell cancer: an unusual and aggressive form of hereditary renal carcinoma. Nat Clin Pract Oncol 2007; 4: 256-61. 


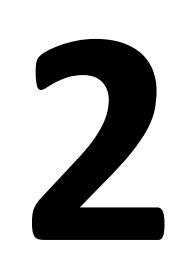

\section{Molecular basis of hereditary cutaneous leiomyomatosis}

Badeloe S, van Geel M, van Steensel MA, Bastida J, Ferrando J, Steijlen PM, Frank J, Poblete-Gutiérrez P. Diffuse and segmental variants of cutaneous leiomyomatosis: novel mutations in the fumarate hydratase gene and review of the literature. Exp Dermatol. 2006 Sep;15(9):735-41.

Badeloe S, Bladergroen RS, Jonkman MF, Burrows NP, Steijlen PM, Poblete-Gutiérrez P, van Steensel MA, van Geel M, Frank J. Hereditary multiple cutaneous leiomyoma resulting from novel mutations in the fumarate hydratase gene. J Dermatol Sci. 2008 Aug;51(2):139-43.

Badeloe S, van Geest AJ, van Marion AM, Frank J. Absence of fumarate hydratase mutation in a family with cutaneous leiomyosarcoma and renal cancer.

Int J Dermatol. 2008 Nov;47 Suppl 1:18-20. 


\title{
2.1 The spectrum of mutations in the fumarate hydratase gene in diffuse and segmental variants of hereditary cutaneous leiomyomatosis
}

\begin{abstract}
Multiple cutaneous and uterine leiomyomatosis (MCUL; OMIM 150800) is an autosomal dominantly inherited disease characterized by leiomyomas of the skin and uterine leiomyomas. Recently, association of MCUL with different forms of renal cancer has been described. This syndrome is referred to as hereditary leiomyomatosis and renal cell cancer (OMIM 605839). Both disorders result from heterozygous germline mutations in the fumarate hydratase $(F H)$ gene that may function as a tumor suppressor. Interestingly, cutaneous leiomyomas do not only manifest in a diffuse and symmetric fashion. Rather frequently, a segmental or band-like manifestation pattern can be observed, usually following the lines of Blaschko. Here, we sought to elucidate the molecular basis of diffuse and segmental cutaneous leiomyomatosis in six unrelated Dutch and Spanish patients and their families. We identified six novel FH mutations, including one missense and one nonsense mutation, two deletions and two splice-site mutations. The segmental phenotype that was observed in various patients with $\mathrm{FH}$ mutations most likely reflects a type 2 segmental manifestation of cutaneous leiomyomatosis as previously also described for other autosomal dominantly inherited skin diseases. The results presented here extend the current data on the molecular basis of familial cutaneous leiomyomatosis and comprise, to the best of our knowledge, the first genetic study in Dutch and Spanish patients with this disorder. In addition, we review the clinical and molecular aspects of the disease.
\end{abstract}




\section{Introduction}

Cutaneous leiomyomas are rare, benign tumors arising from smooth muscle cells. According to their site of origin, they can be classified into three types: (i) those derived from the arrector pili muscle of hair follicles (piloleiomyomas), (ii) those originating from the vascular smooth muscle (angioleiomyomas) and (iii) those arising from the smooth muscle of genital skin (dartoic leiomyomas).

Piloleiomyoma is the most common type among cutaneous leiomyomas $(1,2)$. In contrast to the mainly solitary angioleiomyomas, piloleiomyomas predominantly manifest as multiple tumors (leiomyomatosis) in a symmetrical and diffuse fashion or in a segmental pattern. They typically present in the second to fourth decade of life as grouped papules or nodules on the trunk and limbs and are characteristically painful in response to pressure or low temperature. The pathomechanisms underlying the pain are unknown. Currently, several possible explanations are discussed, including that the pain might be due to pressure on the nerve fibers within the tumor or contraction of smooth muscle fibers developing in leiomyomas. On histological examination, piloleiomyomas are composed of interlacing bundles of smooth muscle fibers that are poorly demarcated. Varying amounts of collagen bundles are intermingled with the smooth muscle bundles (3).

When associated with uterine leiomyomas, cutaneous leiomyomatosis can be inherited as an autosomal-dominant trait referred to as multiple cutaneous and uterine leiomyomatosis (MCUL; OMIM 150800). A small proportion of families with MCUL also cluster renal cancer, either manifesting as papillary renal cell carcinoma type 2 or renal collecting duct cancer. This latter disease variant is referred to as hereditary leiomyomatosis and renal cell cancer (HLRCC; OMIM 605839).

In 2001, Alam et al. reported linkage of MCUL to chromosome 1q42.3-q43 (4). Subsequently, heterozygous germline mutations in the fumarate hydratase $(F H)$ gene were detected in both MCUL and HLRCC, confirming that these disorders are allelic (5-10). The $F H$ gene spans $22 \mathrm{~kb}$ and contains 10 exons. $F H$ codes for the enzyme fumarate hydratase $(\mathrm{FH})$ that catalyzes the conversion of fumarate to malate in the Krebs cycle (5). FH is thought to act as a tumor suppressor gene, as loss of the wildtype allele has been found in biopsies of cutaneous and uterine tumors of patients with MCUL and HLRCC. Moreover, enzymatic FH activity was low or absent in tumors from affected individuals (6-8). In contrast to MCUL and HLRCC, homozygous or compound heterozygous $F H$ germline mutations cause autosomal recessive fumarate hydratase deficiency (FHD; OMIM 136850), a severe metabolic disease characterized by neurological impairment and encephalopathy (11). To date, neither the occurrence of leiomyomas nor renal cancer has been reported in individuals affected with FHD. This may be due to the fact that most individuals suffering from FHD only survive a couple of months with very few patients reaching early adulthood $(5,9)$. Interestingly, several reports indicate that multiple cutaneous leiomyo- 
mas do not exclusively manifest in a diffuse and symmetric fashion. Rather frequently, a segmental or band-like manifestation pattern of these tumors can be observed, usually following the lines of Blaschko (12-14). Here, we studied the molecular basis of diffuse and segmental cutaneous leiomyomatosis in six unrelated patients of Dutch and Spanish origin. Using polymerase chain reaction (PCR)-based techniques, we identified six distinct novel mutations, designated p.Q142K, p.E404X, c.233delA, c.1238delA, c.378+1delG (IVS3+1delG) and c.555+1G>A (IVS4+1G>A). The results presented here extend the current data on the molecular basis of familial cutaneous leiomyomatosis and reflect, to the best of our knowledge, the first genetic studies in Dutch and Spanish patients with this disorder. In addition, our study indicates that, in cutaneous leiomyomatosis, segmental manifestation patterns are apparently encountered more frequently than in other autosomal dominantly inherited skin diseases.

\section{Methods}

\section{Patients, families and controls}

All index patients (individuals $\mathrm{FH} 1-\mathrm{FH} 6$ in Table 1) were unrelated Caucasians of Dutch (FH1, FH2 and $\mathrm{FH} 5$ ) and Spanish (FH3, FH4 and $\mathrm{FH} 6$ ) origin. They were initially seen by us with small, firm reddish to brownish, sometimes painful nodules, predominantly located on the trunk and extremities. In the index patients, diagnosis of cutaneous leiomyomatosis was confirmed by histopathological examination of skin biopsies. The study further comprised a total of 27 clinically affected and 182 unaffected family members as well as 100 unrelated Caucasian control individuals. Of the 27 relatives with clinically overt disease, six individuals (three females and three males) revealed cutaneous leiomyomas exclusively. Ten females suffered from cutaneous and uterine leiomyomas simultaneously. Furthermore, 11 women only revealed uterine leiomyomas. Patient FH1 showed cutaneous leiomyomas and, additionally, had a medical history of a kidney tumor (Table 1). 
Table 1. Clinical characteristics of the index patients and their families in this study.

\begin{tabular}{|c|c|c|c|c|c|c|}
\hline Family & Index patient & $\begin{array}{l}\text { Affected } \\
\text { family } \\
\text { members }\end{array}$ & $\begin{array}{l}\text { Cutaneous } \\
\text { leiomyomas } \\
\text { exclusively }\end{array}$ & $\begin{array}{l}\text { Cutaneous } \\
\text { and uterine } \\
\text { leiomyomas }\end{array}$ & $\begin{array}{l}\text { Cutaneous } \\
\text { leiomyomas an } \\
\text { kidney cancer }\end{array}$ & $\begin{array}{l}\text { Uterine } \\
\text { d leiomyomas }\end{array}$ \\
\hline $\mathrm{FH} 1$ & $\begin{array}{l}\text { Cutaneous leiomyomas and } \\
\text { kidney cancer }\end{array}$ & 1 & - & - & 1 & - \\
\hline $\mathrm{FH} 2$ & Cutaneous leiomyomas & 1 & 1 & - & - & - \\
\hline $\mathrm{FH} 3$ & $\begin{array}{l}\text { Cutaneous and uterine } \\
\text { leiomyomas }\end{array}$ & 2 & - & 1 & - & 1 \\
\hline $\mathrm{FH} 4$ & $\begin{array}{l}\text { Cutaneous and uterine } \\
\text { leiomyomas }\end{array}$ & 18 & 2 & 7 & - & 9 \\
\hline FH5 & Cutaneous leiomyomas & 3 & 1 & 1 & - & 1 \\
\hline FH6 & Cutaneous leiomyomas & 2 & 1 & 1 & - & - \\
\hline
\end{tabular}

\section{DNA isolation, PCR and mutation analysis}

All individuals provided informed consent for inclusion in this study in accordance with guidelines set forth by the local institutional review board. Genomic DNA was isolated from peripheral blood collected in tubes containing ethylenediamine tetraacetic acid according to standard techniques (15). To screen for mutations, the entire coding region and all exon-intron boundaries of the $\mathrm{FH}$ gene were PCR amplified using primer pairs and conditions previously described in detail (11). In brief, PCR was carried out according to the following program: initial denaturation at $95^{\circ} \mathrm{C}$ for $5 \mathrm{~min}$; followed by 35 cycles of denaturation at $95^{\circ} \mathrm{C}$ for $45 \mathrm{~s}$, annealing at $55^{\circ} \mathrm{C}$ for $1 \mathrm{~min}$ and extension at $72^{\circ} \mathrm{C}$ for $1 \mathrm{~min}$ and $15 \mathrm{~s}$; followed by a final extension at $72^{\circ} \mathrm{C}$ for $10 \mathrm{~min}$, in a Biometra ${ }^{\circledR}$ TGradient thermal cycler (Whatman Biometra ${ }^{\circledR}$, Göttingen, Germany). Each amplification reaction contained $100 \mathrm{ng}$ of genomic DNA, $50 \mathrm{ng}$ of each forward and reverse primer and $35 \mu \mathrm{l}$ of Platinum Taq $^{\circ}$ PCR Super Mix (Invitrogen ${ }^{\circledR}$ Life Technologies, Karlsruhe, Germany), as previously described in detail $(16,17)$. Subsequently, PCR products were purified with a MultiScreen-PCR filter plate (Millipore, Billerica, MA, USA) and sequenced directly on an $A B I 377$ genetic analyser from Applied Biosystems Inc. (Foster City, CA, USA), using the BigDye deoxy terminator V3.1 cycle sequencing kit (Applied Biosystems). Sequence analysis was performed with the software tools PHRED, PHRAP and CONSED (Codon Code Corporation, Dedham, MA, USA) (18-20). Sequence deviations were detected by visual inspection and mutation verification was accomplished by automated sequencing of 100 healthy, unrelated control individuals of identical ethnic background. 


\section{Results}

\section{Mutations in the $\mathrm{FH}$ gene}

In all patients studied, we detected heterozygous mutations in the $F H$ gene that have not been reported previously. The mutations consisted of one missense mutation, one nonsense mutation, two small deletions and two splice-site mutations, designated Q142K, E404X, 233delA, 1238delA, IVS3+1delG and IVS4+1G>A, respectively (Table 2). As an illustration of our mutation detection strategy, the results of the mutation analysis in two of the six families are depicted in Figure 1. The localization of the novel mutations identified in this study, along with those mutations already reported by other groups, is shown in Figure 2. To exclude the possibility that the sequence deviations detected were common polymorphisms, we confirmed the absence of these mutations in 200 Caucasian chromosomes by automated sequencing (data not shown).

Table 2. Novel germline fumarate hydratase gene mutations in Dutch and Spanish families with cutaneous leiomyomatosis

\begin{tabular}{lllll}
\hline Patient/Family & Mutation & Exon & Protein & Mutation type \\
\hline FH1 & c.233delA & 2 & p.N78fsX7 & Frameshift \\
FH2 & c.1238delA & 9 & p.1413IfsX36 & Frameshift \\
FH3 & c.555+1G>A & 4 & Not studied & Splice site \\
FH4 & c.378+1delG & 3 & Not studied & Splice site \\
FH5 & c. $1210 G>T$ & 8 & p.E404X & Nonsense \\
FH6 & c. $424 G>A$ & 4 & p.Q142K & Missense \\
\hline
\end{tabular}
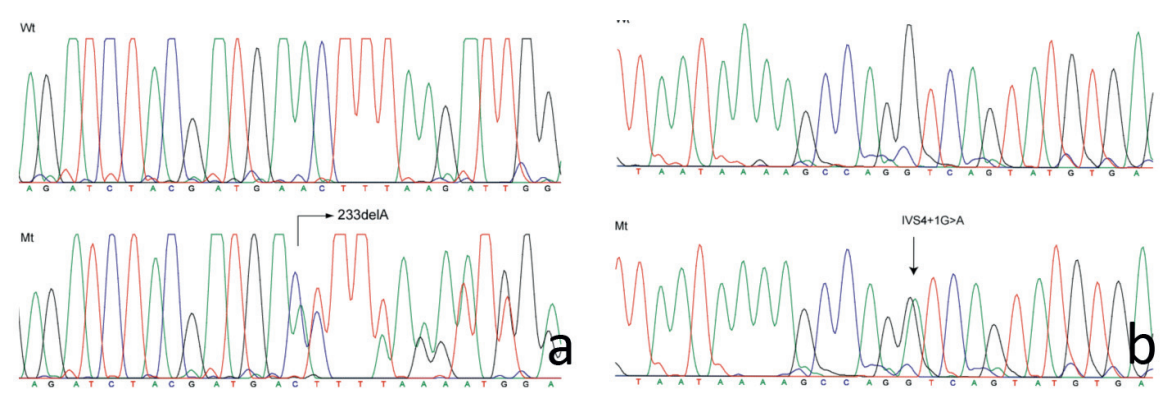

Figure 1. Results of automated sequencing in patients $\mathrm{FH} 1$ and $\mathrm{FH} 4$, depicting the mutated alleles c.233delA (a) and c.555+1G>A (IVS4+1G>A) (b), respectively, compared with the wild-type sequences of an unrelated, unaffected control individual. 


\section{Discussion}

Here, we studied the molecular basis of hereditary cutaneous leiomyomatosis in unrelated Dutch and Spanish patients and their families. Using molecular biological techniques including PCR and automated sequencing, we identified six distinct novel mutations in the $\mathrm{FH}$ gene. In addition to the cutaneous tumors, uterine leiomyomas as well as kidney tumors were observed in some individuals who participated in this investigation. Approximately 68 different mutations have been reported in the $F H$ gene to date $(5-10,12,13)$. The sequence alterations reflect a wide spectrum of possible types of mutations, including single base substitutions, deletions and insertions, which result in missense mutations, nonsense mutations, frameshift mutations and splice-site mutations. These data impressively demonstrate the genetic heterogeneity of hereditary cutaneous leiomyomatosis and associated allelic syndromes as MCUL and HLRCC. All mutations that have been reported to date are depicted at a glance in Figure 2.

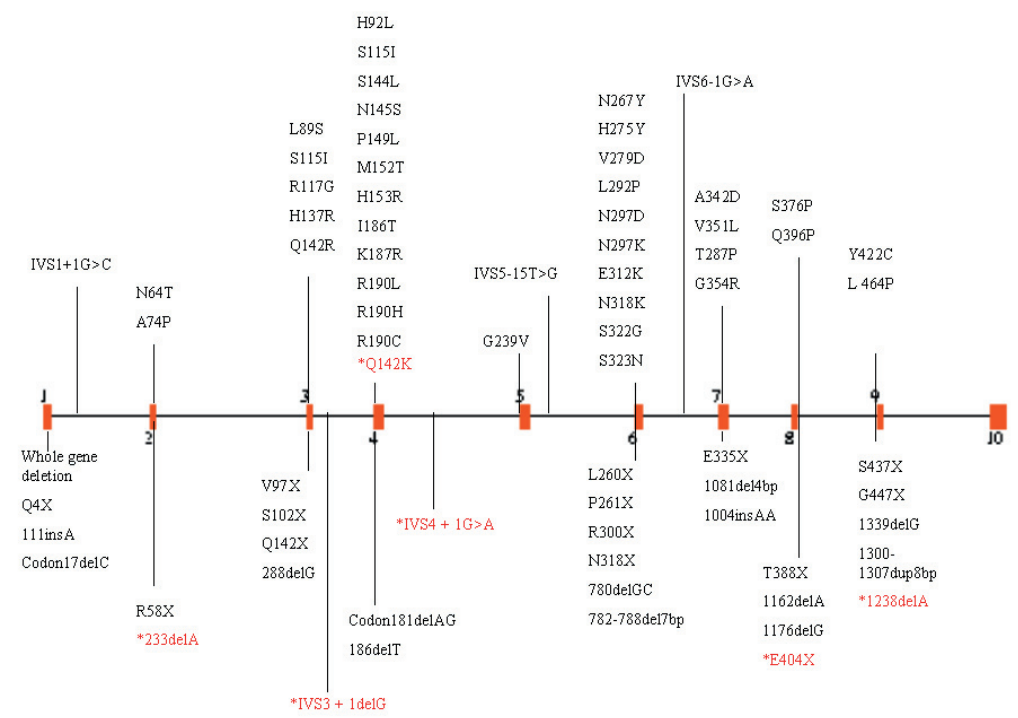

Figure 2. Germline fumarate hydratase gene mutations reported in cutaneous leiomyomatosis to date. The novel mutations detected in this study are marked with an asterisk and highlighted in red. 


\section{Clinical findings}

We studied five females and one male with hereditary cutaneous leiomyomatosis. The sex distribution observed in our study is in discordance with the data from previous genetic studies in this disease $(5-10,12,13)$. In each index patient, the number of skin tumors ranged from a few to more than 100 . Leiomyomas were predominantly observed on the trunk, neck and lower extremities. In line with previous reports (21-23), a diffuse and symmetric as well as a segmental manifestation pattern of leiomyomas could be observed in the patients and families studied here.

Interestingly, at least one individual with a pronounced segmental phenotype could be identified in each family. Even more fascinating, different phenotypic manifestation patterns could be observed within one family in individuals carrying the same mutation. Two female patients of Spanish origin (FH3 and $\mathrm{FH} 4$ ) revealed coexisting skin and uterine leiomyomas. Patient FH1, a woman of Dutch origin, revealed cutaneous leiomyomas and had been diagnosed with a kidney tumor at the age of 30 years.

\section{Germline $\boldsymbol{F H}$ mutations}

Approximately 68 different $\mathrm{FH}$ mutations have been reported in cutaneous leiomyomatosis to date. These mutations comprise 38 missense mutations, 13 nonsense mutations, 13 frameshift mutations, three splice-site mutations and one whole gene deletion, which are distributed over almost all coding regions of the $\mathrm{FH}$ gene $(5-10,12,13)$. Of note, functional analyses have not been performed in all missense mutations reported to date. If such studies were carried out, they consisted of demonstrating reduced FH activity in lymphoblastoid cell lines from patients with these missense mutations when compared with control cell lines $(9,10)$. Some authors performed an evolutionary alignment of FH proteins in different species showing that most missense mutations occurred at amino acid residues that were highly conserved throughout evolution and predominantly affected regions adjacent to active sites of the enzyme. The missense mutation detected in this study consisted of a previously unreported G-to-T transversion at nucleotide position 1210 of the FH cDNA. This base substitution results in an amino acid change from glutamine to lysine, designated p.Q142K. Three lines of evidence suggest that this nucleotide change underlies cutaneous leiomyomatosis in this family. First, it caused an amino acid conversion from an uncharged polar glutamine to a charged basic lysine residue. Therefore, this mutation may cause local and/or distant destabilization of specific amino acid interactions in $\mathrm{FH}$ and impair proper functioning of the encoded protein. Second, a comparison of nucleotide-deduced amino acid sequences revealed that this glutamine residue is strictly conserved in humans, dogs, mice, rats, chickens, zebrafish, Drosophila, Caenorhabditis elegans, Arabidopsis and 
the yeast Saccharomyces cerevisiae through evolution (Figure 3). Third, the sequence deviation could not be detected in 100 healthy control individuals, thereby excluding that this nucleotide change is a common polymorphism. These data indicate that the mutated glutamine residue at codon 142 of $\mathrm{FH}$ is highly important for proper protein function.

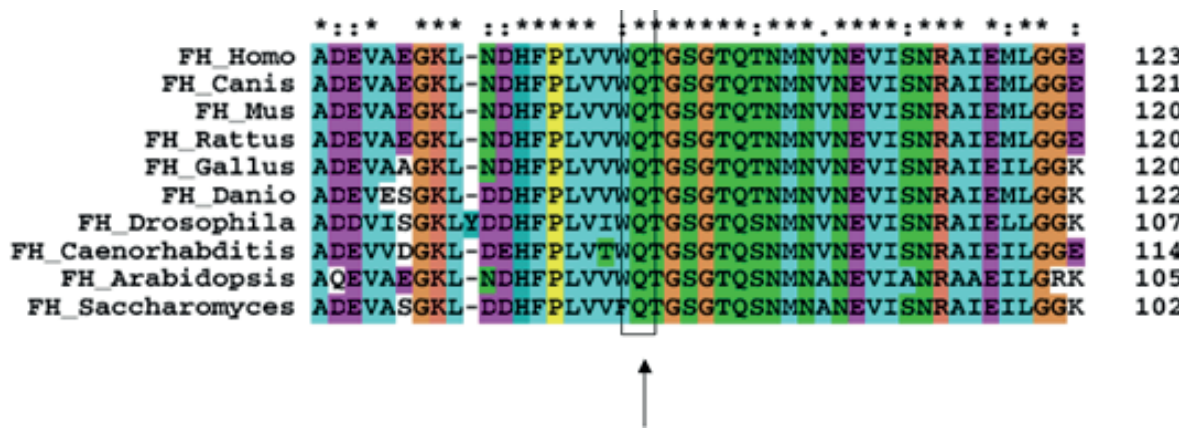

Figure 3. Alignment of nucleotide-deduced amino acid sequences from codon 126 to 170 (numbering derived from the human sequence) of fumarate hydratase. Note that the glutamine residue at codon 142 (arrow) is strictly conserved in humans (Homo sapiens), dogs (Canus familiaris), mice (Mus musculus), rats (Rattus norvegicus), chickens (Gallus gallus), zebrafish (Danio rerio), fruit flies (Drosophila melanogaster), worms (Caenorhabditis elegans), plants (Arabidopsis thaliana) and the yeast (Saccharomyces cerevisiae) through evolution (boxed).

Three splice-site mutations were reported in previous studies $(5,6,10)$. However, in none of these studies, the functional consequence of these mutations was assessed on the cDNA level by, for example, reverse transcriptase-PCR. Unfortunately, tumor material from the two patients carrying the novel splice-site mutations was not available to us to extract RNA and study the functional consequences on the cDNA level. Splice-site mutations usually exert their pathological action by either one of the following mechanisms: (i) exon skipping, (ii) intron retention or (iii) cryptic splicing $(24,25)$. Both the nonsense mutation (p.E404X) and the two small deletions (c.233delA and c.1238delA) detected in this study result in premature termination codons and might either act by nonsense-mediated mRNA decay $(26,27)$ or exert dominant-negative effects resulting from the formation of truncated proteins (28, 29). Most of the $\mathrm{FH}$ mutations reported to date are private mutations that exclusively occur in one family. The notable exceptions to this rule are mutations $\mathrm{p} . \mathrm{R} 58 \mathrm{X}$ and p.R190H, respectively (5). For both mutations, it remains elusive if they represent mutational hotspots in $\mathrm{FH}$ or arose on a common genetic background, thus reflecting founder effects. 


\section{Somatic FH mutations}

Three previous studies have reported on the prevalence of somatic $\mathrm{FH}$ mutations in sporadic leiomyomas. Kiuru et al. analyzed 41 uterine leiomyomas and did not detect any mutations (30). Barker et al. examined 129 leiomyomas from 21 individuals. Only $5 \%$ (seven out of 129 ) of these leiomyomas showed allele imbalance at 1q42q43, and no somatic FH mutations were identified (31). Lehtonen et al. described two somatic $F H$ mutations in a study of 153 uterine leiomyomas from 46 individuals (32). Collectively, these data indicate that $F H$ gene mutations are rarely encountered outside the context of MCUL/HLRCC.

Similarly, $\mathrm{FH}$ mutations do not appear to contribute significantly to the development of sporadic leiomyosarcomas. Barker et al. were not able to demonstrate mutations in a series of 26 leiomyosarcomas (31). Kiuru et al. analysed 20 leiomyosarcomas and identified a germline $F H$ mutation in one of their patients (30). Molecular studies in 15 sporadic renal cell carcinomas did not reveal mutations in the $F H$ gene (33). Lehtonen et al. analysed a series of 299 malignant tumors representing 10 different malignant tumor types for $\mathrm{FH}$ mutations. However, no pathogenic $\mathrm{FH}$ mutations were detected (32).

Besides somatic $\mathrm{FH}$ gene mutations being apparently rare in sporadic smooth muscle tumors, previous data provide no evidence that epigenetic inactivation of $\mathrm{FH}$ expression is a hallmark of these tumors. Although sporadic and MCUL/HLRCC smooth muscle tumors reveal identical morphological features as the tumors encountered in hereditary cutaneous leiomyomatosis, the underlying etiopathogenesis and the pathways leading to tumorigenesis may be fundamentally different (34).

\section{Genotype-phenotype correlation in cutaneous leiomyomatosis}

Currently, there is no strong evidence for a putative genotype-phenotype correlation in cutaneous leiomyomatosis. Previous studies suggested that $\mathrm{FH}$ mutations occurring at $5^{\prime}$ of codon 250 of $\mathrm{FH}$ could be associated with an increased risk of developing renal cell cancer and the Leiomyoma Consortium reported that $92 \%$ of mutations associated with HLRCC were located between codons 1 and 249 (10). However, a subsequent study from Toro et al. indicated that only $55 \%$ of $\mathrm{FH}$ mutations in HLRCC were located at $5^{\prime}$ of codon 250, a notion that was confirmed by Wei et al. who reported on $F H$ mutations distributed over the entire gene, of which merely a low percentage was located before codon 250 . These data suggest that $F H$ mutations associated with HLRCC are not preferentially clustered in the aminoterminal part of the protein. 


\section{Segmental manifestation of cutaneous leiomyomatosis}

It has long been known that autosomal dominant skin disorders, which usually present in a diffuse and symmetrical fashion, may also show segmental manifestation patterns that most likely reflect mosaicism. This clinical observation led to the postulation of a novel genetic concept for the segmental manifestation of dominantly inherited skin diseases by Happle. Whenever the segmental skin lesions reveal the same degree of severity as that found in the corresponding non-mosaic trait and a germline mutation is absent, a type 1 segmental involvement is present. Occasionally, however, the severity of cutaneous involvement observed in the segmentally affected skin areas is far more pronounced. Already 10 years ago, Happle suggested that this phenomenon can be explained by loss of heterozygosity (LOH) at the same locus that caused the phenotypically less severe, diffuse involvement (35). Although the type 2 segmental manifestation has only rarely been reported, Happle noted that cutaneous leiomyomatosis apparently represents an autosomal-dominant skin disorder in which the segmental manifestation pattern, preferably the type 2 segmental involvement, is rather frequently observed $(7,13,21-23,36)$. Recently, the hypothesis for the type 2 segmental manifestation of autosomal dominant skin disorders has been confirmed on the cellular and molecular level in Hailey-Hailey disease (37).

Of note, we also observed the segmental type 2 manifestation in several patients who carried a heterozygous $F H$ germline mutation and, moreover, in all families studied here, at least one individual revealed a severe segmental involvement superimposed on the ordinary diffuse phenotype. This latter observation strongly supports the previous notion from other colleagues and investigators who emphasized the more frequent occurrence of the type 2 segmental manifestation in cutaneous leiomyomatosis $(7,13,21-23,36)$.

\section{Future lines of investigation in cutaneous leiomyomatosis}

Obviously, the aforementioned observations give rise to some interesting questions. The first one is why the type 2 segmental manifestation, which is very rare in autosomal dominant skin disorders, is so frequently observed in cutaneous leiomyomatosis? The second eminent question is which molecular and cellular mechanisms govern the type 2 segmental manifestation in this disease? If Happle's concept also holds true for cutaneous leiomyomatosis, the type 2 segmental phenotype observed in several of our patients and relatives would reflect a cutaneous mosaicism due to a heterozygous germline mutation in association with postzygotic LOH that occurred at an early stage in embryogenesis. But will LOH indeed play a major role in this syndrome and, more importantly, is it to be the only conceivable mechanism that can give rise to the segmental type 2 manifestation in cutaneous leiomyomatosis? Surely, further molecular genetic studies on DNA and RNA derived from blood 
and tumor samples, which are currently underway in our laboratory, will be necessary to clarify if the recently confirmed genetic concept of type 2 segmental manifestation also holds true for cutaneous leiomyomatosis and if $\mathrm{LOH}$ is the principal pathophysiological mechanism underlying mosaicism in this disorder.

\section{Acknowledgements}

We highly appreciate the skillful help and excellent technical assistance of Reno S. Bladergroen. MAMvS is supported by grants from the GROW research institute of the University Hospital Maastricht, the La Roche Posay Research Foundation and Barrier Therapeutics NV.

\section{References}

1. Virchow R. Uber Makroglossie und pathologische Neubildung quergestreifter Muskelfasern. Virchows Arch Pathol Anat 1854: 7: 126-138.

2. Fischer Z W C, Helwig E B. Leiomyomas of the skin. Arch Dermatol 1963: 88: 510-520.

3. Holst V A, Junkins-Hopkins J M, Elenitas R. Cutaneous smooth muscle neoplasms: clinical features, histologic findings, and treatment options. J Am Acad Dermatol 2002: 46: 477-490.

4. Alam N A, Bevan S, Churchman M et al. Localization of a gene (MCUL1) for multiple cutaneous leiomyomata and uterine fibroids to chromosome 1q42.3- q43. Am J Hum Genet 2001: 68: 12641269.

5. Wei M-H, Toure O, Glenn G M et al. Novel mutations in FH and expansion of the spectrum of phenotypes expressed in families with hereditary leiomyomatosis and renal cell cancer. J Med Genet 2006: 43: $18-27$.

6. Chuang G S, Martinez-Mir A, Geyer A et al. Germline fumarate hydratase mutations and evidence for a founder mutation underlying multiple cutaneous and uterine leiomyomata. J Am Acad Dermatol 2005: 52: 410-416.

7. Alam N A, Olpin S, Leigh I M. Fumarate hydratase mutations and predisposition to cutaneous leiomyomas, uterine leiomyomas and renal cancer. Br J Dermatol 2005: 153: 11-17.

8. Chuang G S, Martinez-Mir A, Engler D E et al. Multiple cutaneous and uterine leiomyomata resulting from missense mutations in the fumarate hydratase gene. Clin Exp Dermatol 2005: 31: 118-121.

9. Alam N A, Rowan A J, Wortham N C et al. Genetic and functional analyses of FH mutations in multiple cutaneous and uterine leiomyomatosis, hereditary leiomyomatosis and renal cancer, and fumarate hydratase deficiency. Hum Mol Genet 2003: 12: 1241-1252.

10. Tomlinson I P, Alam N A, Rowan A J et al. Germline mutations in FH predispose to dominantly inherited uterine fibroids, skin leiomyomata and papillary renal cancer. Nat Genet 2002: 30: 406-410.

11. Gellera C, Uziel G, Rimoldi M et al. Fumarase deficiency is an autosomal recessive encephalopathy affecting both the mitochondrial and the cytosolic enzymes. Neurology 1990: 40: 495-499.

12. Martinez-Mir A, Glaser B, Chuang G S et al. Germline fumarate hydratase mutations in families with multiple cutaneous and uterine leiomyomata. J Invest Dermatol 2003: 121: 741-744.

13. Martinez-Mir A, Gordon D, Horev L et al. Multiple cutaneous and uterine leiomyomas: refinement of the genetic locus for multiple cutaneous and uterine leiomyomas on chromosome $1 q 42.3-43$. J Invest Dermatol 2002: 118: 876-880.

14. Toro J R, Nickerson M L, Wei M H et al. Mutations in the fumarate hydratase gene cause hereditary leiomyomatosis and renal cell cancer in families in North America. Am J Hum Genet 2003: 73: 95106. 
15. Sambrook J, Fritsch E F, Maniatis T, eds. Molecular Cloning: A Laboratory Manual. Cold Spring Harbor, NY: Cold Spring Harbor Laboratory Press, 1989.

16. Frank J, Cserhalmi-Friedman P B, Ahmad W, Panteleyev A A, Aita V M, Christiano A M. Characterization of the desmosomal cadherin gene family: genomic organization of two desmoglein genes on human chromosome 18q12. Exp Dermatol 2001: 10: 90-94.

17. Poblete-Gutierrez $\mathrm{P}$, Mendez $\mathrm{M}$, Wiederholt $\mathrm{T}$ et al. The molecular basis of porphyria cutanea tarda in Chile: identification and functional characterization of mutations in the uroporphyrinogen decarboxylase gene. Exp Dermatol 2004: 13: 372-379.

18. Ewing B, Green P. Base-calling of automated sequencer traces using PHRED. II. Error probabilities. Genome Res 1998: 8: 186-194.

19. Ewing B, Hillier L, Wendl M C, Green P. Base-calling of automated sequencer traces using PHRED. I. Accuracy assessment. Genome Res 1998: 8: 175-185.

20. Gordon D, Abajian C, Green P. CONSED: a graphical tool for sequence finishing. Genome Res 1998: 8: 195- 202.

21. König A, Happle R. Two cases of type 2 segmental manifestation in a family with cutaneous leiomyomatosis. Eur J Dermatol 2000: 10: 590-592.

22. Lang K, Reifenberger J, Ruzicka T, Megahed M. Type 1 segmental cutaneous leiomyomatosis. Clin Exp Dermatol 2002: 27: 649-650.

23. Ritzman S, Hanneken S, Neumann N J et al. Type 2 segmental manifestation of cutaneous leiomyomatosis in four unrelated women with additional uterine leiomyomatosis (Reed's syndrome). Dermatology 2006: 212: 84-87.

24. Cooper T A, Mattox W. The regulation of splice-site selection, and its role in human disease. Am J Hum Genet 1997: 61: 259-266.

25. Krawczak M, Reiss J, Cooper D N. The mutational spectrum of single base-pair substitutions in mRNA splice junctions of human genes: causes and consequences. Hum Genet 1992: 90: 41-54.

26. Hentze M W, Kulozik A E. A perfect message: RNA surveillance and nonsense-mediated decay. Cell 1999: 96: 307-310.

27. Byers $\mathrm{PH}$. Killing the messenger: new insights into nonsense-mediated mRNA decay. J Clin Invest 2002: 109: 3-6.

28. Wagner E, Lykke-Andersen J. mRNA surveillance: the perfect persist. J Cell Sci 2002: 115: 3033-3088.

29. Den Dunnen J T, Van Ommen G J. The protein truncation test: a review. Hum Mutat 1999: 14: 95102.

30. Kiuru M, Lehtonen R, Arola J et al. Few FH mutations in sporadic counterparts of tumor types observed in hereditary leiomyomatosis and renal cell cancer families. Cancer Res 2002: 62: 4554-4557.

31. Barker K T, Bevan S, Wang R et al. Low frequency of somatic mutations in the FH/multiple cutaneous leiomyomatosis gene in sporadic leiomyosarcomas and uterine leiomyomas. Br J Cancer 2002: 87: 446- 448.

32. Lehtonen $\mathrm{R}$, Kiuru $\mathrm{M}$, Vanharanta $\mathrm{S}$ et al. Biallelic inactivation of fumarate hydratase (FH) occurs in nonsyndromic uterine leiomyomas but is rare in other tumours. Am J Pathol 2001: 164: 17-22.

33. Morris M R, Maina E, Morgan N V et al. Molecular genetic analysis of FIH-1, FH, and SDHB candidate tumour suppressor genes in renal cell carcinoma. J Clin Pathol 2004: 57: 706-711.

34. Barker K T, Spendlove H E, Banu N S et al. No evidence for epigenetic inactivation of fumarate hydratase in leiomyomas and leiomyosarcomas. Cancer Lett 2006: 235: 136-140.

35. Happle R. Segmental forms of autosomal dominant skin disorders: different types of severity reflect different states of zygosity. Am J Med Genet 1996: 66: 241-242.

36. Kiuru M, Launonen V, Hietala $M$ et al. Familial cutaneous leiomyomatosis is a two-hit condition associated with renal cell cancer of characteristic histopathology. Am J Pathol 2001: 159: 825-829.

37. Poblete-Gutie'rrez P, Wiederholt T, König A et al. Allelic loss underlies type 2 segmental HaileyHailey disease, providing molecular confirmation of a novel genetic concept. J Clin Invest 2004: 114: 1467-1476. 


\title{
2.2 Hereditary cutaneous leiomyomatosis resulting from novel missense mutations in the fumarate hydratase gene
}

\begin{abstract}
Hereditary multiple cutaneous leiomyomatosis is an autosomal dominantly inherited disease characterized by multiple leiomyoma of the skin. The disorder results from heterozygous germline mutations in the fumarate hydratase gene that is thought to act as a tumor suppressor. More than half of these mutations consist of single nucleotide changes resulting in amino acid substitutions. Here, we ascertained a new British and Dutch patient with cutaneous leiomyomatosis and sought to elucidate the molecular basis of the disorder in both individuals. Using polymerase chain reaction based techniques and automated DNA sequencing we screened the fumarate hydratase gene for sequence deviations. Genetic testing revealed two previously unreported missense mutations, designated FH:c.1103T>C, p.M368T and FH:c.1002T>G, p.S334R. Both sequence deviations affect evolutionarily fully conserved amino acid residues at functional important sites of the encoded protein indicating that these mutations will impair proper protein functioning. Our data contribute to the comprehension of missense mutations in the fumarate hydratase gene underlying hereditary multiple cutaneous leiomyomatosis.
\end{abstract}




\section{Introduction}

Familial cutaneous leiomyomatosis is an autosomal dominantly inherited disorder characterized by disseminated leiomyoma of the skin. When associated with uterine leiomyoma it is referred to as multiple cutaneous and uterine leiomyoma (MCUL; OMIM 150800). Both disease variants result from heterozygous germline mutations in the fumarate hydratase (FH) gene (1). This gene codes for $\mathrm{FH}$, which catalyzes the conversion of fumarate to malate in the Krebs cycle and supposedly functions as tumor suppressor $(1,2)$. Here, we report on two individuals with cutaneous leiomyomatosis resulting from novel missense mutations in the $\mathrm{FH}$ gene.

\section{Methods}

\section{Patients}

The first patient (individual III-2 in Fig. 1a) is an otherwise healthy 35-year-old British Caucasian male who developed erythematous papules on his back and left leg in 2002 (Fig. 1b). His mother (individual II-2 in Fig. 1a) underwent hysterectomy for unknown reason at the age of 30 and his grandmother (individual I-2 in Fig. 1a) had a kidney removed for polyps at early age. The second patient (individual II-2 in Fig. $1 \mathrm{~d}$ ) is a healthy 40-year-old Dutch Caucasian male who developed painful skin tumors on the left shoulder at the age of 14 , which subsequently spread out to his left arm, chest, and both legs (Fig. 1e). His mother (individual I-2 in Fig. 1d) was known with uterine and cutaneous leiomyoma and his older brother (individual II-1 in Fig. 1d) also had cutaneous leiomyoma. Histopathological examination confirmed the diagnosis of cutaneous leiomyomatosis.

\section{Mutation detection}

We extracted genomic DNA and amplified by polymerase chain reaction (PCR) the coding regions and exon-intron boundaries of the $\mathrm{FH}$ gene using primer pairs and conditions that were described previously (3). PCR products were purified with ExoSAP-IT (Biolynx Inc., Brockville, Ontario, Canada) and sequenced directly on an ABI 377 genetic analyzer from Applied Biosystems Inc., using the BigDye deoxy terminator V3.1 cycle sequencing kit (Applied Biosystems, Foster City, CA). Sequence analysis was performed with the software tools Phred, Phrap and Consed, as described previously (3). Subsequently, we used the SWISS-MODEL, a protein modeling server (http://swissmodel.expasy. org/), to localize the new mutations in the predicted 3D-structure of the human FH enzyme (4). 


\section{Results}

Sequencing analysis in the first patient (individual III-2 in Fig. 1a) revealed a heterozygous T-to-C transition at nucleotide position 1103 of the FH cDNA. This sequence deviation in exon 7 of the $\mathrm{FH}$ gene leads to the substitution of a methionine by a threonine residue, designated p.M368T (Fig. 1c). In the second patient (individual II-2 in Fig. 1d), we found a T-to-G transversion at nucleotide position 1002 of the $\mathrm{FH}$ CDNA, also located in exon 7 of the $\mathrm{FH}$ gene and resulting in the conversion of a serine to an arginine residue, designated p.S334R (Fig. 1f). Both sequence deviations were absent in 100 control individuals. Our nucleotide numbering for mutation designation includes the first 129 nucleotides of exon 1, the mitochondrial form of the $F H$ gene, in accordance with guidelines for the description of changes in DNA and protein sequences suggested by the Nomenclature Working Group (5). Hence, nomenclature may differ from previous reports of other authors. 
(a)

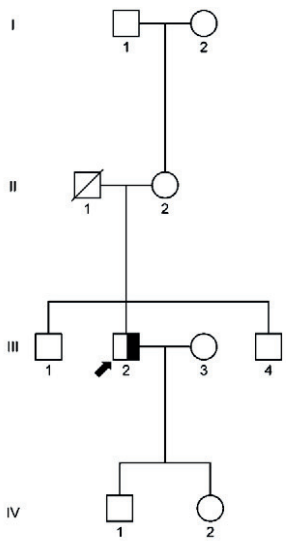

(c)
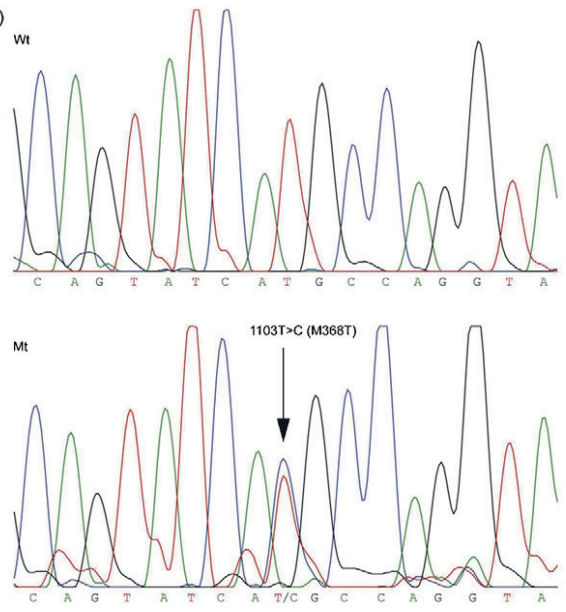

(e)

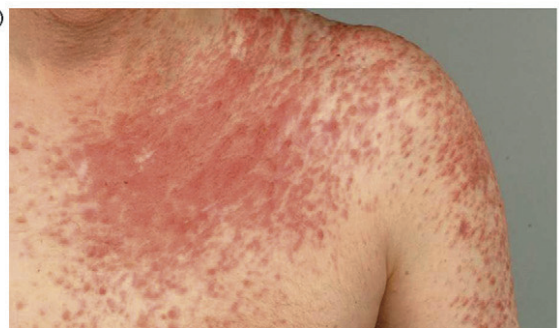

(b)

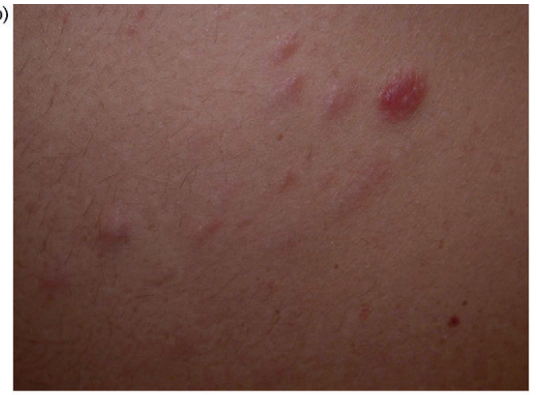

(d) ।

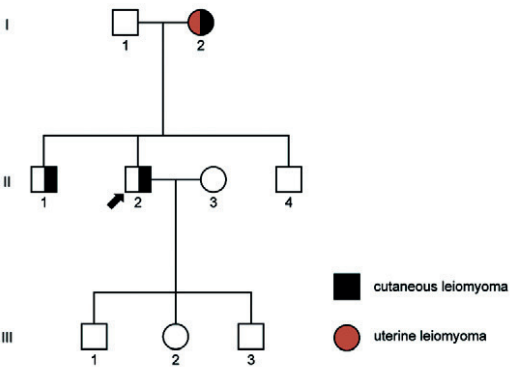

(f)
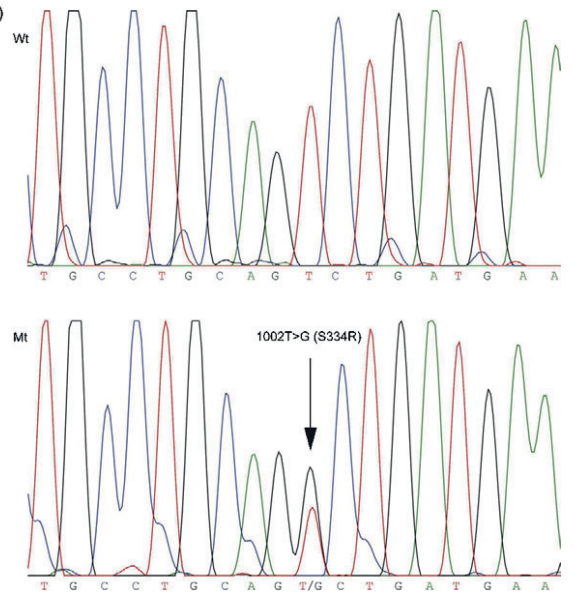

Figure 1. (a) Pedigree of family 1. The index patient (individual III-2) is depicted with a black symbol and an arrow; (b) firm skin-colored to erythematous papules on the left back of individual III-2; (c) results of mutation analysis in individual III-2. Missense mutation p.M368T in exon 7 of the $\mathrm{FH}$ gene, consisting of a heterozygous T-to-C transition (arrow; lower panel), compared to the wild-type sequence of a control individual (top panel); (d) pedigree of family 2. The three individuals affected with cutaneous leiomyoma are depicted with black symbols. Note that individual I-2 also had a history of uterine leiomyoma indicated by a red symbol; (e) segmentally distributed erythematous papules and nodules on the left shoulder and chest of individual II-2; (f) results of mutation analysis in individual II-2. Missense mutation p.S334R in exon 7 of the $\mathrm{FH}$ gene, consisting of a heterozygous T-to-G transversion (arrow: lower panel), compared to the wild-type sequence of a control individual (top panel). 


\section{Discussion}

Three lines of evidence suggest that the new mutations c.1103T>C, p.M368T and c.1002T>G, p.S334R are pathogenic. First, the sequence deviations could not be detected in 100 control individuals, thereby excluding a common polymorphism. Second, they cause amino acid conversions in which the side chains change in hydrophobicity or charge ( $\mathrm{p.M} 368 \mathrm{~T}$, a non-polar methionine to an uncharged polar threonine; and p.S334R, an uncharged polar serine to a charged polar basic arginine) which both might impair proper protein functioning. Third, a comparison of nucleotide-deduced amino acid sequences revealed that both altered residues are strictly conserved through evolution (Fig. 2a). The evolutionary conservation of FH in different species allows the application of their three-dimensional structures as models for predicting the effect of missense mutations on FH function(6). Computational analysis deduced from the human FH homology model at the SWISS-MODEL repository indicated that both sequence deviations detected in this study involve functional important regions of the enzyme. Mutation p.M368T occurs at the active A-site, whereas mutation p.S334R is localized in the subunit-subunit binding domain (Fig. 2b and c). 


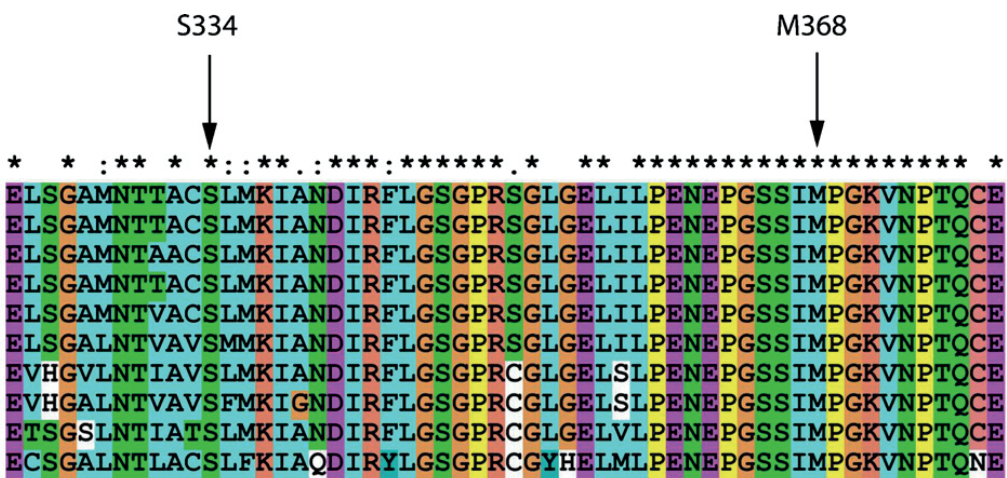

(b)

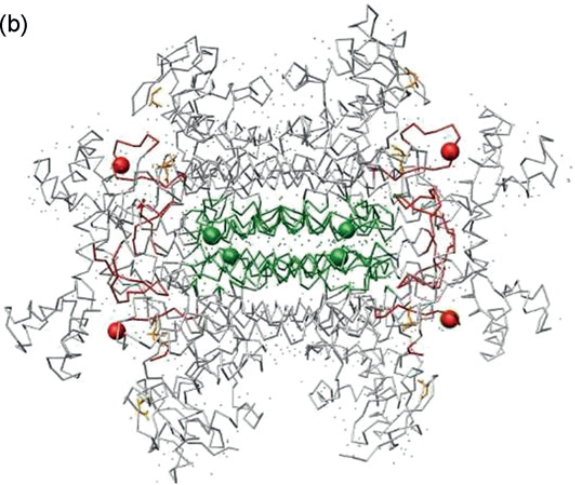

(c)

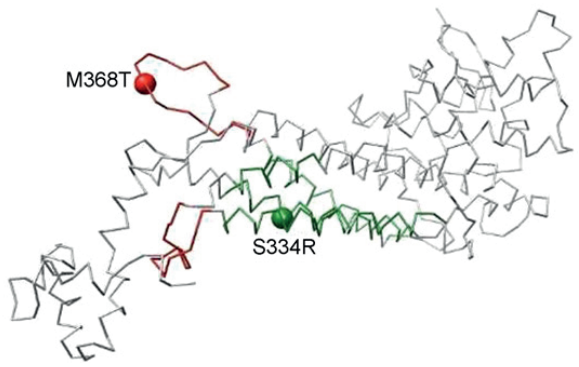

Figure 2. (a) Alignment of nucleotide-deduced amino acid sequences from codon 323 to 378 of fumarate hydratase. Note that the serine residue at position 334 and the methionine residue at position 368, respectively, are strictly conserved in human (Homo sapiens), dog (Canus familiaris), mouse (Mus musculus), rat (Rattus norvegicus), chicken (Gallus gallus), zebrafish (Danio rerio), fruitfly (Drosophila melanogaster), worm (Caenorhabditis elegans), plant (Arabidopsis thaliana), and the yeast (Saccharomyces cerevisiae) through evolution. (b) Three-dimensional homotetramer of fumarase $\mathrm{C}$ from Escherichia coli with depiction of the active site (red wire), subunit interface site (green wire), and the positions of the missense mutations detected in this study, p.M368 (red dot) and p.S334 (green dot). Illustration generated using UCSF Chimera. (c) Three-dimensional model of the human FH monomer, showing the positions of the amino acid changes within the protein structure. Illustration generated using UCSF Chimera.

Missense mutations in the $F H$ gene play an important role in familial cutaneous leiomyomatosis. To date, approximately 75 different $\mathrm{FH}$ mutations in cutaneous leiomyomatosis have been reported, consisting of at least 45 distinct missense mutations. The majority of previously reported $\mathrm{FH}$ missense mutations occur at highly conserved amino acid residues and, more importantly, these missense mutations apparently reduce $\mathrm{FH}$ activity to the same degree as frameshift mutations (7). The localization of the two novel mutations at functionally important and fully conserved sites of FH supports the notion that these sequence deviations are responsi- 
ble for hereditary cutaneous leiomyomatosis in the two patients reported here and is in line with the results of previous studies $(1-3,7,8)$.

It is well established that between 1 and $14 \%$ of families with MCUL also cluster renal cancer, a constellation referred to as hereditary leiomyomatosis and renal cell cancer (HLRCC; OMIM 605839)(1, 9). Interestingly, the first patient's grandmother (individual I-2 in Fig. 1a) had a medical history of nephrectomy for polyps. Unfortunately, the precise nature of these tumors is unknown. Renal polyps represent a usually benign fibroepithelial neoplasia of the upper urinary tract (10). Still, the possibility that these so-called polyps were malignant renal tumors fitting HLRCC cannot be completely ruled out. Although kidney tumors have not been detected yet in the two index patients studied here, careful screening of these individuals and their relatives carrying $\mathrm{FH}$ mutations is mandatory because the overall risk of developing renal cancer within this group is significantly higher than in the normal population. Taken together, our data and those of other groups strongly suggest that missense mutations in the $\mathrm{FH}$ gene perturb normal $\mathrm{FH}$ function, giving rise to familial cutaneous leiomyomatosis or the disease variants MCUL and HLRCC. Knowledge of the underlying genetic defect in these patients does not only allow for adequate genetic counseling but also for specific screening of family members at risk. This might contribute to the early detection of renal cancer in affected individuals.

\section{Acknowledgements}

We are grateful to the patients for their interest and participation in this study. MAMvS is supported by grants from the GROW research institute of the University Hospital Maastricht, the La Roche Posay Research Foundation, Barrier Therapeutics NV, and ZONMW grant 907-00-202.

\section{References}

1. Tomlinson IP, Alam NA, Rowan AJ, Barclay E, Jaeger EE, Kelsell. et al. Germline mutations in FH predispose to dominantly inherited uterine fibroids, skin leiomyomata and papillary renal cancer. Nat Genet 2002;30:406-10.

2. Chuang GS, Martinez-Mir A, Geyer A, Engler DE, Glaser B, Cserhalmi-Friedman PB, et al. Germline fumarate hydratase mutations and evidence for a founder mutation underlying multiple cutaneous and uterine leiomyomata. J Am Acad Dermatol 2005;52:410-6.

3. Badeloe S, van Geel M, van Steensel MA, Bastida J, Ferrando J, Steijlen PM, et al. Diffuse and segmental variants of cutaneous leiomyomatosis: novel mutations in the fumarate hydratase gene and review of the literature. Exp Dermatol 2006;15:735-41.

4. Kopp J, Schwede T. The SWISS-MODEL Repository of annotated three-dimensional protein structure homology models. Nucleic Acids Res 2004;32:230-4. 
5. Den Dunnen JT, Antonarakis SE. Mutation nomenclature extensions and suggestions to describe complex mutations: a discussion. Human Mutat 2000;15:7-12.

6. Lee D, Redfern $\mathrm{O}$, Orengo $\mathrm{C}$. Predicting protein function from sequence and structure. Nat Rev Mol Cell Biol 2007;8:995- 1005.

7. Pithupakorn M, Wei MH, Toure O, Steinbach PJ, Glenn GM, Zbar B, et al. Fumarate hydratase enzyme activity in lymphoblastoid cells and fibroblasts of individuals in families with hereditary leiomyomatosis and renal cell cancer. J Med Genet 2006;43:755-62.

8. Makino T, Nagasaki A, Furuichi M, Matsui K, Watanabe H, Sawamura D, et al. Novel mutation in a fumalate hydratase gene of a Japanese patient with multiple cutaneous and uterine leiomyomatosis. J Dermatol Sci 2007;48:151-3.

9. Alam NA, Rowan AJ, Wortham NC, Pollard PJ, Mitchell M, Tyrer JP, et al. Genetic and functional analyses of $\mathrm{FH}$ mutations in multiple cutaneous and uterine leiomyomatosis, hereditary leiomyomatosis and renal cancer, and fumarate hydratase deficiency. Hum Mol Genet 2003;12: 1241-52.

10. Nowak MA, Marzich CS, Scheetz KL, McElroy JB. Benign fibroepithelial polyps of the renal pelvis. Arch Pathol Lab Med 1999;123:850-2. 


\title{
2.3 Absence of fumarate hydratase mutation in a family with cutaneous leiomyosarcoma and renal cancer
}

\begin{abstract}
A 41-year-old man was diagnosed with a cutaneous leiomyosarcoma on the left shoulder. Family history revealed that his brother had died of a metastatic kidney tumor at young age. Although apparently rare, the familial occurrence of cutaneous leiomyosarcoma with renal cancer has been described in the context of hereditary cutaneous leiomyomatosis and renal cell cancer (HLRCC). This rare genetic syndrome is caused by heterozygous mutations in the fumarate hydratase $(F H)$ gene. Hence, the manifestation of these two rare malignancies within one family was strongly suggestive of a common underlying genetic defect. However, mutation analysis in the $F H$ gene excluded HLRCC in this family. Although the familial occurrence of these rare tumors might be coincidental, it cannot be ruled out that, besides $F H$, mutations in another as yet unknown gene could give rise to both leiomyosarcoma and kidney cancer.
\end{abstract}




\section{Introduction}

Cutaneous leiomyosarcoma is a rare, usually sporadic, malignant, smooth muscle tumor derived from the arrector pili or genital dartoic muscle of the skin (1). Together with subcutaneous leiomyosarcoma, which is thought to arise from the smooth muscle wall of blood vessels, it forms the superficial leiomyosarcoma group. This group accounts for approximately $2-3 \%$ of all soft tissue sarcomas (2). Cutaneous leiomyosarcoma arises in the dermis, with or without extension to the subcutis, whereas the primary origin of subcutaneous leiomyosarcoma is within the subcutis (3). In contrast with subcutaneous and even deeper localized soft tissue leiomyosarcoma, the clinical course of cutaneous leiomyosarcoma tends to be more indolent (4). Without gender preponderance, cutaneous leiomyosarcoma predominantly manifests in the fourth decade of life and has a predilection for the lower extremities $(5,6)$. Despite the high risk of local recurrence, metastases develop only infrequently $(4,7,8)$. Nevertheless, long-term follow-up of patients with cutaneous leiomyosarcoma is mandatory for the early detection of local recurrence and distant metastases, which can occur even years after the initial diagnosis and tumor excision. Recently, the occurrence of cutaneous leiomyosarcoma in two families with hereditary cutaneous leiomyomatosis and renal cell cancer (HLRCC) has been reported $(9,10)$. Patients with this rare inherited tumor syndrome have a predisposition to the development of cutaneous leiomyoma, uterine leiomyoma, and renal cancer. HLRCC is inherited in an autosomal dominant pattern and results from heterozygous mutations in the fumarate hydratase $(F H)$ gene $(11,12)$.

\section{Methods}

\section{Patient}

A 41-year-old man presented at our outpatient clinic with a painful tumor that had developed 6 months earlier in a smallpox vaccination scar. His further medical history was unremarkable. His family history revealed an older brother who had died of metastatic renal cell cancer at the age of 47 years. On clinical examination, there was a skin-colored to erythematous tumor of $2 \times 3 \mathrm{~cm}$ on the left shoulder (Fig. 1a). There were no palpable axillary lymph nodes. Histopathologic examination showed a poorly demarcated dermal tumor composed of proliferative bundles of spindle cells intermingled with collagen fibers (Fig. 1b). In addition, mitotic figures and atypical cells were detected (Fig. 1c). Immunohistochemistry revealed positive staining for anti- $\alpha$-smooth muscle actin (Fig. 1d) and desmin. Based on the clinical and histologic findings, we made a diagnosis of superficial cutaneous leiomyosarcoma (T1aNOM0). Subsequently, the tumor was radically excised. 

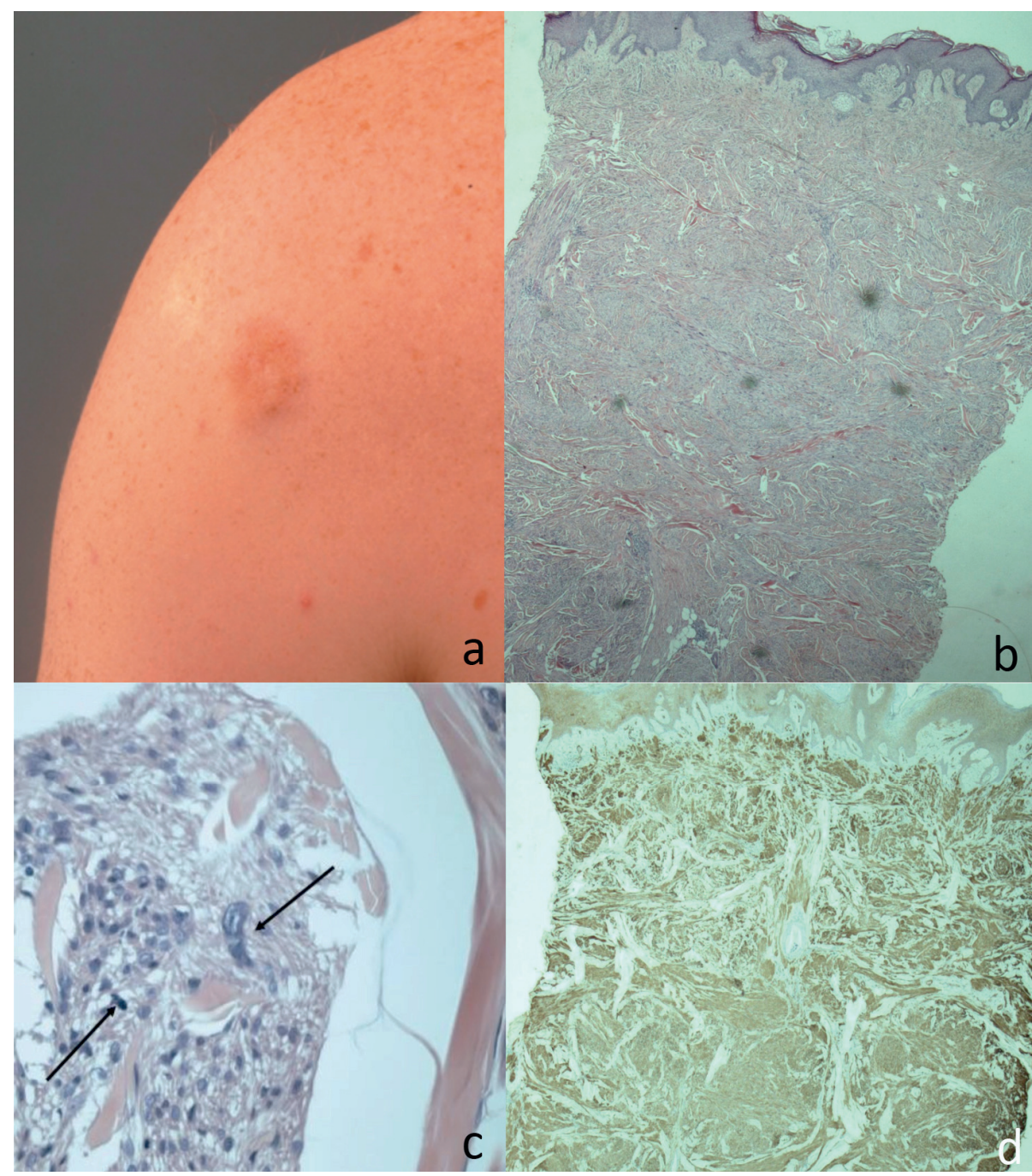

Figure 1 (a) Tumor on the left shoulder of the index patient. (b) Histopathology of superficial cutaneous leiomyosarcoma with proliferative spindle cell bundles intermingled with collagen fibers (hematoxylin and eosin; magnification, $\times 25$ ). (c) Atypical cell and mitosis (hematoxylin and eosin; magnification, $\times 400$ ). (d) Positive staining for anti- $\alpha$-smooth muscle actin (magnification, $\times 25$ ).

Following informed consent, mutation analysis of the $\mathrm{FH}$ gene was performed on DNA extracted from peripheral blood mononuclear cells. By polymerase chain reaction (PCR), the entire coding region and all exon-intron boundaries were amplified as described previously (13). PCR products were sequenced on an ABI 3730 genetic analyzer (Applied Biosystems Inc., Nieuwerkerk a/d ljssel, the Netherlands), and analyzed with the software tools Phred, Phrap, and Consed (14-16). 


\section{Results}

DNA analysis did not reveal any pathogenic sequence deviation (data not shown).

\section{Discussion}

Rather uncommonly, the index patient described here developed a cutaneous leiomyosarcoma in a previous smallpox vaccination site. Although the occurrence of benign and malignant tumors in such vaccination sites is well documented, $(17,18)$ the reasons for the occasional development of malignant skin tumors in smallpox vaccination scars are not well understood. To our knowledge, the manifestation of a cutaneous leiomyosarcoma in this site has not been reported previously.

In addition to the sporadic occurrence of cutaneous leiomyosarcoma, as described above, this neoplasm can also develop in the context of $\operatorname{HLRCC}(9,10)$. In this rare hereditary tumor syndrome, cutaneous leiomyosarcoma is associated with the occurrence of different forms of kidney cancer $(9,10)$. Interestingly, the brother of our index patient died from metastatic kidney cancer at a relatively young age. The occurrence of these two rare malignant tumors within one family is highly suggestive of a genetic predisposition for a hereditary tumor syndrome. Because the manifestation of cutaneous leiomyosarcoma and renal cancer has been reported in the autosomal dominantly inherited HLRCC, which is caused by heterozygous mutations in the $F H$ gene, $(9,10)$ we performed DNA analysis in the index patient. Nevertheless, we did not detect any germline mutation in the coding region or adjacent splice-sites of $F H$, thereby largely excluding a hereditary predisposition for HLRCC in this family. Hence, currently we cannot explain the familial occurrence of these two tumors by any known monogenetic pathomechanism. The simultaneous occurrence of cutaneous leiomyosarcoma and renal cancer has not been reported in any hereditary tumor syndrome other than HLRCC.

Recently, however, non-Mendelian inheritance mechanisms including, for example, epigenetic phenomena, which alter the expression of a given gene or gene family without changing the nucleotide sequence of the gene, have received increasing interest, particularly in renal cancer formation (19). In this context, a better understanding of the so-called pseudohypoxic pathway has provided us with novel insights into the different molecular mechanisms possibly involved in renal carcinogenesis (20). By contrast, the pathogenetic mechanisms contributing to the development of cutaneous leiomyosarcoma are currently not well understood. Thus, it will be a future challenge to identify molecules and/or molecular mechanisms possibly linking the formation of cutaneous leiomyosarcoma with the pathways of renal carcinogenesis. The identification of the genes responsible for hereditary tumor syndromes manifesting with both skin and kidney cancer is important, because it 
will allow for the early diagnosis of individuals at risk by molecular genetic analysis. Moreover, timely recognition of these rare disorders is crucial in order to offer affected individuals and mutation carriers within the family potentially life-saving regular prophylactic screening examinations for cutaneous and renal tumors. In the patient described here, further molecular genetic studies will be needed to determine whether the familial occurrence of the two different tumors is associated with a common underlying monogenetic defect or merely a coincidence.

\section{References}

1. Holst VA, Junkins-Hopkins JM, Elenitsas R. Cutaneous smooth muscle neoplasms: clinical features, histologic findings, and treatment options. J Am Acad Dermatol 2002;46: 477-490; quiz, 91-94.

2. Stout AP, Hill WT. Leiomyosarcoma of the superficial soft tissues. Cancer 1958; 11: 844-854.

3. Guillen DR, Cockerell CJ. Cutaneous and subcutaneous sarcomas.Clin Dermatol 2001; 19: 262-268.

4. Svarvar C, Bohling T, Berlin O,et al. Clinical course of nonvisceral soft tissue leiomyosarcoma in 225 patients from the Scandinavian Sarcoma Group. Cancer 2007;109: 282-291.

5. Auroy S, Contesso G, Spatz A,et al. [Primary cutaneous leiomyosarcoma: 32 cases).Ann Dermatol Venereol 1999;126: 235-242.

6. Limaiem F, Chelly I, Bellil S, et al. Primary cutaneousleiomyosarcoma: a histological and immunohistochemical study of 4 cases. Pathologica 2007;99: 415-419.

7. Dahl I, Angervall L. Cutaneous and subcutaneous leiomyosarcoma. A clinicopathologic study of 47 patients. Pathol Eur1974;9: 307-315.

8. Porter CJ, Januszkiewicz JS. Cutaneous leiomyosarcoma. Plast Reconstr Surg 2002;109: 964-967.

9. Toro JR, Nickerson ML, Wei MH,et al. Mutations in the fumarate hydratase gene cause hereditary leiomyomatosis and renal cell cancer in families in North America. Am J Hum Genet 2003;73: 95106.

10. Wei MH, Toure O, Glenn GM,et al. Novel mutations in FH and expansion of the spectrum of phenotypes expressed in families with hereditary leiomyomatosis and renal cell cancer. J Med Genet2006;43: 18-27.

11. Tomlinson IP, Alam NA, Rowan AJ,et al. Germline mutations in FH predispose to dominantly inherited uterine fibroids, skin leiomyomata and papillary renal cell cancer. Nat Genet 2002;30: 406-410.

12. Huter $\mathrm{E}$, Wortham NC, Hartschuh $\mathrm{W}$, et al. Single basemutation in the fumarate hydratase gene leading tosegmental cutaneous leiomyomatosis.Acta Derm Venereol 2008;88: 63-65.

13. Badeloe S, van Geel M, van Steensel MA, Bastida J, FerrandoJ, Steijlen PM,et al. Diffuse and segmental variants ofcutaneous leiomyomatosis: novel mutations in the fumarate hydratase gene and review of the literature. Exp Dermatol 2006;15:735-741.

14. Ewing B, Green P. Base-calling of automated sequencer traces using phred. II. Error probabilities. Genome Res 1998;8: 186-194.

15. Ewing B, Hillier L, Wendl MC, Green P. Base-calling of automated sequencer traces using phred. I. Accuracy assessment Genome Res 1998;8: 175-185.

16. Gordon D, Abajian C, Green P. Consed: a graphical tool for sequence finishing. Genome Res 1998; 8: 195-202.

17. Curry JL, Goulder SJ, Nickoloff BJ. Occurrence of a basal cell carcinoma and dermatofibroma in a smallpox vaccination scar.Dermatol Surg 2008; 34: 132-133

18. Waibel KH, Walsh DS. Smallpox vaccination site complications. Int J Dermatol2006;45: 684-688. 
19. Banks RE, Tirukonda P, Taylor C, et al. Genetic and epigenetic analysis of von Hippel-Lindau (VHL) gene alterations and relationship with clinical variables in sporadic renal cancer. Cancer Res2006;66: 2000-2011.

20. Bratslavsky G, Sudarshan S, Neckers L,et al. Pseudohypoxic pathways in renal cell carcinoma. Clin Cancer Res2007;13:4667-4671. 



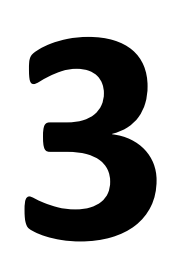

Type 2 segmental manifestation in hereditary cutaneous leiomyomatosis

S Badeloe, A Rübben, RS Bladergroen, M Kamps, PM Steijlen, P Poblete-Gutiérrez, A van Marion, MF Jonkman, R Happle, M van Geel, and J Frank. Molecular genetic support for type 2 segmental manifestation in hereditary cutaneous leiomyomatosis.

submitted 


\begin{abstract}
Multiple cutaneous and uterine leiomyomata (MCUL) is an autosomal dominant tumor syndrome that is associated with an increased risk of renal cancer. The disorder is caused by heterozygous mutations in the fumarate hydratase $(F H)$ gene. Interestingly, several patients with MCUL show a rather pronounced segmental arrangement of cutaneous leiomyomas, most likely reflecting mosaicism. This segmental phenotype could be explained by Happle's theory of the type 2 segmental manifestation of autosomal dominant skin disorders. Accordingly, the segmental manifestation would result from loss of heterozygosity (LOH) in a heterozygous individual at an early developmental stage. In MCUL, however, this hypothesis has not yet been proven at the molecular level. Here, we ascertained two patients with the clinical characteristics of a type 2 segmental manifestation of the disorder. By DNA sequencing and microsatellite analysis we detected two distinct heterozygous germline mutations and LOH in all segmentally arranged leiomyomas. To the best of our knowledge, we provide for the first time molecular support for the type 2 segmental manifestation of MCUL.
\end{abstract}




\section{Introduction}

Multiple cutaneous and uterine leiomyomata (MCUL; OMIM 150800) represent a rare genetic tumor syndrome that is transmitted as an autosomal dominant trait. The disease is characterized by multiple leiomyomas of the skin and uterus. When associated with kidney cancer this syndrome is referred to as hereditary leiomyomatosis and renal cell cancer (HLRCC; OMIM 605839). Both disease variants are caused by heterozygous mutations in the fumarate hydratase $(F H)$ gene that encodes for an enzyme in the Krebs cycle. Here, it catalyzes the conversion of fumarate to malate and is thought to act as a tumor suppressor since loss of the wildtype allele has been demonstrated in cutaneous, uterine, and renal tumors of patients with MCUL and $\operatorname{HLRCC}(1,2)$.

The hallmark of the disease are cutaneous leiomyomas, which typically present in the second to fourth decade of life and gradually increase in size and number over time. The extent of skin lesions is variable, even within one family. Some patients only have a few inconspicuous papules whereas others suffer from hundreds of leiomyomas covering large areas of the body.

Interestingly, cutaneous leiomyomas do not exclusively manifest in a diffuse and symmetric fashion. Rather frequently, a segmental or band-like manifestation pattern can be observed, most likely reflecting mosaicism (3-24). In 1996, Happle postulated a genetic concept for the segmental manifestation of autosomal dominantly inherited skin diseases (9). According to this rule of dichotomy, two types of segmental manifestation can be distinguished. The type 1 reflects heterozygosity for the underlying somatic mutation and shows a degree of severity similar to that of the corresponding non-mosaic trait caused by a germline mutation. The type 2 originates from postzygotic loss of heterozygosity (LOH) or an additional somatic gene mutation that occurred in a heterozygous embryo at an early developmental stage. The segmentally arranged cutaneous lesions usually develop prior to the diffuse phenotype and can even manifest shortly after birth or in early infancy. Affected body areas show a more severe clinical manifestation that is usually superimposed on the disseminated lesions of the ordinary trait (9). Although the type 2 segmental manifestation of autosomal dominant genodermatoses is rarely observed, Happle and others have reported it rather frequently in MCUL (3-24).

Recently, the hypothesis for the type 2 segmental manifestation of autosomal dominant skin disorders has been confirmed at the cellular and molecular level in HaileyHailey disease (25). In hereditary cutaneous leiomyomatosis, however, this concept has not yet been proven. Here we studied two unrelated patients with the clinical characteristics of a type 2 segmental manifestation of MCUL at the molecular genetic level. 


\section{Material and methods}

\section{Patients}

The first patient $(\mathrm{FH}-1)$ is an otherwise healthy 28-year-old Dutch Caucasian man who initially developed cutaneous leiomyomas at the age of 13 years in a segmental area on his back (Fig. 1a). These tumors were painful in response to cold or touch. More recently, he also developed two small asymptomatic solitary skin colored papules on his right arm. The family history revealed a paternal grandfather with leiomyoma. Neither the patient nor his relatives had a medical history of renal tumors.

The second patient (FH-2) is a 40-year-old Dutch Caucasian man who developed leiomyoma of the skin at the age of 14 years. The tumors initially manifested on his left shoulder and subsequently spread out, in a segmental pattern, to the left arm and chest (Fig. 1b). Only in later years he developed several nonsegmental leiomyomas that were distributed on both legs. Interestingly, the tumors growing in a segmental fashion were bigger and painful upon exposure to pressure or cold. The patient's further medical history was unremarkable. His deceased mother was known with uterine and cutaneous leiomyomas and his older brother also had cutaneous leiomyomas.

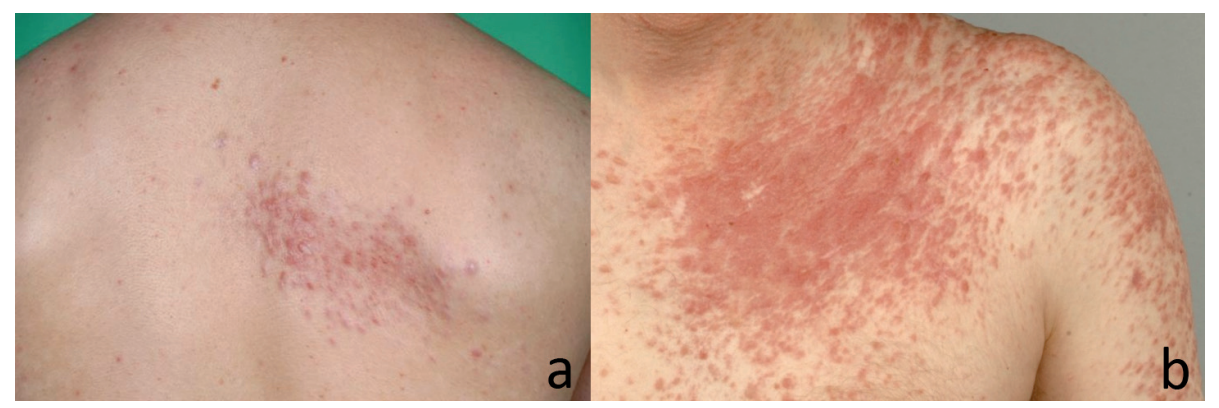

Figure 1 a) Firm skin-colored to erythematous papules on the right back of individual FH-1; b) Erythematous tumors in a segmental pattern on the left shoulder, the left arm and chest of individual FH-2.

From both patients skin biopsies for histological and molecular examination were taken after informed consent. Histopathologic examination showed interlacing bundles of smooth muscle cells intermingled with various amounts of collagen bundles, in accordance with the diagnosis of cutaneous leiomyomatosis (data not shown). All experimental procedures were carried out in accordance with the declaration of Helsinki and guidelines set forth by the local institutional review board. 


\section{Germline mutation detection}

EDTA anti-coagulated blood samples were obtained from both index patients and the parents of patient FH-1. Genomic DNA was extracted from peripheral blood leucocytes using standard methods. We amplified by polymerase chain reaction (PCR) the entire coding region and all exon-intron boundaries of the $F H$ gene using primer pairs and conditions that were previously described in detail (5). PCR products were purified with ExOSAP-IT (USB corporation, Cleveland, OH, USA) and sequenced directly on an $A B I 3730$ genetic analyzer (Applied Biosystems Inc. Foster City, CA, USA), using the BigDye terminator V1.1cycle sequencing kit (ABI). Sequence analysis was performed with the software tools Phred, Phrap and Consed (26-28). To exclude common polymorphisms, automated DNA sequencing was performed in 100 healthy and unrelated Dutch Caucasian control individuals.

\section{LOH studies}

Skin punch biopsies of cutaneous leiomyomas from segmentally affected areas, diffuse or nonsegmental leiomyomas that were clearly located outside the segmental area, and normal skin were taken from both patients. The tissue samples were directly frozen in liquid nitrogen. Frozen tissue sections of 10 micrometers were fixated with acetone and methanol and subsequently stained with hematoxylin and eosin. Liquid coverslip laser microdissection was performed using the P.A.L.M. Robot MicroBeam system (P.A.L.M., Bernried, Germany) as previously described in detail (29). Dissected tissue was captured on plastic cups and treated with tissue lysis buffer containing proteinase K (Qiagen Benelux BV, Venlo, The Netherlands). Subsequently, DNA was extracted using the DNeasy Tissue Kit (Qiagen Benelux BV, Venlo, The Netherlands), according to the manufacturer's instructions.

We compared DNA samples obtained from segmental and nonsegmental leiomyoma with DNA derived from blood and clinically normal tissue. For exclusion of second somatic FH gene mutations, DNA was subjected to PCR and automated DNA sequencing analysis using the previously published primers and conditions. For LOH analysis, we amplified microsatellite repeats flanking the $\mathrm{FH}$ locus on chromosome 1 (Table 1 ) in both proximal and distal direction using a method described by $\mathrm{M}$. Schuelke (30). PCR reactions (total volume $25 \mu \mathrm{l}$ ) contained $2.5 \mu \mathrm{l} 10 \mathrm{x}$ buffer (Invitrogen, Carlsbad, USA), $1 \mu$ dNTPs (5mM), $0.75 \mu$ DMSO, $1.5 \mathrm{mM} \mathrm{MgCl2,} 50 \mathrm{ng}$ forward primer, $100 \mathrm{ng}$ reverse primer, $100 \mathrm{ng}$ M13F-FAM labeled primer, and 0.75 $\mathrm{U}$ Taq DNA polymerase (Invitrogen). The PCR conditions were 35 cycles of $95^{\circ} \mathrm{C}$ for 30 seconds, annealing temperature (Table 2 ) for 45 seconds, and $72^{\circ} \mathrm{C}$ for 30 seconds; followed by 8 cycles of $95^{\circ} \mathrm{C}$ for 30 seconds, $53^{\circ} \mathrm{C}$ for 45 seconds, $72^{\circ} \mathrm{C}$ for 45 seconds; first initiated at $95^{\circ} \mathrm{C}$ for 5 minutes and ending with 7 minutes at $72^{\circ} \mathrm{C}$. Fluorescence-labeled PCR products were detected with an ABI3730 automated 
sequencer and analyzed with the Peak Scanner Software v1.0 (Applied Biosystems, Foster City, CA). All experiments were carried out in duplicate.

Table 1. PCR primer sequences and annealing conditions for $\mathrm{LOH}$ analysis

\begin{tabular}{|c|c|c|}
\hline $\begin{array}{l}\text { Microsatellite } \\
\text { marker }\end{array}$ & Primers & $\begin{array}{l}\text { Annealing } \\
\text { Temperature }\left({ }^{\circ} \mathrm{C}\right)\end{array}$ \\
\hline D1s2868 & $\begin{array}{l}\text { F: gtaaaacgacggccagtAGGTATAATCTGCAATAAAAAACTT } \\
\text { R: AAAGTAAAACAATATGAAGCCAC }\end{array}$ & 53 \\
\hline D1s218 & $\begin{array}{l}\text { F: tgtaaaacgacggccagtTGTAAAAGCAAACTGTAGACGAT } \\
\text { R: TTTATGTTATCACCAAGGCTTCT }\end{array}$ & 53 \\
\hline D1s2800 & $\begin{array}{l}\text { F: tgtaaaacgacggccagtAACCTCTCTGGTATGAAGCC } \\
\text { R: TTGTTCAAGGGTCAAATGC }\end{array}$ & 55 \\
\hline MS-1 & $\begin{array}{l}\text { F: tgtaaaacgacggccagtAGCAATGATGGTTTCTCTCTCA } \\
\text { R: CAGCACTAGCAGAATATGTGTAA }\end{array}$ & 55 \\
\hline MS-2 & $\begin{array}{l}\text { F: tgtaaaacgacggccagtCATAATTGGAAGCCACTGGAG } \\
\text { R: CATCACCCAACTCAAGGTCA }\end{array}$ & 53 \\
\hline D1s304 & $\begin{array}{l}\text { F: tgtaaaacgacggccagtACCCTTTTTCCTCCAATCAT } \\
\text { R: AGAAGCTGAAAGCTGAGTGG }\end{array}$ & 53 \\
\hline Micro-5 & $\begin{array}{l}\text { F: tgtaaaacgacggccagtTGGAGGTACTAGCCAGCATGGA } \\
\text { R: tttCCTGTTGACTGAATGGTGGA }\end{array}$ & 55 \\
\hline Micro-9 & $\begin{array}{l}\text { F: tgtaaaacgacggccagtATTGTATATTTACTGTCAACCA } \\
\text { R: AAACACTGATCCACTTGTCTCT }\end{array}$ & 55 \\
\hline D1s184 & $\begin{array}{l}\text { F: tgtaaaacgacggccagtTGACAGGCTCTAATTCCTTCAACACA } \\
\text { R: ggagtcacatattttgctgcccta }\end{array}$ & 55 \\
\hline D1s547 & $\begin{array}{l}\text { F: tgtaaaacgacggccagtCTGAAGTGGGAGGATTGCTT } \\
\text { R: AATTCAGGGGAGTTCCAGAG }\end{array}$ & 59 \\
\hline D1s2842 & $\begin{array}{l}\text { F: tgtaaaacgacggccagtTCACCTGACCTGTCCC } \\
\text { R: TGGTTCTCAGCCACAA }\end{array}$ & 55 \\
\hline D1s423 & $\begin{array}{l}\text { F: tgtaaaacgacggccagtGGGCAACAAGAATGAAACTC } \\
\text { R: GGCCTAAGATTGCTGTGAAG }\end{array}$ & 55 \\
\hline D1s2830 & $\begin{array}{l}\text { F: tgtaaaacgacggccagtAAAAGGATTAGGTAAGAGTGAGAAA } \\
\text { R: TCCAGATGTGATAAATGTGC }\end{array}$ & 55 \\
\hline
\end{tabular}

\section{Results}

\section{Germline mutation analysis}

In patient $\mathrm{FH}-1$ we detected a single nucleotide deletion in exon 9 of the $\mathrm{FH}$ gene at nucleotide position 1239, designated c.1239delT. This mutation causes a frameshift and leads to a premature termination codon 35 amino acids downstream of the deletion site (p.I413IfsX36) (Fig. 2). The same heterozygous mutation was found in his father. The mutation nucleotide position is based on NCBI-reference mRNA se- 
quence BC003108, which includes the first 129 nucleotides within exon 1 of the mitochondrial form of the $\mathrm{FH}$ gene. This nomenclature (31) may differ from that of other authors.

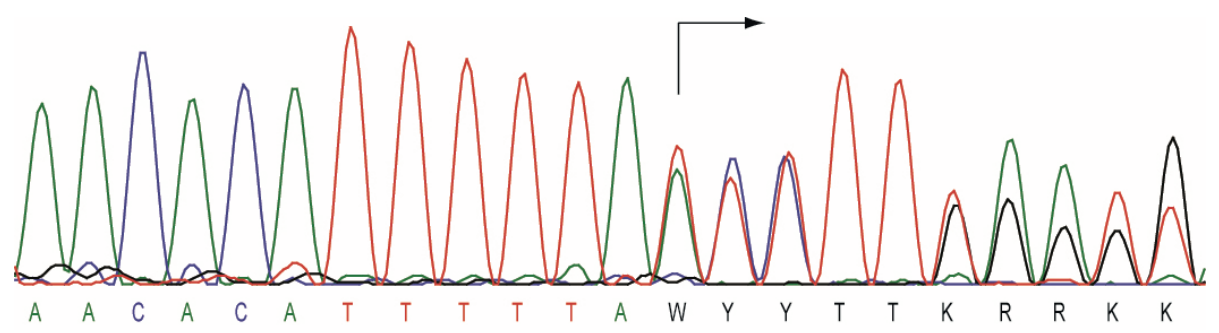

Figure 2. Results of mutation analysis in individual $\mathrm{FH}-1$, showing a single base pair deletion of a $\mathrm{T}$ at nucleotide position 1239 (c.1239delT) in exon 9 (note the sequence trace is depicted in the reverse complement orientation).

In patient $\mathrm{FH}-2$ we detected a heterozygous T-to-G transversion at nucleotide position 1002 (c.1002T>G) in exon 7 of the $F H$ gene (Fig. 3; top panel). This mutation leads to the conversion of a serine to an arginine residue at amino acid 334 of the encoded protein, designated p.S334R. Both mutations were absent in 100 control individuals.

\section{LOH studies}

In patient FH-1 microsatellite analysis revealed loss of the wild-type allele in the tumor tissue of a segmentally arranged leiomyoma. The chromosomal region affected by LOH spanned at least 1.9 Mb, between markers MS-2 and D1s2842 (Table 2). $\mathrm{LOH}$ analysis in this tumor and genotyping of family members showed that in DNA isolated from the tumor tissue of this individual the maternal allele was lost (data not shown). By contrast, we did not detect LOH in a nonsegmental leiomyoma of this individual.

In patient $\mathrm{FH}-2$ we observed allelic loss in both segmental leiomyomas studied and also in a nonsegmental leiomyoma. The chromosomal region affected by LOH spanned at least $68 \mathrm{Mb}$ in all leiomyomas (Table 2). In line with this finding, the sequence chromatograms of tumor tissue from both segmental and the diffuse leiomyomas predominantly showed the mutated G-allele whereas the wild-type Tsignal was barely visible (Figure 3; middle and bottom panel). 

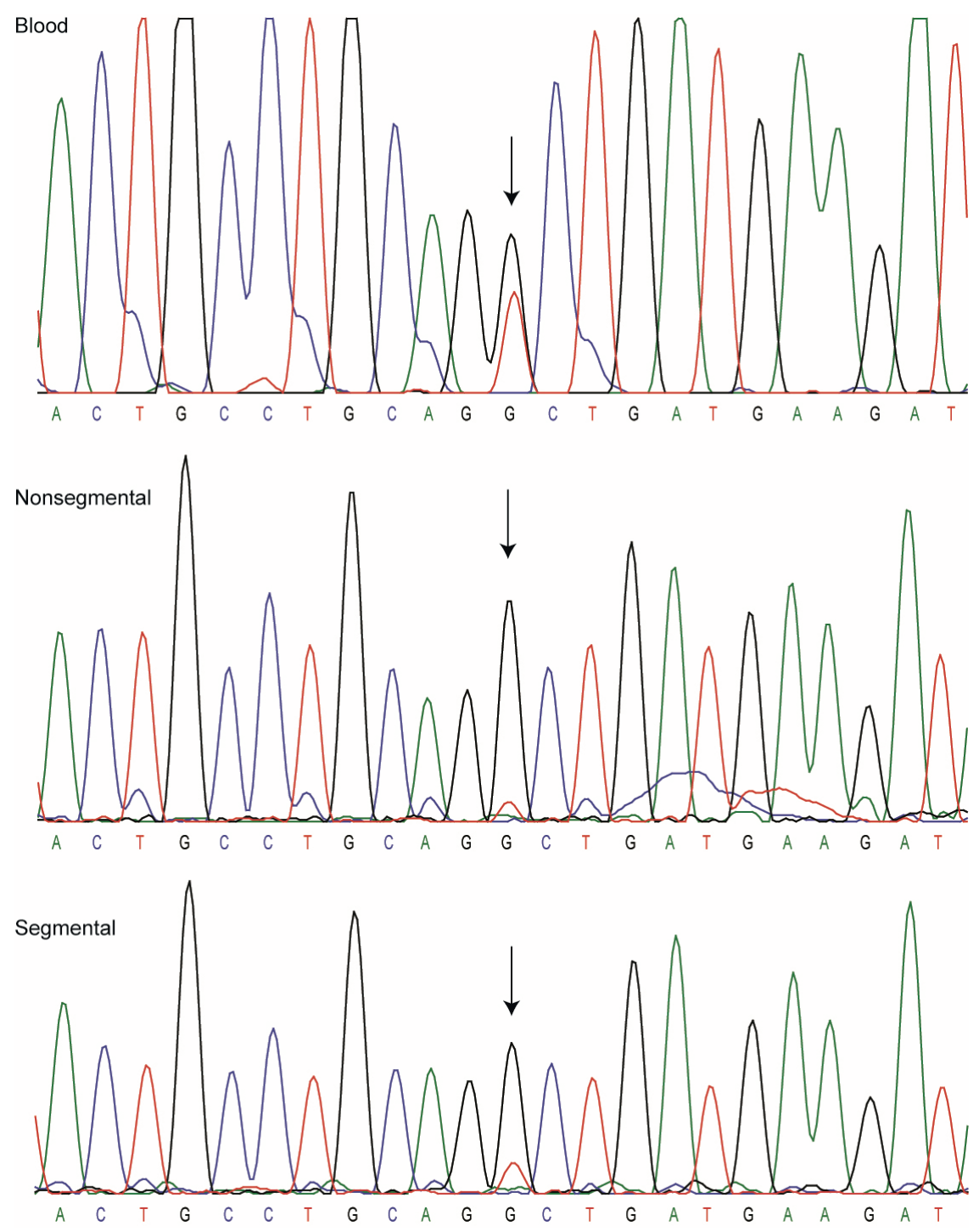

Figure 3. Results of mutation analysis in individual FH-2. Missense mutation p.S334R in exon 7 of the $\mathrm{FH}$ gene (c.1002T>G) detected in DNA from leucocytes (top panel), detected in DNA from tumor tissue of a nonsegmental leiomyoma (middle panel) and DNA from a segmental leiomyoma (bottom panel). Note that only the mutated G-allele is present whereas the wild-type T-signal is either absent or barely visible, as compared to the germline mutation (top panel). 
Table 2. Results of $\mathrm{LOH}$ analysis at 13 microsatellite markers flanking the $\mathrm{FH}$ gene. Microsatellite order: centromere, D1s2830, D1s2868, D1s218, D1s2800, MS-1, MS-2, D1s304, D1s184, FH gene/Micro-9, Micro-5, D1s547, D1s2842, D1s423, telomere. The possible LOH region is depicted in bold. $\mathrm{Ni}=$ not informative, $(-)=$ Not done, $\left({ }^{*}\right)=$ Failed.

\begin{tabular}{|c|c|c|c|c|c|c|c|}
\hline \multirow{2}{*}{$\begin{array}{l}\text { Micro- } \\
\text { satellite } \\
\text { marker }\end{array}$} & \multicolumn{3}{|c|}{ Patient FH-1 } & \multicolumn{4}{|c|}{ Patient FH-2 } \\
\hline & $\begin{array}{l}\text { Segmental } \\
\text { tumor }\end{array}$ & $\begin{array}{c}\text { Nonsegmental } \\
\text { tumor }\end{array}$ & $\begin{array}{l}\text { Normal } \\
\text { skin }\end{array}$ & $\begin{array}{l}\text { Segmental } \\
\text { tumor } 1\end{array}$ & $\begin{array}{c}\text { Segmental } \\
\text { tumor } 2\end{array}$ & $\begin{array}{l}\text { Nonsegmental } \\
\text { tumor }\end{array}$ & $\begin{array}{c}\text { Normal } \\
\text { skin }\end{array}$ \\
\hline D1s2830 & ni & $\mathrm{ni}$ & - & ni & ni & ni & - \\
\hline D1s2868 & - & - & - & $\mathrm{No} L O H$ & $\mathrm{No} L O H$ & $\mathrm{No} L O H$ & - \\
\hline D1s218 & ni & ni & - & LOH & LOH & LOH & - \\
\hline D1s2800 & ni & ni & - & LOH & LOH & LOH & - \\
\hline MS-1 & ni & ni & - & LOH & LOH & LOH & - \\
\hline MS-2 & LOH & No $\mathrm{LOH}$ & - & LOH & LOH & LOH & No $\mathrm{LOH}$ \\
\hline D1s304 & ni & ni & - & LOH & LOH & LOH & No $\mathrm{LOH}$ \\
\hline D1s184 & ni & ni & ni & ni & ni & ni & ni \\
\hline Micro-9 & LOH & $\mathrm{No} \mathrm{LOH}$ & $\mathrm{No} \mathrm{LOH}$ & ni & ni & ni & ni \\
\hline Micro-5 & LOH & $\mathrm{No} \mathrm{LOH}$ & No $\mathrm{LOH}$ & LOH & LOH & LOH & No $\mathrm{LOH}$ \\
\hline D1s547 & ni & ni & ni & LOH & LOH & LOH & No LOH \\
\hline D1s2842 & LOH & $\mathrm{No} \mathrm{LOH}$ & $\mathrm{No} \mathrm{LOH}$ & LOH & LOH & LOH & No LOH \\
\hline D1s423 & $*$ & $*$ & - & - & - & - & - \\
\hline
\end{tabular}

Beside the germline mutations we did not detect additional sequence changes indicative of somatic second hit mutations in any of the segmental or nonsegmental leiomyomas of both patients.

\section{Discussion}

Both individuals studied here fulfilled the clinical criteria of a type 2 segmental manifestation of MCUL, as suggested by Happle $(9,10,32)$. First, they developed cutaneous leiomyomas in a segmental area at young age, which were bigger and more painful than those normally observed in the ordinary diffuse trait. Later in life they 
developed additional leiomyomas that were diffusely distributed outside the segmentally affected body sites and clinically less severe.

In both patients we detected the underlying $F H$ germline mutations, which have been published previously $(4,5)$. Herewith the diagnosis of MCUL was unequivocally confirmed and formed the prerequisite for assessing Happle's theory at the genetic level. In patient FH-1 we found a frameshift mutation, designated c.1239delT. Of note, this mutation was previously published by our group as c.1238delA (5). This deletion results in a frameshift mutation that may exert its pathogenic effects either through nonsense-mediated mRNA decay, cryptic splicing (the site is located close to the exon 9 acceptor splice site and may be an exonic splice enhancer) or the formation of a truncated FH protein (33-36). Although the pathogenicity of this mutation is not doubtful we still excluded this sequence deviation in 100 controls. In patient FH-2 we detected a missense mutation, designated c.1002T>G, p.S334R. Three lines of evidence suggest that this mutation is pathogenic. First, a common polymorphism was excluded by demonstrating the absence of this nucleotide change in 100 ethnically matched control individuals. Second, the sequence deviation causes an amino acid conversion from an uncharged polar serine to a charged polar basic arginine residue, which might disturb proper functioning of the encoded protein. Third, the serine residue at position 334 of human $\mathrm{FH}$ is strictly conserved throughout evolution (data not shown).

LOH studies in patient FH-1 revealed allelic loss in the segmental leiomyoma. The minimal chromosomal region involved spans approximately $1.9 \mathrm{Mb}$ (Table 2). Since both parents were available for DNA, haplotype analysis revealed that this individual had inherited the germline mutation c.1239delT from his father and we detected a consistent loss of the maternal wild-type allele in all segmental leiomyomas (data not shown). LOH was absent in both the nonsegmental leiomyomas and healthy skin. These findings are in concordance with Happle's postulation (32).

In patient $\mathrm{FH}-2$ we had the opportunity to study two segmental leiomyomas. In both tumors we found LOH. Importantly, the minimal region of LOH was identical in these two segmental leiomyomas (Table 2). This is in perfect support of Happle's theory of dichotomy in autosomal dominant skin disorders. Interestingly, we also detected the same region of $\mathrm{LOH}$ in the nonsegmental leiomyoma of this patient. This may raise the question if the leiomyoma on the right lower leg was indeed a "nonsegmental" leiomyoma. Since this tumor was located far away from the segmentally affected body area and had arisen more than 20 years after the segmental leiomyomas, we strongly believe that this leiomyoma indeed deserved the designation of a nonsegmental one. Albeit the finding of $\mathrm{LOH}$ in this nonsegmental tumor is not in contradiction with Happle's concept. LOH is frequently observed in benign tumors associated with autosomal dominantly inherited cutaneous tumor syndromes, such as MCUL (37). In the type 2 segmental variant of these disorders, this mutational event is supposed to occur at an early developmental stage, giving rise to an early 
manifestation of the disease in a segmental and rather pronounced pattern. Beside this early segmental phenotype though, nonsegmental tumors may also manifest at any time during life, due to late postzygotic $\mathrm{LOH}$ events. The fact that the region of $\mathrm{LOH}$ is the same in the nonsegmental compared to the two segmental leiomyoma may be coincidental. The fact that we did not find LOH or a second somatic mutation in the nonsegmental leiomyoma of patient FH-1 suggests that as hitherto unknown pathomechanisms such as, e.g. epigenetic silencing through methylation may play a role in tumorigenesis in MCUL. This notion is supported by previous studies $(1,38)$.

In conclusion, we studied two patients with the clinical characteristics of a type 2 segmental manifestation of MCUL. In both individuals we detected a heterozygous $\mathrm{FH}$ germline mutation and somatic $\mathrm{LOH}$ in all segmentally arranged leiomyomas, thereby for the first time providing molecular genetic support for the type 2 segmental manifestation of the disease.

\section{References}

1. Tomlinson IP, Alam NA, Rowan AJ, Barclay E, Jaeger EE, Kelsell D, et al. (2002) Germline mutations in $\mathrm{FH}$ predispose to dominantly inherited uterine fibroids, skin leiomyomata and papillary renal cell cancer. Nat Genet 30:406-410.

2. Toro JR, Nickerson ML, Wei MH, Warren MB, Glenn GM, Turner ML, et al. (2003) Mutations in the fumarate hydratase gene cause hereditary leiomyomatosis and renal cell cancer in families in North America. Am J Hum Genet 73:95-106.

3. Agarwalla A, Thakur A, Jacob M, Joshi A, Garg VK, Agrawal S (2000) Zosteriform and disseminated lesions in cutaneous leiomyoma. Acta Derm Venereol 80:446.

4. Badeloe S, Bladergroen RS, Jonkman MF, Burrows NP, Steijlen PM, Poblete-Gutierrez P, et al. (2008) Hereditary multiple cutaneous leiomyoma resulting from novel mutations in the fumarate hydratase gene. J Dermatol Sci.

5. Badeloe S, van Geel M, van Steensel MA, Bastida J, Ferrando J, Steijlen PM, et al. (2006) Diffus and segmental variants of cutaneous leiomyomatosis: novel mutations in the fumarate hydratase gene and review of the literature. Exp Dermatol 15:735-741.

6. Badeloe S, van Geel M, van Steensel MA, Steijlen PM, Poblete-Gutierrez P, Frank JA (2007) [From gene to disease; cutaneous leiomyomatosis]. Ned Tijdschr Geneeskd 151:300-304.

7. Berendes U, Kuhner A, Schnyder UW (1971) Segmentary and disseminated lesions in multiple hereditary cutaneous leiomyoma. Humangenetik 13:81-82.

8. Fleta Asin B, Berzal Rosende M, Carrillo Gijon R, Fernandez-Guarino M, Jaen Olasolo P (2009) Type 2 segmental cutaneous leiomyomatosis: an example of mosaicism. Eur J Dermatol 19:183-184.

9. Happle R (1996) Segmental forms of autosomal dominant skin disorders: different types of severity reflect different states of zygosity. Am J Med Genet 66:241-242.

10. Happle R (2001) [Segmental type 2 manifestation of autosome dominant skin diseases. Development of a new formal genetic concept]. Hautarzt 52:283-287.

11. Happle R (2002) Dohi Memorial Lecture. New aspects of cutaneous mosaicism. J Dermatol 29:681692.

12. Huter E, Wortham NC, Hartschuh W, Enk A, Jappe $U$ (2008) Single base mutation in the fumarate hydratase gene leading to segmental cutaneous leiomyomatosis. Acta Derm Venereol 88:63-65. 
13. Konig A (2005) [Segmental leiomyomatosis: from haplotype to type Happle]. J Dtsch Dermatol Ges 3:671-672.

14. Konig A, Happle R (2001) Type 2 segmental cutaneous leiomyomatosis. Acta Derm Venereol 81:383.

15. Lang K, Reifenberger J, Ruzicka T, Megahed M (2002) Type 1 segmental cutaneous leiomyomatosis. Clin Exp Dermatol 27:649-650.

16. Martinez-Mir A, Glaser B, Chuang GS, Horev L, Waldman A, Engler DE, et al. (2003) Germline Fumarate hydratase mutations in families with multiple cutaneous and uterine leiomyomata. J Invest Dermatol 121:741-744.

17. Martinez-Mir A, Gordon D, Horev L, Klapholz L, Ott J, Christiano AM, et al. (2002) Multiple cutaneous and uterine leiomyomas: refinement of the genetic locus for multiple cutaneous and uterine leiomyomas on chromosome 1q42.3-43. J Invest Dermatol 118:876-880.

18. Renner R, Sticherling M (2005) [Familial occurrence of a type 2 segmental manifestation of cutaneous leiomyomatosis]. J Dtsch Dermatol Ges 3:695-699.

19. Richter G (1965) [Primary Segmental Localization of Multiple Leiomyomas.]. Hautarzt 16:177-179.

20. Ritzmann S, Hanneken S, Neumann NJ, Ruzicka T, Kruse R (2006) Type 2 segmental manifestation of cutaneous leiomyomatosis in four unrelated women with additional uterine leiomyomas (Reed's Syndrome). Dermatology 212:84-87.

21. Sada A, Misago N, Inoue T, Narisawa Y (2007) Segmental multiple cutaneous piloleiomyoma with an overlying epidermal proliferation. J Dermatol 34:665-667.

22. Smith CG, Glaser DA, Leonardi C (1998) Zosteriform multiple leiomyomas. J Am Acad Dermatol 38:272-273.

23. Suwattee $P$, Dakin C (2008) Bilateral segmental leiomyomas: a case report and review of the literature. Cutis 82:33-36.

24. Tsoitis G, Kanitakis J, Papadimitriou C, Hatzibougias Y, Asvesti K, Happle R (2001) Cutaneous leiomyomatosis with type 2 segmental involvement. J Dermatol 28:251-255.

25. Poblete-Gutierrez P, Wiederholt T, Konig A, Jugert FK, Marquardt Y, Rubben A, et al. (2004) Allelic loss underlies type 2 segmental Hailey-Hailey disease, providing molecular confirmation of a novel genetic concept. J Clin Invest 114:1467-1474.

26. Ewing B, Green P (1998) Base-calling of automated sequencer traces using phred. II. Error probabilities. Genome Res 8:186-194.

27. Ewing B, Hillier L, Wendl MC, Green P (1998) Base-calling of automated sequencer traces using phred. I. Accuracy assessment. Genome Res 8:175-185.

28. Gordon D, Abajian C, Green P (1998) Consed: a graphical tool for sequence finishing. Genome Res 8:195-202.

29. Rubben A, Bausch B, Nikkels A (2006) Somatic deletion of the NF1 gene in a neurofibromatosis type 1-associated malignant melanoma demonstrated by digital PCR. Mol Cancer 5:36.

30. Schuelke M (2000) An economic method for the fluorescent labeling of PCR fragments. Nat Biotechnol 18:233-234.

31. den Dunnen JT, Antonarakis SE (2000) Mutation nomenclature extensions and suggestions to describe complex mutations: a discussion. Hum Mutat 15:7-12.

32. Happle R (1997) A rule concerning the segmental manifestation of autosomal dominant skin disorders. Review of clinical examples providing evidence for dichotomous types of severity. Arch Dermatol 133:1505-1509.

33. Byers PH (2002) Killing the messenger: new insights into nonsense-mediated mRNA decay. J Clin Invest 109:3-6.

34. Den Dunnen JT, Van Ommen GJ (1999) The protein truncation test: A review. Hum Mutat 14:95-102.

35. Hentze MW, Kulozik AE (1999) A perfect message: RNA surveillance and nonsense-mediated decay. Cell 96:307-310.

36. Happle R (1999) Loss of heterozygosity in human skin. J Am Acad Dermatol 41:143-164.

37. Wagner E, Lykke-Andersen J (2002) mRNA surveillance: the perfect persist. J Cell Sci 115:3033-3038. 
38. Alam NA, Rowan AJ, Wortham NC, Pollard PJ, Mitchell M, Tyrer JP, et al. (2003) Genetic and functional analyses of $\mathrm{FH}$ mutations in multiple cutaneous and uterine leiomyomatosis, hereditary leiomyomatosis and renal cancer, and fumarate hydratase deficiency. Hum Mol Genet 12:1241-1252. 



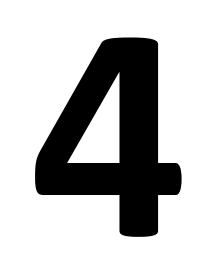

\section{Hereditary leiomyomatosis and renal cell cancer in the Netherlands: a nationwide study}

Smit DL, Mensenkamp AR, Badeloe S, Breuning MH, Simon ME, van Spaendonck KY, Aalfs CM, Post JG, Shanley S, Krapels IP, Hoefsloot LH, van Moorselaar RJ, Starink TM, Bayley JP, Frank J, van Steensel MA, Menko FH. Hereditary leiomyomatosis and renal cell cancer in families referred for fumarate hydratase germline mutation analysis. Clin Genet. 2011 Jan;79(1):49-59. 


\begin{abstract}
Heterozygous fumarate hydratase $(F H)$ germline mutations cause hereditary leiomyomatosis and renal cell cancer (HLRCC), an autosomal dominant syndrome characterized by multiple cutaneous piloleiomyomas, uterine leiomyomas and papillary type 2 renal cancer. The main objective of our study was to evaluate clinical and genetic data from families suspected of HLRCC on a nationwide level. All families referred for $\mathrm{FH}$ mutation analysis in the Netherlands were assessed. We performed $\mathrm{FH}$ sequence analysis and multiplex ligation-dependent probe amplification. Families with similar FH mutations were examined for haplotype sharing. In 14 out of 33 families, we identified 11 different pathogenic $\mathrm{FH}$ germline mutations, including 4 novel mutations and 1 whole-gene deletion. Clinical data were available for $35 \mathrm{FH}$ mutation carriers. Cutaneous leiomyomas were present in all $F H$ mutation carriers older than 40 years of age. Eleven out of 21 female $F H$ mutation carriers underwent surgical treatment for symptomatic uterine leiomyomas at an average of 35 years. Two $F H$ mutation carriers had papillary type 2 renal cancer and a Wilms tumor, respectively. We evaluated the relevance of our findings for clinical practice and have proposed clinical diagnostic criteria, indications for $F H$ mutation analysis and recommendations for management.
\end{abstract}




\section{Introduction}

Hereditary leiomyomatosis and renal cell cancer (HLRCC, OMIM \#605839) or multiple cutaneous and uterine leiomyomas (MCULs, OMIM \#150800) form an autosomal dominant tumor syndrome caused by heterozygous germline mutations in the $f u$ marate hydratase $(F H)$ gene $(1,2)$. The condition is characterized by multiple cutaneous piloleiomyomas and early-onset, severely symptomatic uterine leiomyomas; in addition, a subset of patients develops renal cell cancer, mainly of the papillary type 2. Patients with both skin and uterine leiomyomas have been described in case reports since the 1950s. The eponym 'Reed's syndrome' is based on the publication by Reed et al. in 1973 (3) on two families with this particular combination of clinical manifestations. In this report, one patient also had disseminated renal cancer. Launonen et al. (1) established the association with papillary type 2 renal cancer. Insight into the molecular genetic background started with the mapping and subsequent identification of the $\mathrm{FH}$ gene $(1,2)$.

The $F H$ gene maps to chromosome $1 q 42.3-43$ and encodes the 50-kDa subunit of the homotetramer FH. Both cytosolic and mitochondrial FH isotypes are known. Whereas the first is possibly involved in amino acid metabolism, mitochondrial $\mathrm{FH}$ functions as an enzyme in the tricarboxylic acid (TCA) cycle, where it catalyzes the conversion of fumarate into malate (2). In HLRCC, tumor formation presumably follows Knudson's two-hit model in which tumors arise from the inactivation of the wild-type $\mathrm{FH}$ allele in somatic cells (4).

More than 200 families have been reported to carry germline $\mathrm{FH}$ mutations. The majority of these families were documented in case series from the United Kingdom, North America and Finland $(2,4-8)$. Single reports of families from India and Japan suggest that the disorder occurs worldwide $(9,10)$.

In exceptional cases in which both parents are heterozygous $\mathrm{FH}$ germline mutation carriers, homozygous $\mathrm{FH}$ germline mutations may occur in the offspring. This leads to fumarase deficiency (OMIM \#606812), a severe metabolic disorder characterized by growth retardation and neurological abnormalities. This condition is usually fatal in early childhood (11).

Reportedly, DNA sequence analysis detects mutations in about $90 \%$ of families with a clinical picture compatible with HLRCC (5-8). In one family, Ahvenainen et al. (12) found an $\mathrm{FH}$ germline deletion using multiplex ligation dependent probe amplification (MLPA).

Here, we present a systematic nationwide study of $\mathrm{FH}$ germline mutation analysis. We examined 33 families with presumed HLRCC by DNA sequence analysis and MLPA testing. We assessed clinical variability in families with identified FH mutations. Based on these data, we propose clinical diagnostic criteria for HLRCC and indications for $\mathrm{FH}$ germline mutation analysis. We also consider options for surveillance aimed at early diagnosis and treatment of HLRCC manifestations. 


\section{Patients and methods}

\section{Family recruitment}

In the Netherlands, FH germline mutation analysis is performed in one single diagnostic laboratory (Radboud University Medical Centre Nijmegen). Patient and pedigree data were collected for all 33 apparently unrelated index patients who have been analyzed since $\mathrm{FH}$ mutation analysis became available in 2004 . These included 29 Dutch probands and 4 from different European countries. Genetic counseling was performed following standard procedures including informed consent.

Cutaneous leiomyomas were diagnosed by expert dermatological examination and histological investigation in all cases. Routinely, initial renal imaging was performed after detection of an $\mathrm{FH}$ germline mutation. However, long-term surveillance data were not available. Data on five index patients (LMY04, LMY05, LMY10, LMY13, LMY20) have been published previously (13-15).

\section{Mutation screening}

DNA was isolated according to standard techniques. All exons of the $F H$ gene (accession number NM 000143.2) and flanking intron sequences were amplified by polymerase chain reaction (PCR). Primer and PCR amplification data are available upon request. Subsequently, sequence analysis was performed using a 3730 automated sequencer (Applied Biosystems, Foster City, CA). Mutation nomenclature follows the guidelines given at http://www.hgvs.org/mutnomen, with the $A$ of the translation initiation codon in the reference sequence numbered as +1 . The initiation codon is codon 1 . Newly identified missense mutations were analyzed using at least 50 healthy controls.

The DNA samples from mutation-negative patients were screened for exon deletions and/or duplications of the $F H$ gene by MLPA analysis with a commercially available kit, according to the manufacturer's instructions (SALSA P198 kit, MRCHolland, Amsterdam, the Netherlands; http://www.mrc-holland.com).

\section{Haplotype analysis}

Haplotypes were determined by analysis of microsatellite markers surrounding $\mathrm{FH}$ (i.e. D1S1634, D1S304, D1S180, D1S1594, D1S2785, and D1S2679) for available family members with a common $\mathrm{FH}$ mutation and analyzed using the GeneMapper program (Applied Biosystems). The genomic localization of the markers was derived from the Marshfield map and the University of California Santa Cruz (UCSC) human genome database (build hg18, October 2006; http://www.genome.ucsc.edu). 


\section{Results}

\section{Proband data}

The indications for $\mathrm{FH}$ germline mutation analysis in the 33 families suspected of HLRCC are summarized in Table 1, which also shows the 14 kindreds positive for $F H$ germline mutations. For these 14 families, an $\mathrm{FH}$ mutation was confirmed in 35 patients (including the probands). Illustrative pedigrees of three families (LMY05, LMY21, LMY26) are shown in Fig. 1.

Table 1. Indications for fumarate hydratase $(F H)$ mutation analysis for 33 families suspected of hereditary leiomyomatosis and renal cell cancer (HLRCC) ${ }^{a}$

\begin{tabular}{|c|c|c|}
\hline Indication & Numbers of families ${ }^{b}$ & Family codes \\
\hline Cutaneous leiomyomas & 14 & $\begin{array}{l}\text { LMY07, LMY09, LMY04, LMY05, } \\
\text { LMY06, LMY10, LMY13, LMY20, } \\
\text { LMY21, LMY23, LMY26, LMY27, } \\
\text { LMY28, LMY33 }\end{array}$ \\
\hline Uterine leiomyomas & 13 & $\begin{array}{l}\text { LMY07, LMY03, LMY05, LMY06, } \\
\text { LMY10, LMY12 LMY28, LMY31, } \\
\text { LMY32, LMY20, LMY21, LMY22, } \\
\text { LMY33 }\end{array}$ \\
\hline Renal cancer & 11 & $\begin{array}{l}\text { LMY08, LMY05, LMY11, LMY13, } \\
\text { LMY14, LMY15', LMY16, LMY17, } \\
\text { LMY24, LMY25, LMY30 }\end{array}$ \\
\hline Uterine leiomyosarcoma & 3 & LMY18, LMY19, LMY02 \\
\hline $\begin{array}{l}\text { Non-cutaneous and non-uterine } \\
\text { leiomyomas, other malignancies }\end{array}$ & 8 & $\begin{array}{l}\text { LMY01, LMY16, LMY17, LMY12, } \\
\text { LMY21, LMY24, LMY29, LMY11 }\end{array}$ \\
\hline
\end{tabular}

${ }^{a}$ Families depicted in bold exhibited pathogenic $\mathrm{FH}$ germline mutations. ${ }^{\mathrm{b}}$ Thirteen probands had more

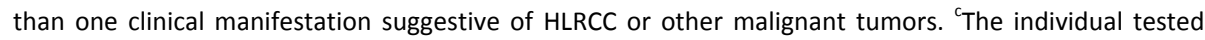
was a healthy sibling of a deceased affected family member.

\section{Mutation analysis}

DNA sequence analysis revealed 10 different germline mutations in 13 families. Of these, 6 were missense mutations (p.Arg233His, p.Gly275Glu, p.His318Tyr, p.Ser334Arg, p.Met382Val, p.Gly397 Arg), 3 were nonsense (p.Glu53X, p.Glu404X, p.Met412X) and 1 was a frameshift (p.Asn78fsX85). The mutations p.Arg233His and p.Glu404X were found in two and three different families, respectively. Haplotype 


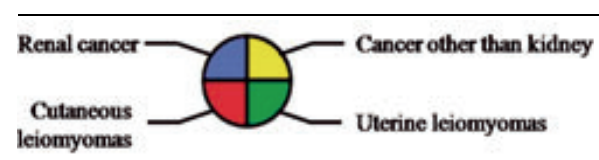

a
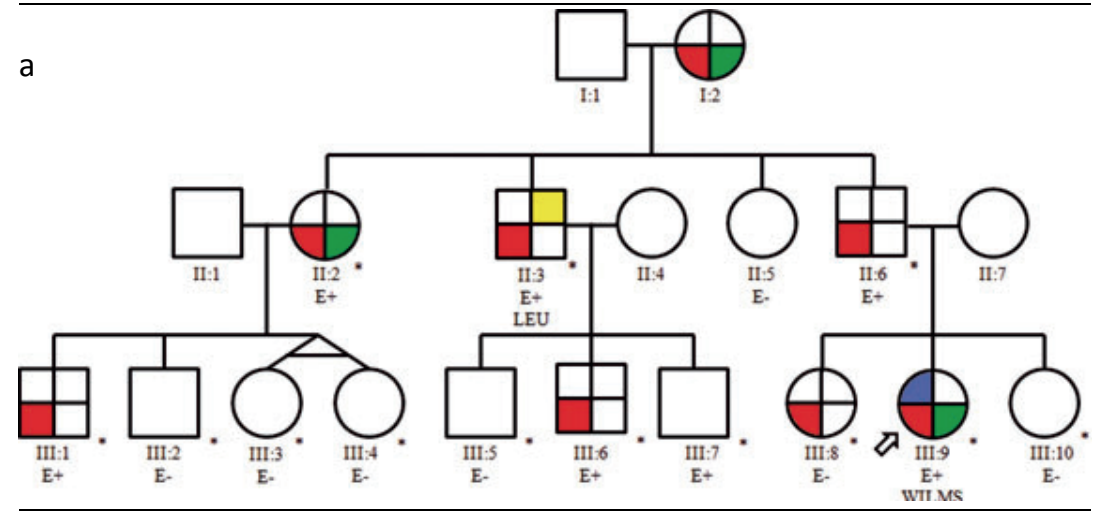

b
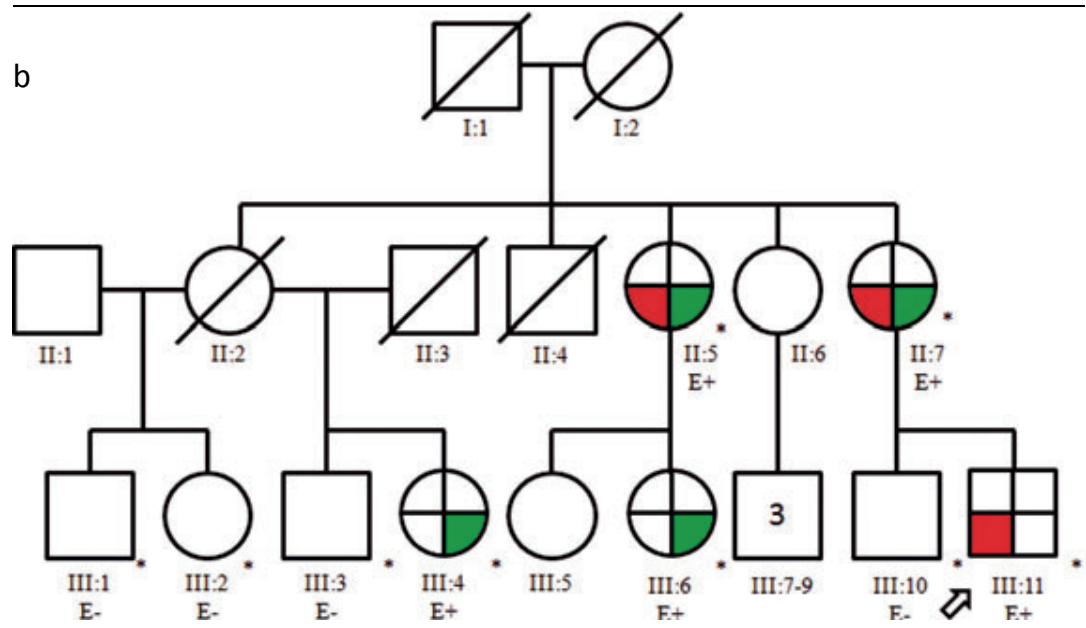

C
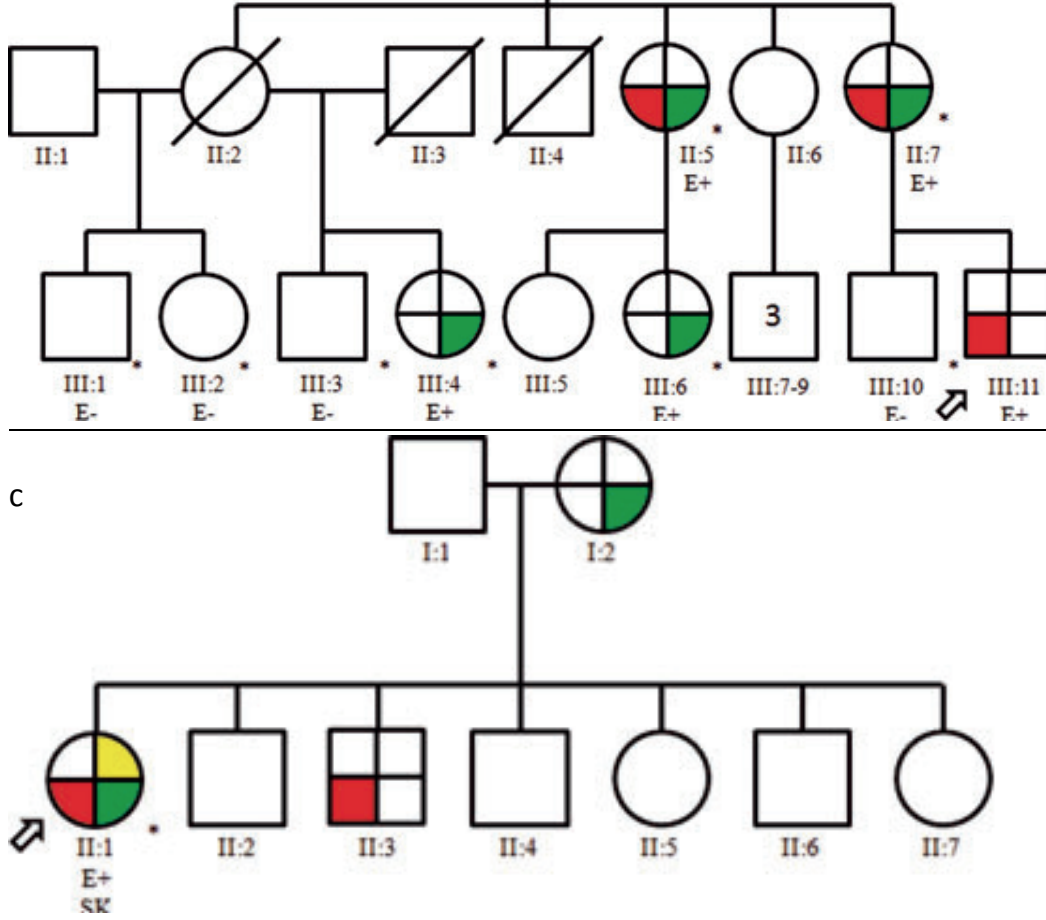
Figure 1. Pedigrees of three families with a documented pathogenic fumarate hydratase (FH) germline mutation. (a) LMY05 (15), the 25-year-old individual III:7 was the only unaffected mutation carrier in our cohort; (b) LMY26; (c) LMY21. Asterisks indicate whether FH mutation analysis has been performed for the corresponding individual, E+ corresponds to mutation carrier and E- to non-carriers. LEU, leukaemia; SK, skin cancer; WILMS, Wilms tumor.

analysis revealed identical repeat lengths of several microsatellite markers in the index patients with the recurrent p.Glu404X mutation (Fig. 2), but not in those with the p.Arg233His mutation (data not shown).

MLPA analysis was performed for the index patients from 20 families without a detectable mutation using sequence analysis, which led to the identification of a whole-gene deletion in one index patient (LMY09), denoted as c.1-? c.*100del.

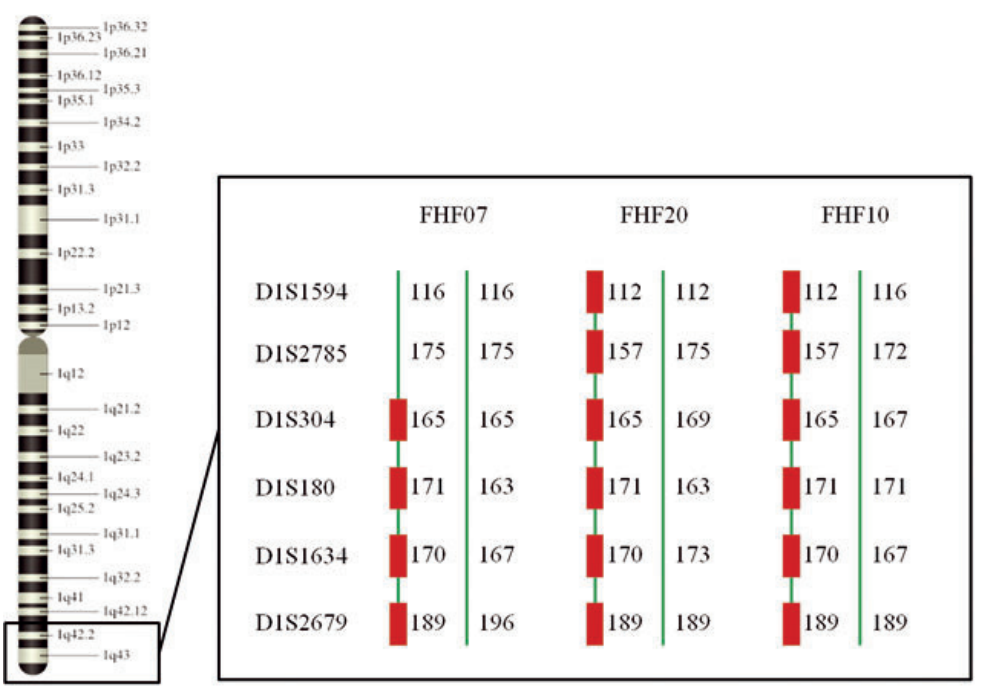

Figure 2. Haplotype analysis of probands with the recurrent p.Glu404X fumarate hydratase ( $F H$ ) germline mutation (LMY07, LMY20 and LMY10). Probands from LMY20 and LMY10 displayed identical marker lengths for all microsatellite markers. The proband from LMY07, however, had identical repeat lengths on only four out of six markers, with the two markers farthest upstream from $\mathrm{FH}$ being different.

\section{Clinical findings}

Multiple cutaneous leiomyomas occurred in all $\mathrm{FH}$ mutation positive families, whereas no such lesions were present in mutation-negative families (Table 2). In all families with an $\mathrm{FH}$ mutation, the cutaneous lesions had been diagnosed histopathologically as piloleiomyomas in at least one family member (Fig. 3). Cutaneous leiomyomas typically became manifest in the second to fourth decade of life. Common locations of involvement were extremities, shoulders and trunk, and to a lesser 
extent face and neck. The lesions varied from a few to over one hundred and were $0.2-2.0 \mathrm{~cm}$ in diameter (Fig. 4). The nodules, erythematous to skin-colored,

Table 2. Overview of the 14 families with a fumarate hydratase $(F H)$ germline mutation ${ }^{a}$

\begin{tabular}{|c|c|c|c|c|c|}
\hline Family & $\begin{array}{l}\mathrm{FH} \text { germline muta- } \\
\text { tion }\end{array}$ & $\begin{array}{l}\text { Evaluated family } \\
\text { members }\end{array}$ & $\begin{array}{l}\text { Cutaneous leio- } \\
\text { myomas }\end{array}$ & $\begin{array}{l}\text { Uterine leio- } \\
\text { myomas }\end{array}$ & Renal cell cancer \\
\hline LMY04 & c. $1002 T>G$ & $4(2)$ & 4 & 1 & - \\
\hline LMY05 & c. $1189 \mathrm{G}>\mathrm{A}$ & $8(4)$ & 8 & 3 & 1 \\
\hline LMY06 & c. $157 \mathrm{G}>\mathrm{T}$ & $2(2)$ & 1 & 2 & - \\
\hline LMY07 & c. $1210 \mathrm{G}>\mathrm{T}$ & $3(3)$ & 3 & 3 & - \\
\hline LMY09 & c.1-? c. ${ }^{*} 100 \mathrm{del}$ & $3(2)$ & 1 & 2 & - \\
\hline LMY10 & c. $1210 \mathrm{G}>\mathrm{T}$ & $1(1)$ & 1 & 1 & - \\
\hline LMY13 & c. $233 \mathrm{del}$ & $1(1)$ & 1 & - & 1 \\
\hline LMY20 & c. $1210 \mathrm{G}>\mathrm{T}$ & $3(3)$ & 3 & 3 & - \\
\hline LMY21 & c. $698 \mathrm{G}>\mathrm{A}$ & $3(2)$ & 2 & 2 & - \\
\hline LMY23 & c.1234del & $4(2)$ & 4 & 1 & - \\
\hline LMY26 & c. $824 G>A$ & $5(4)$ & 3 & 4 & - \\
\hline LMY27 & c. $698 \mathrm{G}>\mathrm{A}$ & $7(6)$ & 5 & 5 & 1 \\
\hline LMY28 & c. $1144 A>G$ & $2(1)$ & 2 & 1 & - \\
\hline LMY33 & c. $952 C>T$ & $2(2)$ & 2 & 2 & - \\
\hline
\end{tabular}

${ }^{a}$ Evaluated family members in the third column also include patients with manifestations clinically suggestive of hereditary leiomyomatosis and renal cell cancer (HLRCC) who have not undergone $F H$ mutation analysis. The numbers between parentheses denote the number of evaluated women.

were usually distributed in groups. Six patients also had scattered lesions. One patient showed only scattered lesions limited to the left upper arm and trunk. During the course of life, lesions had a tendency to grow in size and increase in number. In about $75 \%$ of patients the leiomyomas caused symptoms, in particular pain or itching in response to touching or temperature changes. The severity of such symptoms was highly variable.

Uterine leiomyomas occurred in 17 out of 21 female $\mathrm{FH}$ mutation carriers and usually were of early onset ( $86 \%<40$ years). The leiomyomas required surgical treatment in 11 out of 17 cases due to severe symptoms of abdominal pain, menorrhagia and metrorrhagia. Treatment consisted of hysterectomy in nine cases and myomectomy combined with oral contraceptives in the remaining two. The mean age at which surgery was performed was 35 years (range: 25-39 years) (Table 3). Two unrelated $\mathrm{FH}$ mutation-positive families each had a mutation carrier affected by renal cell cancer. One patient had a Wilms tumor at the age of 2 (III:9 in Fig. 1a). The other individual was initially diagnosed with a clear cell carcinoma of the kidney at the age of 30 , but pathological reassessment showed a papillary type 2 renal cell 
carcinoma (Fig. 5). In a third family, according to family history a patient had died at the age of 21 due to metastatic kidney cancer; no further data were available (Table 3).

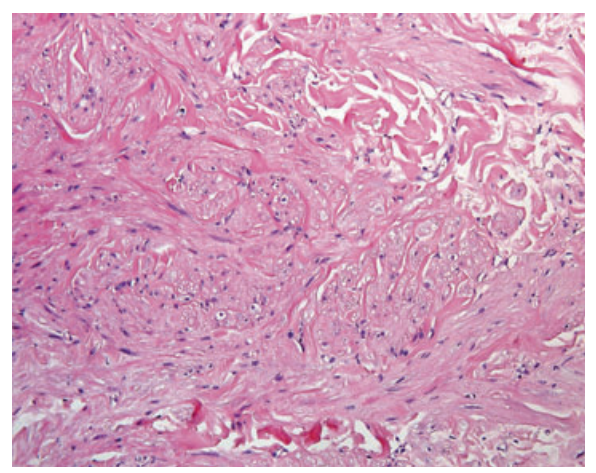

Figure 3. Characteristic histopathology of a cutaneous piloleiomyoma from patient II:7 from family LMY26 (Fig. 1b). The lesion consists of various bundles of smooth muscle cells interspersed with ample collagen fibers . Characteristic of piloleiomyoma are the elongated and blunt-ended nuclei in the smooth muscle tumor cells (hematoxylin eosin stain, magnification 100x).

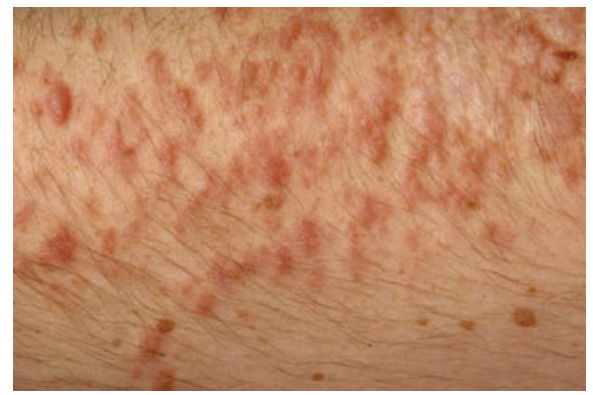

Figure 4. Picture of multiple cutaneous leiomyomas on the upper arm of patient III:11 from family LMY26 (Fig. 1b). The lesions developed when the patient was about 10 years old and subsequently increased in size and number.

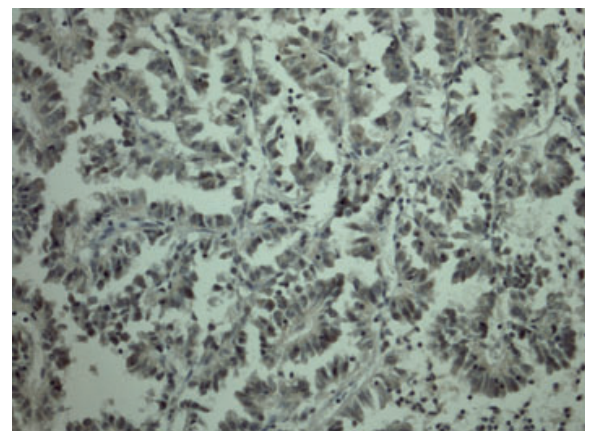

Figure 5. Histopathology of type 2 papillary renal cell carcinoma in patient II:2 of family LMY13. The tumor is composed of voluminous eosinophilic epithelial cells with pseudostratification of large oval nuclei on papillary cores (hematoxylin eosin stain, magnification 100x).

In three $\mathrm{FH}$ mutation carriers, malignancies other than renal cancer occurred. In each of two families (LMY20, LMY21), one patient had a basal cell carcinoma (Fig. 1c), while patient II:3 in LMY05 had leukemia (Fig. 1a). Abdominal imaging of proband III:11 from LMY26 (Fig. 1b) revealed an adrenal adenoma. In one family (LMY27), three $\mathrm{FH}$ mutation carriers but also a non-carrier had thyroid pathology. Renal cancers of various histological subtypes were often the indication for $\mathrm{FH}$ mutation analysis: 22 individuals in 19 FH mutation-negative families had a history of 
renal cancer, including 8 clear cell and 4 papillary carcinomas, and 1 renal leiomyosarcoma. The histological subtypes of the remaining cases were unknown. The age at diagnosis, known for 20 patients, was an average of 55 years (range: 37-89).

Table 3. Clinical details of uterine and/or renal pathology in confirmed fumarate hydratase (FH) mutation carriers $\left({ }^{*}\right)$ and clinically affected family members ${ }^{a}$

\begin{tabular}{|c|c|c|c|c|c|c|}
\hline \multirow[b]{2}{*}{ Family } & \multirow[b]{2}{*}{ Patient } & \multicolumn{3}{|c|}{ Uterine leiomyomas } & \multicolumn{2}{|c|}{ Renal cancer } \\
\hline & & $\begin{array}{l}\text { Age at diagno- } \\
\text { sis (years) }\end{array}$ & Treatment & $\begin{array}{c}\text { Age at } \\
\text { treatment } \\
\text { (years) }\end{array}$ & Histological subtype & $\begin{array}{c}\text { Age at } \\
\text { diagnosis } \\
\text { (years) }\end{array}$ \\
\hline LMY04 & II:4* & 39 & Hysterectomy & 39 & - & - \\
\hline \multirow[t]{2}{*}{ LMY05 } & $11: 2^{*}$ & 38 & Hysterectomy & 38 & - & - \\
\hline & III:9* & 24 & Myomectomy & 25,30 & Wilms tumor & 2 \\
\hline \multirow[t]{2}{*}{ LMY06 } & III:1* & 38 & Hysterectomy & 38 & - & - \\
\hline & III:2 & 35 & Hysterectomy & 35 & - & - \\
\hline LMY07 & III:1* & 40 & Myomectomy & 40 & - & - \\
\hline \multirow[t]{2}{*}{ LMY09 } & $\mathrm{I}: 4$ & NA & Hysterectomy & NA & - & - \\
\hline & II:9 & 30 & - & - & - & - \\
\hline LMY10 & III:2* & 22 & Hysterectomy & 34 & - & - \\
\hline LMY13 & $\mathrm{II}: 2^{*}$ & - & - & - & Papillary type 2 & 30 \\
\hline \multirow[t]{2}{*}{ LMY20 } & II:1 & NA & Hysterectomy & NA & - & - \\
\hline & II:3* & 48 & - & - & - & - \\
\hline \multirow[t]{2}{*}{ LMY21 } & II:14 & 39 & Hysterectomy & 39 & - & - \\
\hline & III:1* & 37 & - & - & - & - \\
\hline LMY23 & III:4* & NA & Hysterectomy & NA & - & - \\
\hline \multirow[t]{4}{*}{ LMY26 } & II:5* & 65 & - & - & - & - \\
\hline & $\mathrm{II}: 7^{*}$ & 27 & Hysterectomy & 27 & - & - \\
\hline & III:4* & 30 & Hysterectomy & 37 & - & - \\
\hline & III:6* & 31 & - & - & - & - \\
\hline \multirow[t]{6}{*}{ LMY27 } & $\mathrm{l}: 2$ & NA & Hysterectomy & NA & - & - \\
\hline & $\mathrm{II}: 1^{*}$ & 39 & Hysterectomy & 39 & - & - \\
\hline & II:2 & 36 & Hysterectomy & 36 & - & - \\
\hline & II:3* & 32 & Hysterectomy & 32 & - & - \\
\hline & II:4 & - & - & - & NA & 21 \\
\hline & III:4 & 36 & Hysterectomy & 36 & - & - \\
\hline LMY33 & III:1* & NA & - & - & - & - \\
\hline
\end{tabular}

${ }^{a}$ All patients listed in this table were females. A minus (-) indicates the absence of pathology or no treatment performed, whereas NA designates that detailed data were not available. 


\section{Discussion}

The main objective of our study was the combined analysis and correlation of clinical and genetic data from families suspected of HLRCC on a nationwide level, in order to develop diagnostic criteria and indications for $\mathrm{FH}$ mutation analysis. In the Netherlands, diagnostic $F H$ mutation analysis is centralized in one single laboratory and referring human genetics centers throughout the country cooperated closely in the collection of pedigree data. We identified 14 families with a pathogenic $F H$ germline mutation.

A limitation of our study is its retrospective nature in which data were collected from medical records of probands investigated in various clinical genetic centers. Diagnostic procedures and initial renal imaging in probands and family members were documented in detail, but long-term surveillance data were not available.

The frequency of HLRCC in the Dutch population is currently unknown. We presume underdiagnosis of the disorder for several reasons: (i) cutaneous leiomyomas may be inconspicuous and asymptomatic; therefore, many affected individuals will not undergo medical examination, (ii) uterine leiomyomas are very common in the general population and a genetic cause is rarely considered, and (iii) papillary renal cell cancer accounts for about $15 \%$ of all sporadic malignant kidney tumors and only occurs in a small subset of patients with HLRCC.

\section{Clinical manifestations}

In this study, all $F H$ germline mutation carriers older than 40 years had cutaneous leiomyomas. In line with this, Alam et al. (6) observed an $80-100 \%$ penetrance of cutaneous lesions in their study group. The clinical expression varied between and within families from a few asymptomatic leiomyomas to hundreds of painful lesions.

Uterine leiomyomas in HLRCC are reportedly of early onset and often cause severe symptoms. Accordingly, more than $80 \%$ of female $\mathrm{FH}$ mutation carriers in our cohort developed uterine leiomyomas, mainly in early adulthood, two thirds of whom required surgery. We observed renal cancer in 2 out of 35 (6\%) FH mutation carriers. Typically, papillary type 2 renal cell carcinoma is associated with $\operatorname{HLRCC}(16,17)$. Collecting duct and clear cell types, as well as oncocytic renal tumors, have also been reported in HLRCC families $(5-7,12,17,18)$. However, Wilms tumor has hitherto not been described in this syndrome (15). We are currently investigating a possible causal link between Wilms tumor and HLRCC. We found an adrenal incidentaloma in one FH mutation carrier. In the literature, tumors observed in HLRCC include testicular Leydig cell tumors, ovarian cystadenomas, gastrointestinal stromal tumors (GISTs) and adrenal gland tumors (4, 19-22). Our finding may support the proposed causal relationship between HLRCC and adrenal tumors (19). 


\section{Mutation spectrum}

The 11 different $F H$ germline mutations detected in this study are presented in Table 4. The two missense mutations p.Gly275Glu and p.Met382Val have not been reported previously. These missense changes are likely to be pathogenic as the respective amino acid changes affect residues of the encoded $\mathrm{FH}$ protein which are highly conserved throughout evolution. In addition, we found cosegregation of these mutations with clinical manifestations and the absence of the mutations in at least 100 control alleles. The novel c.157G>T mutation (p.Glu53X) and c.1234del (p.Met412X) mutations were each found in one family and are predicted to be pathogenic, as the premature termination of protein translation leads to either nonsense-mediated decay of the resulting mRNA or production of a truncated FH protein. MLPA of families with a negative DNA sequence analysis revealed a wholegene deletion in one family. This indicates that MLPA testing is a valuable complement to $F H$ sequence analysis.

Table 4. Fumarate hydratase $(F H)$ germline mutations detected in our case series by DNA sequence analysis $^{\mathrm{a}}$

\begin{tabular}{|c|c|c|c|}
\hline $\mathrm{FH}$ germline mutation & Amino acid change & Mutation type & $\begin{array}{l}\text { Mutation previously } \\
\text { published (references) }\end{array}$ \\
\hline c.1-? c. ${ }^{*} 100 \mathrm{del}$ & p.? & Whole/gene deletion & $(2,6,18)$ \\
\hline c. $157 \mathrm{G}>\mathrm{T}$ & p.Glu53X & Nonsense & Novel \\
\hline c.233del & p.Asn78fsX85 & Frameshift & (14) \\
\hline c. $698 \mathrm{G}>\mathrm{A}$ & p.Arg233His & Missense, $†, \ddagger, \S 300$ & $(2,5,7,18,27)$ \\
\hline c. $824 \mathrm{G}>\mathrm{A}$ & p.Gly275Glu & Missense, $†, \S 100$ & Novel \\
\hline c. $952 \mathrm{C}>\mathrm{T}$ & p.His318Tyr & Missense, $†, \S 420$ & $(5,34)$ \\
\hline c. $1002 T>G$ & p.Ser334Arg & Missense, $†, \ddagger, \S 100$ & (14) \\
\hline c. $1144 A>G$ & p. Met382Val & Missense, $†, \S 100$ & Novel \\
\hline c. $1189 \mathrm{G}>\mathrm{A}$ & p. Gly397Arg & Missense, $†, \ddagger, \S 100$ & $(18,33)$ \\
\hline c. $1210 \mathrm{G}>\mathrm{T}$ & p.Glu404X & Nonsense & (13) \\
\hline c.1234del & p.Met412X & Nonsense & Novel \\
\hline
\end{tabular}

${ }^{\text {a }}$ The mutation code in column 'amino acid change' is the same notation as used in the online $\mathrm{FH}$ mutation database (26). Pathogenicity of missense mutations is indicated by: $\dagger$, evolutionary conservation of the amino acid; $¥$, a known functional domain of $\mathrm{FH}$ is affected by the mutation; and $\S$, the absence of the change in control alleles (number added).

Linkage analysis showed that two of the three families (LMY10, LMY20) with the Glu404X mutation are likely to be related. The index patient from the third family had different nucleotide repeat frequencies on the two markers farthest upstream from $F H$, which could be due to a single recombination event. The Glu404X mutation in the third family (LMY07) thus may represent the same founder mutation. 
This is in line with the fact that all three families live in the same province in the Netherlands. Founder mutations have previously been shown to underlie HLRCC. For example, Chuang et al. (23) found the 905-1G>A FH mutation in four families of Jewish Iranian origin. Evidence for a founder effect of the c.173G>C FH mutation was observed in a German and English family $(24,25)$.

All reported variants of $F H$ are documented in an online database (26). Including the four novel mutations detected in our study, 82 different pathogenic $\mathrm{FH}$ germline mutations have now been found to underlie HLRCC. Of these, 21 have been detected in families with renal cancer. These are 11 missense, 7 frameshift and 2 nonsense changes as well as 1 splice-site change, and they are equally distributed over the $F H$ gene, excluding exon 6 (Fig. 6). Renal cancer does not always develop in families with one of these mutations. In our cohort for example, the c.Arg233His mutation was observed in two families with and without renal cancer, respectively. In total, this presumed hotspot mutation has now been detected in 24 families, whereas renal cancer occurred in only $7(2,5,7,18,27,28)$. Based on these data, no indication for a genotype-phenotype correlation was found. It is likely that all FH germline mutations are associated with a varying range of clinical manifestations (18). 


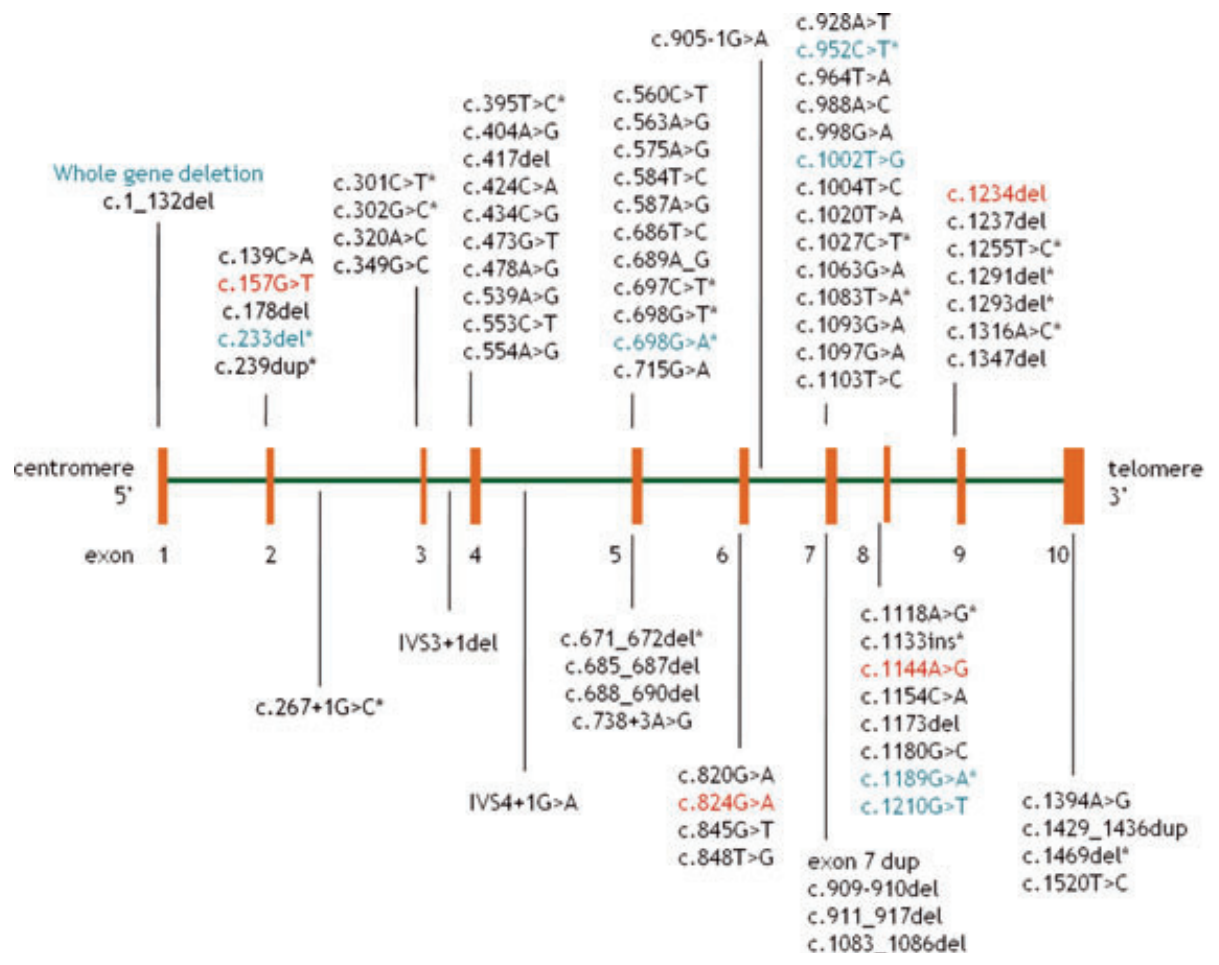

Figure 6. Overview of all reported pathogenic germline mutations in the fumarate hydratase (FH) gene that have been associated with hereditary leiomyomatosis and renal cell cancer (HLRCC). Asterisks indicate mutations that have been detected in HLRCC families with renal cell cancer. Novel and other mutations detected in this study are depicted in red and blue, respectively.

\section{Clinical and molecular diagnosis}

We did not find FH germline mutations in 19 of 33 kindreds with suspected HLRCC. Notably, evaluation of these families did not reveal strong clinical indications for HLRCC. In particular, no cutaneous leiomyomas were reported. Women from these families with severe clinical symptoms due to uterine leiomyomas required treatment at an average age of 47 years, which is more than 10 years older than the average for affected female $F H$ mutation carriers. Kiuru et al. (29) showed the presence of $F H$ germline mutations in 1-2\% of apparently sporadic early-onset uterine leiomyosarcomas. In our cohort, uterine leiomyosarcoma was the indication for $\mathrm{FH}$ mutation analysis in three probands, none of whom showed $\mathrm{FH}$ germline mutations. Renal cancer was also an important indication for $\mathrm{FH}$ mutation analysis. However, neither age at diagnosis nor histological subtype was in fact indicative of HLRCC in families without an $\mathrm{FH}$ mutation. 
Based on data from previous reports and our study group, we propose criteria for the clinical diagnosis of HLRCC (Table 5). A likely or suspected clinical diagnosis should be confirmed by detection of a pathogenic $\mathrm{FH}$ germline mutation. Indeed, $\mathrm{FH}$ mutation analysis was positive for all our probands with a likely clinical diagnosis of HLRCC according to these criteria, whereas no $F H$ mutations could be detected in index patients who did not fulfill the clinical diagnostic criteria. The accurateness of our criteria should be further evaluated prospectively. $F H$ germline mutations are rare in apparently sporadic renal cell cancer (25). However, FH mutation analysis might be justified for all patients with type 2 papillary renal cell carcinomas younger than 40 years. The yield of $F H$ mutation analysis is probably low in families in which multiple members have uterine leiomyomas as sporadic uterine leiomyomas are common in the general population. Due to the rareness of uterine leiomyosarcoma in HLRCC, FH mutation analysis only seems indicated if more signs indicative of HLRCC are present in the index patient or family. We found no reason for referral of patients with leiomyomas in other organs than skin or uterus, as such leiomyomas have not yet been reported in association with HLRCC.

Table 5. Proposed criteria for the clinical diagnosis of hereditary leiomyomatosis and renal cell cancer (HLRCC) $^{a}$

Major criterion

- Multiple cutaneous piloleiomyomas, histopathologically confirmed.

Minor criteria

- Surgical treatment for severely symptomatic uterine leiomyomas before age 40.

- Type 2 papillary renal cell carcinoma before age 40.

- A first-degree ${ }^{b}$ family member who meets one of the above-mentioned criteria.

${ }^{a}$ The diagnosis is likely when a proband meets the major criterion. HLRCC may be suspected when a proband meets at least two minor criteria. ${ }^{b}$ Occurrence of severely symptomatic uterine leiomyomas $<40$ years in second-degree paternal family members may also be relevant.

\section{Management and surveillance}

Cutaneous leiomyomas may cause serious pain and cosmetic distress. Skin lesions were sensitive in $90 \%$ of individuals with cutaneous leiomyomas documented by Wei et al. (7) We found symptoms in approximately $75 \%$ of $\mathrm{FH}$ mutation carriers affected by cutaneous leiomyomas. Whereas single painful skin lesions can easily be treated by wide surgical excision, management of multiple symptomatic lesions is difficult. Treatment options include pharmaceutical agents (i.e. nifedipine, gabapentine and doxasozine) and invasive therapy, such as extensive surgical excision, $\mathrm{CO}_{2}$ laser ablation and cryotherapy. However, as treatment outcome is highly variable, additional strategies are needed (30). 
Uterine leiomyomas in HLRCC are of early onset and cause severe clinical symptoms. In total, $70 \%$ of women with uterine leiomyomas reported by Toro et al. (5) were younger than 30 years old at the time of diagnosis. In our study group, 35 years was the mean age at which surgery was performed. Annual gynecological ultrasound examination of female $\mathrm{FH}$ mutation carriers starting at age 20 may reveal asymptomatic uterine leiomyomas, which could be monitored for future development. In addition, although leiomyosarcoma is probably rare, early signs of malignancy may be detected (i.e. inhomogeneous internal pattern, central necrosis, irregular vessel distribution) (31). Women affected with HLRCC should be counseled about family planning and treatment options.

The main focus of management in HLRCC is prevention of disease and death due to renal cancer. Relevant issues are the lifetime risk of renal cancer in $\mathrm{FH}$ mutation carriers, age at onset, biological behavior of the disease and options for early diagnosis and treatment. However, current knowledge regarding these issues is limited. Renal cancer risk apparently cannot be attributed to specific genotypes. It has been suggested that the risk could be increased in certain families due to shared genetic and environmental factors. If proven, surveillance for renal cancer might be aimed at only those families in which renal cancer had occurred previously. However, Vahteristo et al. (32) found no evidence for genetic modifiers of renal cancer risk in HLRCC and concluded that all FH mutation carriers may have an increased renal cancer risk. Previous reports showed that among $66 \mathrm{FH}$ mutation carriers with renal cancer the mean age at diagnosis was 43 (range: 11-90) years. The course of the disease was aggressive and approximately two thirds presented with stage III/IV disease at the time of diagnosis. In contrast to other forms of hereditary renal cancer, both unifocal and unilateral presentations are common $(5,6,16,18,23)$.

In our study group, we have recommended renal ultrasound and magnetic resonance imaging (MRI) at the age of 20 , followed by annual MRI and semi-annual ultrasound examinations. Based on the data of Vahteristo et al. (32), surveillance should be recommended for all $\mathrm{FH}$ germline mutation carriers. As renal cancer in HLRCC has occurred before age 20 , it has been proposed that screening should start at the age of 18 or even 5 years $(32,33)$. Prospective studies should provide data for evaluation of current policies. Due to the aggressive nature of HLRCC renal carcinoma, treatment should probably be prompt and include total nephrectomy. Experience with nephron-sparing surgery is limited (17).

\section{Conclusion}

This study generated additional data on the clinical and genetic variability of HLRCC and allowed comparison of $\mathrm{FH}$ mutation-positive with mutation-negative families. Genomic deletions can be detected by complementing MLPA testing to DNA se- 
quence analysis. FH mutations were found in all families with cutaneous leiomyomas; these skin lesions seem to be a typical and highly penetrant feature of the syndrome. Uterine leiomyomas often lead to severe symptoms, which warrant counseling about family planning and treatment strategies. Renal cell cancer is infrequent but aggressive and may occur at a very young age. We propose frequent renal imaging with MRI and ultrasound. Multi-centred studies providing longterm follow-up data will lead to further development of HLRCC management.

\section{Supporting Information}

The following Supporting information is available for this article: Table S1. PCR conditions. Fastmix: GeneAmp Fast PCR mastermix (Applied Biosystems), 360 MIX: Amplitaq Gold 360 Mastermix (Applied Biosystems). Additional Supporting information may be found in the online version of this article. Please note: Wiley-Blackwell Publishing is not responsible for the content or functionality of any supplementary materials supplied by the authors. Any queries (other than missing material) should be directed to the corresponding author for the article.

\section{Acknowledgements}

We are grateful to Joan Paterson, consultant in clinical genetics, Addenbrookes Hospital, Cambridge, United Kingdom for providing clinical information. MAMvS is supported by the Dutch Cancer Society (KWF) grant UM2009-4352 and the GROW School for Oncology and Developmental Biology

\section{References}

1. Launonen V, Vierimaa $\mathrm{O}$, Kiuru $\mathrm{M}$ et al. Inherited susceptibility to uterine leiomyomas and renal cell cancer. Proc Natl Acad Sci USA 2001: 98: 3387-3392.

2. Tomlinson IP, Alam NA, Rowan AJ et al. The Multiple Leiomyoma Consortium. Germline mutations in $\mathrm{FH}$ predispose to dominantly inherited uterine fibroids, skin leiomyomata and papillary renal cell cancer. Nat Genet 2002: 30: 406-410.

3. Reed WB, Walker R, Horowitz R. Cutaneous leiomyomata with uterine leiomyomata. Acta Dermatovenereol 1973: 53: 409-416.

4. Lehtonen HJ, Kiuru M, Ylisaukko-oja SK et al. Increased risk of cancer in patients with fumarate hydratase germline mutation. J Med Genet 2006: 43: 523-526.

5. Toro JR, Nickerson ML, Wei M-H et al. Mutations in the fumarate hydratase gene cause hereditary leiomyomatosis and renal cell cancer in families in North America. Am J Hum Genet 2003: 73: 95106. 
6. Alam NA, Barclay E, Rowan AJ et al. Clinical features of multiple cutaneous and uterine leiomyomatosis. An underdiagnosed tumor syndrome. Arch Dermatol 2005: 14: 199-206.

7. Wei M-H, Toure O, Glenn GM et al. Novel mutations in FH and expansion of the spectrum of phenotypes expressed in families with hereditary leiomyomatosis and renal cell cancer. J Med Genet 2006: 43: $18-27$.

8. Stewart L, Glenn GM, Stratton P et al. Association of germline mutations in the fumarate hydratase gene and uterine fibroids in women with hereditary leiomyomatosis and renal cell cancer. Arch Dermatol 2008: 144: 1584-1592.

9. Makino $T$, Nagasaki A, Furuichi $M$ et al. Novel mutation in a fumarate hydratase gene of a Japanese patient with multiple cutaneous and uterine leiomyomatosis. J Dermatol Sci 2007: 48: 151-153.

10. Soni SS, Gowrishankar S, Adikey GK et al. Hereditary leiomyomatosis with renal cell carcinoma. Indian J Dermatol Venereol Leprol 2008: 74: 63-64.

11. Deschauer M, Gizatullina Z, Schulze A et al. Molecular and biochemical investigations in fumarase deficiency. Mol Genet Metab 2006: 88: 146-152.

12. Ahvenainen $\mathrm{T}$, Lehtonen $\mathrm{HJ}$, Lehtonen $\mathrm{R}$ et al. Mutation screening of fumarate hydratase by multiplex ligationdependent probe amplification: detection of exonic deletion in a patient with leiomyomatosis and renal cell cancer. Cancer Genet Cytogenet 2008: 183: 83-88.

13. Badeloe S, van Geel M, van Steensel MAM et al. Diffuse and segmental variants of cutaneous leiomyomatosis: novel mutations in the fumarate hydratase gene and review of literature. Exp Dermatol 2006: 15: 735-741.

14. Badeloe S, Bladergroen RS, Jonkman MF et al. Hereditary multiple cutaneous leiomyoma resulting from novel mutations in the fumarate hydratase gene. J Dermatol Sci 2008: 51: 139-143.

15. Badeloe S, van Spaendonck-Zwarts KY, van Steensel MAM et al. Wilms tumour as a possible early manifestation of hereditary leiomyomatosis and renal cell cancer? Br J Dermatol 2009: 160: 707709.

16. Merino MJ, Torres-Cabala $C$, Pinto $P$ et al. The morphologic spectrum of kidney tumors in hereditary leiomyomatosis and renal cell carcinoma (HLRCC) syndrome. Am J Surg Pathol 2007: 31: 1578-1585.

17. Grubb RL III, Franks ME, Toro J et al. Hereditary leiomyomatosis and renal cell cancer: a syndrome associated with an aggressive form of inherited renal cancer. J Urol 2007: 177: 2074-2079.

18. Alam NA, Rowan AJ, Wortham NC et al. Genetic and functional analyses of FH mutations in multiple cutaneous and uterine leiomyomatosis, hereditary leiomyomatosis and renal cell cancer, and fumarate hydratase deficiency. Hum Mol Genet 2003: 12: 1241-1252.

19. Matyakhina L, Freedman RJ, Bourdeau I et al. Hereditary leiomyomatosis associated with bilateral, massive, macronodular adrenocortical disease and atypical Cushing syndrome: a clinical and molecular genetic investigation. J Clin Endocrinol Metab 2005: 9: 3773-3779.

20. Carvajal-Carmona LG, Alam NA, Pollard PJ et al. Adult Leydig-cell tumors of the testis caused by germline fumarate hydratase mutations. J Clin Endocrinol Metab 2006: 91: 3071-3075.

21. Lamba M, Verma S, Prokopetz R et al. Multiple cutaneous and uterine leiomyomas associated with gastric gist. J Cutan Med Surg 2005: 9: 332-335.

22. Ylisaukko-oja SK, Kiuru M, Lehtonen $\mathrm{HJ}$ et al. Analysis of fumarate hydratase mutations in a population-based series of early onset uterine leiomyosarcoma patients. Int J Cancer 2006: 119: 283-287.

23. Chuang GS, Martinez-Mir A, Geyer A et al. Germline fumarate hydratase mutations and evidence for a founder mutation underlying multiple cutaneous and uterine leiomyomata. J Am Acad Dermatol 2005: 52: 410-416.

24. Chan I, Wong T, Martinez-Mir A et al. Familial multiple cutaneous and uterine leiomyomas associated with papillary renal cell cancer. Clin Exp Dermatol 2005: 30: 75-78.

25. Heinritz W, Paasch $U$, Sticherling $M$ et al. Evidence for a founder effect of the germline fumarate hydratase gene mutation R58P causing hereditary leiomyomatosis and renal cancer (HLRCC). Ann Hum Genet 2008: 72: 35-40. 
26. Bayley J-P, Launonen V, Tomlinson IPM. The FH mutation database: an online database of fumarate hydratase mutations involved in the MCUL (HLRCC) tumor syndrome and congenital fumarase deficiency. BMC Med Genet 2008: 9: 20. (http://chromium.liacs.nl/LOVD2/SDH/home.php?select $\mathrm{db}=\mathrm{FH}$ ). Last accessed on June 26th 2010.

27. Huter $E$, Wortham NC, Hartschuh $W$ et al. Single base mutation in the fumarate hydratase gene leading to segmental cutaneous leiomyomatosis. Acta Derm Venereol 2008: 88: 63-65.

28. Chuang GS, Martinez-Mir A, Engler DE et al. Multiple cutaneous and uterine leiomyomata resulting from missense mutations in the fumarate hydratase gene. Clin Exp Dermatol 2005: 31: 118-121.

29. Kiuru M, Lehtonen R, Arola J et al. Few FH mutations in sporadic counterparts of tumor types observed in hereditary leiomyomatosis and renal cell cancer families. Cancer Res 2002: 62: 4554-4557.

30. Badeloe S, Frank J. Clinical and molecular genetic aspects of hereditary multiple cutaneous leiomyomatosis. Eur J Dermatol 2009: 19: 545-551.

31. Amant F, Coosemans A, Debiec-Rychter $M$ et al. Clinical management of uterine sarcomas. Lancet Oncol 2009: 10: 1188-1198.

32. Vahteristo $P$, Koski TA, N"a"atsaari $L$ et al. No evidence for a genetic modifier for renal cancer risk in HLRCC syndrome. Fam Cancer 2010: 9: 245-251.

33. Alrashdi I, Levine S, Paterson J et al. Hereditary leiomyomatosis and renal cell carcinoma: very early diagnosis of renal cancer in a paediatric patient. Fam Cancer 2010: 9: 239-243.

34. Martinez-Mir A, Glaser B, Chuang GS et al. Germline fumarate hydratase mutations in families with multiple cutaneous and uterine leiomyomata. J Invest Dermatol 2003: 118: 876-880. 



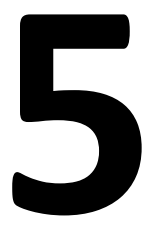

\section{Wilms tumor in hereditary} leiomyomatosis and renal cell cancer

Badeloe S, van Spaendonck-Zwarts KY, van Steensel MA, van Marion AM, van Essen AJ, Jonkman MF, Steijlen PM, Poblete-Gutiérrez P, van Geel M, Frank J.Wilms tumor as an early manifestation of hereditary leiomyomatosis and renal cell cancer? Br J Dermatol. 2009 Mar; 160(3): 707-9. 


\section{Introduction}

Hereditary leiomyomatosis and renal cell cancer (HLRCC) (OMIM 605839) is an autosomal dominantly inherited tumor predisposition syndrome, characterized by cutaneous and uterine leiomyoma and renal cell cancer (RCC) (1). It is caused by heterozygous mutations in the fumarate hydratase $(F H)$ gene that codes for the enzyme fumarate hydratase $(\mathrm{FH})$ and catalyzes the conversion of fumarate to malate in the Krebs cycle $(1,2)$. The exact mechanism by which improper FH function leads to tumor formation is still unclear. However, recent studies suggest a pseudohypoxic drive as a possible link between $\mathrm{FH}$ dysfunction, the von Hippel-Lindauhypoxia-inducible factor (HIF) pathway, and cancer development (3). To date, only four different types of RCC have been observed in HLRCC: papillary type 2 RCC; collecting duct carcinoma; and RCC with oncocytic and with clear cell foci (4).

\section{Case and methods}

A 31-year-old white woman (individual III-2 in Fig. 1a) had developed progressive cutaneous (Fig. 1b) and uterine leiomyoma since the age of 25 years. Her family history revealed cutaneous leiomyoma in her father and sister and uterine leiomyoma in her paternal aunt and grandmother (Fig. 1a). Interestingly, she had been diagnosed at the age of 2 years with a single Wilms tumor (WT) that revealed two solitary metastases in the left and right lung and was successfully treated with surgery and chemotherapy, consisting of dactinomycin and vincristine. The occurrence in this patient of cutaneous and uterine leiomyoma with a kidney cancer was strongly suggestive of HLRCC. Following informed consent, we therefore performed mutation analysis in the $\mathrm{FH}$ gene as previously described in detail (5).

\section{Results and discussion}

By direct sequencing we detected a heterozygous G-to-A transition at nucleotide position 1189 in exon 8 of the $F H$ gene (c.1189G $>A$ ), changing a glycine to an arginine residue, designated p.Gly397Arg (G397R) (Fig. 1C). This mutation was previously described elsewhere as G354R, based on nucleotide numbering excluding the first 129 nucleotides of exon 1 (6). To date, the manifestation of a WT in an individual who carried a heterozygous FH mutation and exhibited cutaneous and uterine leiomyoma has, to the best of our knowledge, not been reported. We propose that this tumor did not develop by chance in our patient but rather represents a novel 


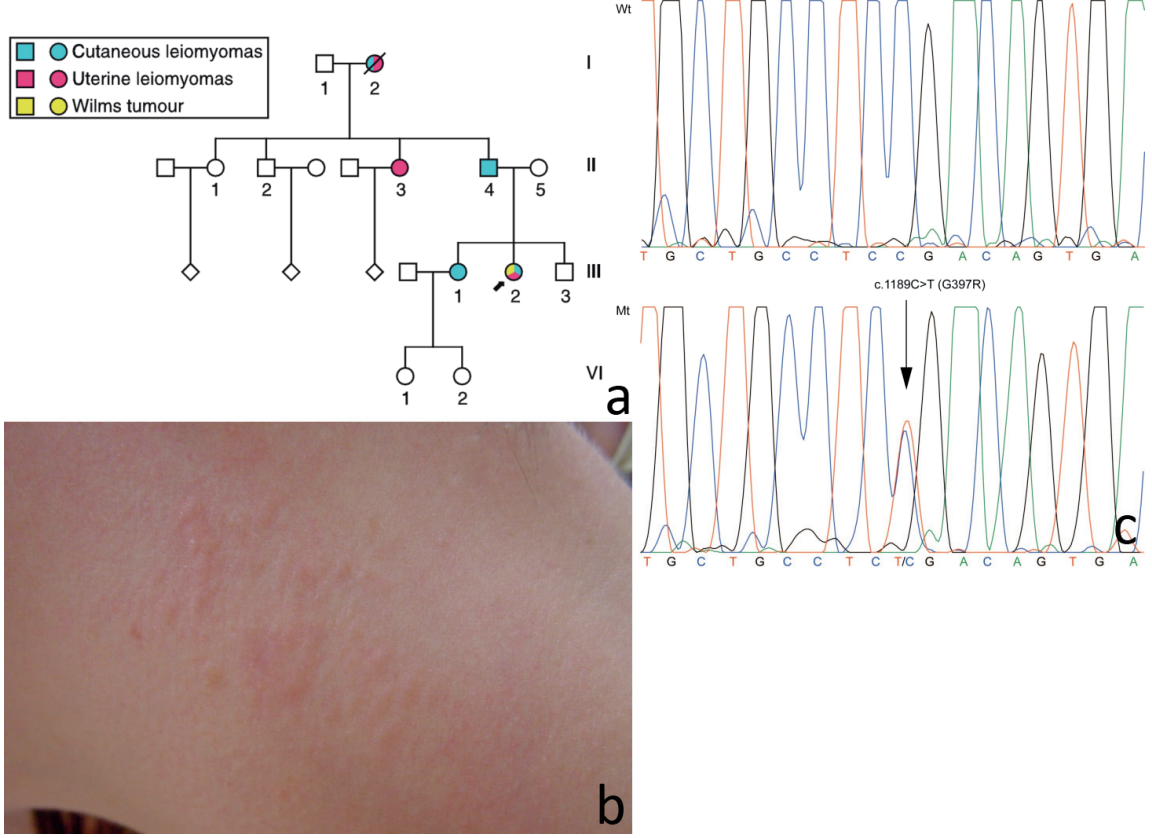

Figure 1 (a) In the pedigree, the index patient (individual III-2) is depicted with an arrow. (b) Firm skincoloured to erythematous papules in the neck of the index patient. (c) Results of mutation analysis in individual III-2 (Mt). Missense mutation G397R in exon 8 of the $\mathrm{FH}$ gene, consisting of a heterozygous Gto-A transition (arrow; lower panel), compared with the wild-type (Wt) sequence of a control individual (top panel). Note that the mutation is depicted in reverse complement $\left(3^{\prime}-5^{\prime}\right)$ orientation.

type of kidney cancer in the context of HLRCC. WT is a renal malignancy of childhood that apparently originates from nephrogenic remnants (7). It occurs in both a sporadic (98\%) and a familial (2\%) form. In the latter, autosomal dominant transmission with variable penetrance and expressivity has been reported. Although the molecular pathogenesis of WT is not yet well understood, heterogeneous genetic events are required for initial transformation of primarily undifferentiated kidney cells, eventually leading to cancer formation. In support of this notion, different genes and chromosomal loci have been associated with the manifestation of this tumor, including WT1, WTX, CTNNB1, and 11p15.5, 1p, 2q, 7p, 9q, 14q, 16q, 17q and 22. Somatic mutations in WT1, WTX or CTNNB1 can be detected in approximately one-third of WTs but the genetic alterations underlying the remaining twothirds remain elusive (8). This suggests a more complex orchestration of molecular events involved in the pathogenesis of WT than that derived from Knudson's second-hit model for malignant tumor formation (9). In line with this notion, it was recently demonstrated that the WNT/ $\beta$-catenin pathway is involved in WT devel- 
opment (7). Furthermore, there is increasing evidence that the pseudohypoxic signaling pathway plays an important role in WT pathogenesis. Interestingly, Wagner et al. showed that WT1 expression is stimulated by activation of HIF-1a and Karth et al. detected coexpression of HIF-1a and vascular endothelial growth factor (VEGF) in WTs $(9,10)$. Changes in HIF protein expression apparently drive tumor formation in HLRCC. Loss of mitochondrial FH leads to an intracellular accumulation of fumarate. Elevated levels of fumarate have been shown to stabilize both HIF-1a and HIF-2a. HIF proteins are key regulators of the hypoxia response and exert their effects via transcriptional regulation of proteins involved in angiogenesis and uncontrolled cell proliferation, including VEGF, platelet-derived growth factor, endothelial growth factor receptor, glucose transporter protein 1 and transforming growth factoralpha. As such, HIF proteins are increasingly implicated in growth and metastasis of malignant tumors (11).

We therefore hypothesize that in our patient the development of WT is closely related to FH dysfunction, as suggested in Figure 2. Further, we propose that (i) $\mathrm{FH}$ mutations might be associated with the development of WT and (ii) WT constitutes an as yet unrecognized type of kidney malignancy in HLRCC. Unfortunately, no more tissue from the WT of our patient was available for genetic analysis. Therefore, desirable additional experiments such as, for example, loss of heterozygosity analysis and search for a somatic FH gene mutation in tumor tissue, could not be performed in this case. Hence, future molecular studies will be crucial to support our hypothesis and delineate the exact role of $\mathrm{FH}$ and HIF in these tumors. 


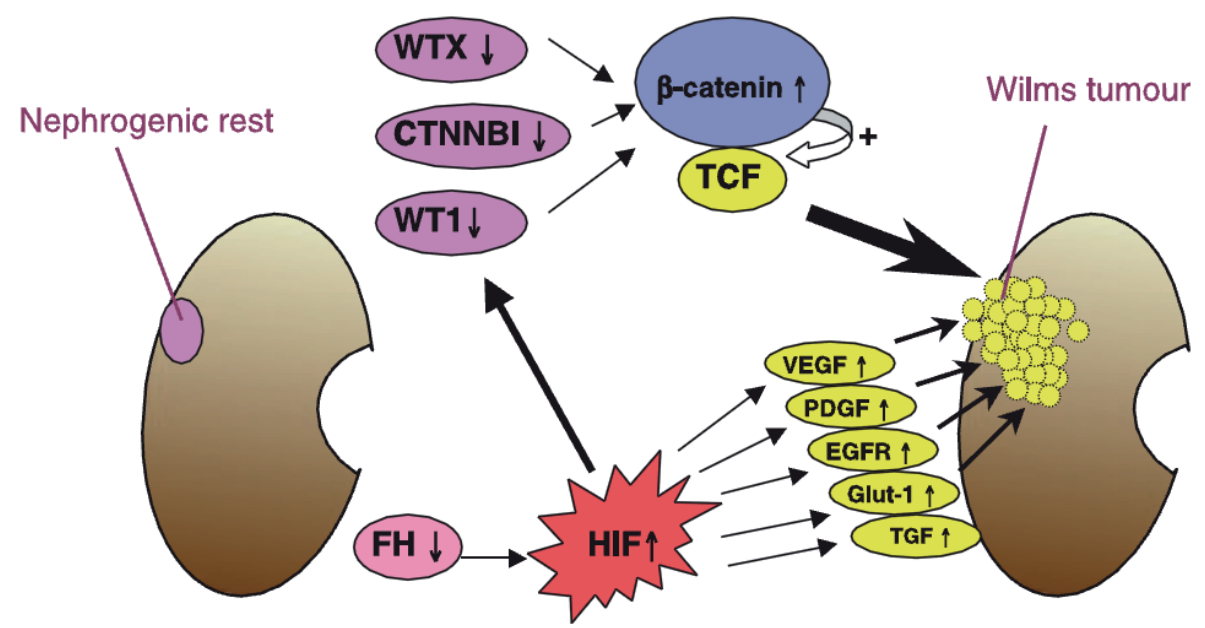

Figure 2. Hypothetical model for the association of Wilms tumor (WT) with FH mutations in hereditary leiomyomatosis and renal cell cancer. Undifferentiated nephrogenic remnants in the kidney undergo transformation as a result of genetic events in distinct, although connected pathways. In the $\beta$-catenin signaling pathway, mutations in WT1, WTX and CTNNB1 lead to induction of $\beta$-catenin in the nucleus, resulting in transcriptional activation of T-cell factor (TCF), which induces proliferation of precursor cells, eventually leading to WT formation. In the pseudohypoxic pathway, loss of function of mitochondrial fumarate hydratase (FH) leads to stabilization of members of the hypoxia-inducible factor (HIF) protein family, resulting in increased transcription of vascular endothelial growth factor (VEGF), platelet-derived growth factor (PDGF), endothelial growth factor receptor (EGFR), glucose transporter protein 1 (Glut-1) and transforming growth factor (TGF)-a, which can also lead to WT formation. WT1 might be the link between both pathways, considering that WT1 expression is regulated by activation of HIF.

\section{References}

1. Tomlinson IP, Alam NA, Rowan AJ et al. Multiple Leiomyoma Consortium. Germline mutations in FH predispose to dominantly inherited uterine fibroids, skin leiomyomata and papillary renal cell cancer. Nat Genet 2002; 30:406-10.

2. Toro JR, Nickerson ML, Wei $\mathrm{MH}$ et al. Mutations in the fumarate hydratase gene cause hereditary leiomyomatosis and renal cell cancer in families in North America. Am J Hum Genet 2003; 73:95106.

3. Isaacs JS, Jung YJ, Mole DR et al. HIF overexpression correlates with biallelic loss of fumarate hydratase in renal cancer: novel role of fumarate in regulation of HIF stability. Cancer Cell 2005; 8:143-53.

4. Lehtonen $\mathrm{HJ}$, Blanco I, Piulats JM et al. Conventional renal cancer in a patient with fumarate hydratase mutation. Hum Pathol 2007; 38:793-6.

5. Badeloe S, van Geel M, van Steensel MA et al. Diffuse and segmental variants of cutaneous leiomyomatosis: novel mutations in the fumarate hydratase gene and review of the literature. Exp Dermatol 2006; 15:735-41.

6. Alam NA, Rowan AJ, Wortham NC et al. Genetic and functional analyses of FH mutations in multiple cutaneous and uterine leiomyomatosis, hereditary leiomyomatosis and renal cancer, and fumarate hydratase deficiency. Hum Mol Genet 2003; 12:1241-52.

7. Schedl A. Renal abnormalities and their developmental origin. Nat Rev Genet 2007; 8:791-802. 
8. Ruteshouser EC, Robinson SM, Huff V. Wilms tumor genetics: mutations in WT1, WTX, and CTNNB1 account for only about one-third of tumors. Genes Chromosomes Cancer 2008; 47:461-70.

9. Wagner KD, Wagner N, Wellmann S et al. Oxygen-regulated expression of the Wilms' tumor suppressor Wt1 involves hypoxia-inducible factor-1 (HIF-1). FASEB J 2003; 17:1364-6.

10. Karth J, Ferrer FA, Perlman E et al. Coexpression of hypoxia-inducible-factor 1-alpha and vascular endothelial growth factor in Wilms' tumor. J Pediatr Surg 2000; 35:1749-53.

11. Bratslavsky G, Sudarshan S, Neckers L et al. Pseudohypoxic pathways in renal cell carcinoma. Clin Cancer Res 2007; 13:4667-71. 


\section{6}

\section{Discussion}

Based on:

DL Smit, S Badeloe, AR Mensenkamp, JP Bayley, ThM Starink, RJA van Moorselaar, LH Hoefsloot, J Frank, MAM van Steensel, FH Menko. Erfelijke leiomyomatosis (deel 1 en 2). Ned Tijdschr Dermatol Venereol. 2010;20: 114-9/333-4.

van Steensel MA, van Geel M, Badeloe S, Poblete-Gutiérrez P, Frank J. Molecular pathways involved in hair follicle tumor formation: all about mammalian target of rapamycin? Exp Dermatol. 2009;18(2):18591. 


\section{Hereditary cutaneous leiomyomatosis: An underdiagnosed tumor syndrome?}

Hereditary cutaneous leiomyomatosis is a rare tumor predisposition disorder that is characterized by multiple cutaneous leiomyomas, uterine leiomyomas and an increased risk of developing renal cancer. This syndrome is caused by heterozygous germline mutations in the fumarate hydratase $(F H)$ gene. The exact prevalence of hereditary cutaneous leiomyomatosis is not known. Worldwide, more than 250 families with this syndrome have been reported to date, including approximately 14 families from the Netherlands (1). However, the disease may be underdiagnosed, mainly due to the following reasons: (i) cutaneous leiomyomas can be inconspicuous and asymptomatic; many affected individuals will not undergo medical examination, (ii) kidney cancer occurs only in a small subset of patients with hereditary cutaneous leiomyomatosis and familial occurrence of renal cancer in this syndrome is rarely seen, (iii) there is still insufficient knowledge about the disease. The dermatologist can play a crucial role in recognizing cutaneous leiomyomas and, subsequently, establishing the diagnosis of hereditary cutaneous leiomyomatosis

\section{Clinical spectrum}

\section{Cutaneous leiomyomas}

Multiple cutaneous leiomyomas are the hallmark of the disease. To the best of our knowledge, all patients older than 40 years of age with hereditary cutaneous leiomyomatosis carrying a mutation in the $F H$ gene published to date, exhibit cutaneous leiomyomas (1). Moreover, all patients and families with multiple cutaneous leiomyomas referred for $\mathrm{FH}$ mutation analysis in the Dutch nationwide study indeed carried a heterozygous $\mathrm{FH}$ germline mutation, as shown in chapter 4 . The number, size and age of occurrence of the cutaneous tumors is highly variable, even within one family. The histopathological features of cutaneous leiomyomas are very characteristic and, thus, histological examination is essential to confirm the diagnosis of cutaneous leiomyomas.

Cutaneous leiomyomas frequently occur in a marked segmental phenotype. This phenotype reflects mosaicism, most likely according to the type 2 segmental manifestation as previously proposed by Happle. The type 2 segmental manifestation is the result of a heterozygous germline mutation in combination with postzygotic $\mathrm{LOH}$. To date, this genetic concept had only been confirmed in Hailey-Hailey disease. In chapter $\mathbf{3}$ we provide the first molecular support for the type 2 segmental manifestation in hereditary cutaneous leiomyomatosis. 


\section{Uterine leiomyomas}

Uterine leiomyomas in hereditary cutaneous leiomyomatosis are of early onset and can cause severe clinical symptoms. In the study in chapter $\mathbf{4}$ we found that more than $80 \%$ of female $F H$ mutation carriers developed uterine leiomyomas, mainly in early adulthood, and two thirds of them required surgery around the age of 35 years. This is in good concordance with the numbers from other groups who have reported that more than $90 \%$ of female $\mathrm{FH}$ mutation carriers develop uterine leiomyomas (2).

\section{Renal cancer}

Different types of renal cancer have been described in patients with hereditary cutaneous leiomyomatosis from 16 to 90 years of age (2). The overall frequency of developing renal cancer is unknown but has been estimated to be between 1 and $14 \%$ when looking at different studies (2). In the Dutch cohort described in chapter 4, two out of 35 patients (approximately 6\%) with hereditary cutaneous leiomyomatosis were diagnosed with a renal malignancy, showing that our findings are in agreement with those of other groups. The papillary type 2 renal cell carcinoma is most frequently observed in this syndrome, though collecting duct and clear cell types as well as oncocytic renal tumors have also been reported. In chapter 5, we describe the first case of a Wilms tumor (nephroblastoma) in a 2-year-old patient with genetically proven hereditary cutaneous leiomyomatosis. Since this is, to the best of our knowledge, the youngest patient described with hereditary cutaneous leiomyomatosis and a kidney tumor the question arises when one should start screening for these tumors in families at risk.

\section{Genetic heterogeneity}

To date, approximately 80 different mutations in the $F H$ gene have been reported in hereditary cutaneous leiomyomatosis. In over $80 \%$ of families suspected from hereditary cutaneous leiomyomatosis a pathogenic $\mathrm{FH}$ mutation could be detected using conventional techniques such as direct DNA sequencing analysis (1). More recently, whole gene deletions were found using multiplex ligation dependent probe amplification (MLPA) as reported in chapter $\mathbf{4}$. In chapter $\mathbf{2}$ and $\mathbf{4}$ we were able to confirm in patients from the Netherlands and other European countries the molecular heterogeneity of the disorder previously described by other groups. The $\mathrm{FH}$ sequence deviations detected comprise missense, nonsense, splice-site and frameshift mutations and a whole gene deletion, and the majority of these sequence deviations were private mutations. All reported mutations in the $\mathrm{FH}$ gene 
causing hereditary cutaneous leiomyomatosis or fumarate hydratase deficiency syndrome can be found in the $\mathrm{FH}$ mutation database: http://chromium.liacs.nl/LOVD2/SDH/home.php?select_db=FH.

There is no evident genotype-phenotype correlation in this syndrome. Even within one family patients with the same $F H$ mutation can exhibit different clinical symptoms. In individuals with the clinical symptoms of hereditary cutaneous leiomyomatosis and absence of an FH mutation one should keep in mind that in some instances the underlying genetic defect cannot be detected with the current molecular diagnostic techniques. Further, the possibility of a different gene causing the same phenotype should be considered. A functional in vitro assay for the measurement of FH activity has been developed to show $\mathrm{FH}$ dysfunction in individuals with undetectable $\mathrm{FH}$ germline mutation.

\section{Molecular mechanisms and signaling pathways}

The $\mathrm{FH}$ gene encodes for the eponymous enzyme $\mathrm{FH}$ that catalyzes the conversion of fumarate to malate in the Kreb's cycle. The $F H$ gene is thought to act as a tumor suppressor but the precise mechanism by which improper FH function leads to tumor formation is complex and has not yet been fully elucidated. However, recent studies suggest a pseudohypoxic drive in the pathogenesis of these tumors, with hypoxia inducible factor (HIF) as a key factor (3). Considering the function of FH in the Krebs cycle, FH dysfunction leads to accumulation of fumarate and, subsequently, to the stabilization of HIF. This occurs because fumarate acts as a competitive inhibitor of HIF prolyl hydroxylase (HPH) (4). Stabilization of HIF induces transcriptional activation of different anti-apoptotic and proliferative genes, such as vascular endothelial growth factor (VEGF), platelet derived growth factor (PDGF), endothelial growth factor receptor (EGFR), glucose transporter protein 1 (Glut-1), and transforming growth factor- $\alpha$ (TGF- $\alpha$ ) (3). Overexpression of these gene products is associated with increased vascularization, autocrine stimulation, uncontrolled cell growth, and increased cell survival. More insights into the pathomechanisms governing tumor formation in hereditary cutaneous leiomyomatosis could lead to the development of targeted therapies. This is further discussed later on in the therapy section.

\section{Towards international guidelines for diagnostic criteria}

The detection of a heterozygous mutation in the $\mathrm{FH}$ gene confirms the diagnosis of hereditary cutaneous leiomyomatosis at the genetic level. Clinical diagnostic criteria for hereditary cutaneous leiomyomatosis had not been defined previously. There- 
fore, we proposed such criteria and also defined indications for $F H$ mutation screening, as presented in table 1 in chapter 4.

Table 1. Proposed criteria for the clinical diagnosis of hereditary leiomyomatosis and renal cell cancer $(\text { HLRCC) })^{a}$

Major criterion

- Multiple cutaneous piloleiomyomas, histopathologically confirmed.

Minor criteria

- Surgical treatment for severely symptomatic uterine leiomyomas before age 40.

- Type 2 papillary renal cell carcinoma before age 40 .

- A first-degree ${ }^{b}$ family member who meets one of the above-mentioned criteria.

${ }^{a}$ The diagnosis is likely when a proband meets the major criterion. HLRCC may be suspected when a

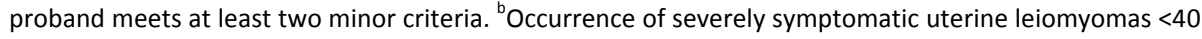
years in second-degree paternal family members may also be relevant.

In section $\mathbf{2 . 3}$ we described a patient with a cutaneous leiomyosarcoma and a positive family history for renal cancer. Mutation analysis did not reveal an FH mutation, thereby almost certainly excluding hereditary cutaneous leiomyomatosis. Still, it cannot be completely ruled out that in this case the causative $\mathrm{FH}$ mutation was not detectable with the current diagnostic techniques. However, considering the clinical criteria outlined above, a cutaneous leiomyosarcoma without additional cutaneous leiomyomas makes the diagnosis of hereditary cutaneous leiomyomatosis in this patient less likely.

\section{Current therapy and future possibilities}

\section{Cutaneous leiomyomas}

Cutaneous leiomyomas may cause cosmetic discomfort. Moreover, recurrent pain arising in these tumors can lead to serious complaints, disturb daily activities and reduce quality of life. Different treatment modalities for multiple cutaneous leiomyomas have been reported, including invasive (surgical) therapies and different pharmacological agents, all with variable success. Unfortunately, several patients do not respond to any of these treatment modalities. Hence, there is a need for additional therapeutic strategies.

\section{Botulinum toxin}

Botulinum toxin A (BTX-A) is broadly used for the treatment of focal muscle overactivity and spasticity (5). Recently, BTX-A also has been used for the treatment of 
different diseases associated with pain, including dystonia, tension-type headache, migraine headache, complex regional pain syndrome, peripheral neuropathy, postherpetic neuralgia, and trigeminal neuralgia (5-7). It is nowadays well established that BTX-A provides muscle relaxation lasting at least several months by inhibiting the release of acetylcholine $(\mathrm{ACH})$ at the neuromuscular junction (8). However, recent studies suggest that the mechanism providing pain relief is not only related to $\mathrm{ACH}$ inhibition but also to a reversible blockage of the parasympathetic nervous system. In line with this evidence, it has been shown that BTX-A leads to inhibition of neuropeptides release other than $\mathrm{ACH}$, including substance $\mathrm{P}$, glutamate, and calcitonine gene-related peptide, resulting in a direct analgesic effect $(6,7)$. Therefore, it has been suggested that BTX-A could be a useful treatment for pain in numerous dermatological conditions $(5,7)$. The direct analgesic effect and the effect on muscle relaxation of BTX-A could make this agent a a suitable therapy for pain in cutaneous leiomyomas.

\section{Rapamycin and rapalogs}

The increasing knowledge of the basic mechanisms of tumor formation in hair follicle tumors may be the starting point for the development of effective causal therapeutic strategies based on novel pathomechanistic insights. For example, in tuberous sclerosis complex (TSC) syndrome, another hair follicle tumor syndrome, preliminary trials suggest that rapamycin or its analogues (so-called rapalogs) may indeed halt disease progression to a certain degree (9). Rapamycin also has been shown to exert antitumoral activity through inhibition of HIF-1 alpha and VEGF in other tumors, such as hepatocellular carcinoma (10). Similarly, in hereditary cutaneous leiomyomatosis it is conceivable that rapamycin could have positive effects on tumor formation and development through inhibition of HIF and its downstream regulational targets.

\section{Uterine leiomyomas and renal cancer}

Symptomatic uterine leiomyomas can be treated with different surgical procedures. Understandably, the choice of treatment should be based on the severity of the symptoms, the effect on quality of life and the possible request to preserve fertility. Renal cancers in hereditary cutaneous leiomyomatosis are highly aggressive. Besides extensive surgical intervention there is a need for additional therapies, especially in metastatic tumors. Also in the field of hereditary renal cancer, the advances in understanding the molecular pathways involved in the etiopathogenesis of these tumors has led to the development of promising targeted therapies (11). 


\section{Screening guidelines}

Renal malignancies in hereditary cutaneous leiomyomatosis are associated with a poor prognosis. Still, there are no specific screening guidelines for this syndrome. The low overall risk of renal malignancies in hereditary cutaneous leiomyomatosis, the great variability regarding age of onset and the different possible forms of associated renal cancer, however, has led to a debate concerning the methods, frequency and initial age of screening for renal malignancies in this syndrome. We propose an initial ultrasound examination and magnetic resonance imaging (MRI) at the age of 20 years. This should be followed by annual MRI and bi-annual ultrasound examinations.

An annual gynecological examination should be considered in female patients with hereditary cutaneous leiomyomatosis.

\section{Dutch working group on hereditary cutaneous leiomyomatosis}

To gain more insight into the prevalence, pathogenesis and clinical features of the disease, the Dutch working group on hereditary cutaneous leiomyomatosis has been founded. Their main objective is to promote knowledge about this rare syndrome among physicians, scientists and patients and to stimulate clinical and basic research in the field. The working group comprises members from different medical disciplines and emphasizes the multidisciplinary approach and cooperation between regional hospitals, teaching hospitals and academic centers.

\section{Future challenges and proposal for further studies}

In spite of the increasing knowledge about hereditary cutaneous leiomyomatosis during the previous 8 years, a number of essential and stimulating questions still remain.

\section{Epidemiological studies}

The prevalence of hereditary cutaneous leiomyomatosis in and outside the Netherlands is unknown. Therefore, it would be advisable to collect clinical and genetic information on patients and families with this syndrome in a commonly accessible international database, such as the FH mutation database. Such a centralized collection of relevant information on patients with hereditary leiomyomatosis would enable transnational large cohort studies on this rare disease. By this we would gain more information on, e.g. the lifetime risk of developing renal cancer, contributing 
(genetic) risk factors for renal cancer, and how to improve management and surveillance. To realize these goals, it would be essential to institute such a database to heighten the awareness of physicians and scientists regarding this syndrome.

\section{Molecular genetic studies on mosaicism}

In chapter 3 we provide the first molecular support for the theory of the type 2 segmental manifestation in hereditary cutaneous leiomyomatosis. In order to fully prove this hypothesis futher studies using e.g. SNP (single nucleotide polymorphism) array techniques might be helpful, in particular to study in the same patient multiple segmental and nonsegmental leiomyomas to elucidate if the regions of $\mathrm{LOH}$ are identical in all segmental leiomyomas. Furthermore, LOH/SNP analysis in different patients should be compared in order to see if the same region of LOH could be repeatedly found in cutaneous leiomyomas from different patients, thereby suggesting the possibility of a region near $\mathrm{FH}$ which is more prone for $\mathrm{LOH}$ as a result of e.g. LINE repeats. Furthermore, these additional molecular studies might give an answer to the question why the segmental manifestation occurs so frequently in hereditary leiomyomatosis.

\section{Therapeutical studies}

Another important aspect is the improvement of current therapeutic strategies in hereditary cutaneous leiomyomatosis by, e.g. the development and clinical initiation of targeted therapies, such as rapamycin. In this context, a clinical trial on the topical application of rapamycin on cutaneous leiomyomas could be very interesting, particularly considering the fact that systemic rapamycin has a broad range of side-effects.

As mentioned before, administration of BTX-A in painful cutaneous leiomyomas might be helpful in hereditary cutaneous leiomyomatosis, especially in patients with leiomyomas covering large areas of the body, in which surgical approaches are not feasible.

\section{Spectrum of renal malignancies}

The spectrum of renal malignancies associated with hereditary cutaneous leiomyomatosis should be explored in more depth. Particularly, the possible link between Wilms tumor (WT) and FH mutations could be an important line of investigation. Additional molecular genetic and cell biological studies, which are currently underway in our laboratory, will be necessary to clarify if the development of WT may be related to $\mathrm{FH}$ dysfunction due to $\mathrm{FH}$ gene mutations. 


\section{References}

1. DL Smit, S Badeloe, AR Mensenkamp, et al.. Erfelijke leiomyomatosis (deel 1 en 2). Ned Tijdschr Dermatol Venereol. 2010;20: 114-9/ 333-4.

2. S. Badeloe, Frank J. Clinical and molecular genetic aspects of hereditary multiple cutaneous leiomyomatosis. Eur J Dermatol. 2009 Nov-Dec;19(6):545-5.

3. Bratslavsky G, Sudarshan S, Neckers L, Linehan WM. Pseudohypoxic pathways in renal cell carcinoma. Clin Cancer Res 2007; 13: 4667-71.

4. Isaacs JS, Jung YJ, Mole DR, et al. HIF overexpression correlates with biallelic loss of fumarate hydratase in renal cancer: novel role of fumarate in regulation of HIF stability. Cancer Cell. 2005 Aug;8(2):143-53.

5. Bhidayasiri R, Truong DD. Expanding use of botulinum toxin. J Neurol Sci 2005; 235: 1-9.

6. Jeynes LC, Gauci CA. Evidence for the use of botulinum toxin in the chronic pain setting--a review of the literature. Pain Pract 2008; 8: 269-76.

7. Klein AW. The therapeutic potential of botulinum toxin. Dermatol Surg 2004; 30: 452-5.

8. Brin MF. Botulinum toxin: chemistry, pharmacology, toxicity, and immunology. Muscle Nerve Suppl 1997; 6: S146-68.

9. Herry I, Neukirch C, Debray M P, et al. Dramatic effect of sirolimus on renal angiomyolipomas in a patient with tuberous sclerosis complex. Eur J Intern Med 2007: 18: 76-77.

10. Whittaker S, Marais R, Zhu AX. The role of signaling pathways in the development and treatment of hepatocellular carcinoma. Oncogene. 2010 Sep 9;29(36):4989-5005.

11. Cohen D, Ming Z. Molecular genetics of familial renal cell carcinoma syndromes. Clin Lab Med. 2005 Jun;25(2):259-77. 



\section{Summary}

Hereditary cutaneous leiomyomatosis is a rare autosomal dominantly inherited disease characterized by cutaneous leiomyomas, uterine leiomyomas and an increased risk for the development of renal cancer. This syndrome is nowadays referred to as multiple cutaneous and uterine leiomyomatosis syndrome (MCUL; OMIM 150800) or hereditary leiomyomatosis and renal cell cancer (HLRCC; OMIM 605839). The disease is caused by heterozygous germline mutations in the fumarate hydratase $(F H)$ gene. This gene encodes for the enzyme fumarate hydratase (FH) that plays an important role in the Krebs cycle.

In chapter 1 we provide a general introduction on hereditary cutaneous leiomyomatosis and review the current state of knowledge. We give an overview of clinical and genetic features of the disorder and discuss management and current therapeutic strategies.

Chapter $\mathbf{2}$ is subdivided in three sections and reflects the genetic heterogeneity encountered in hereditary cutaneous leiomyomatosis.

In 2.1 we describe six unrelated Dutch and Spanish patients/families with the clinical characteristics of hereditary cutaneous leiomyomatosis. We identified six distinct novel pathogenic $\mathrm{FH}$ mutations, including one missense and one nonsense mutation, two deletions and two splice-site mutations, designated p.Q142K, p.E404X, c.233delA, c.1238delA, c.378+1delG and c.555+1G>A. Of interest, a diffuse as well as a segmental phenotype could be observed. Our study indicates that the segmental phenotype is rather frequent in cutaneous leiomyomatosis and we identified at least one individual with a pronounced segmental phenotype in each family. In accordance with previous reports from other groups we suggest that the accentuated segmental phenotype superimposed on the ordinary diffuse trait resembles the type 2 segmental manifestation of hereditary cutaneous leiomyomatosis as previously proposed by Happle. This phenotype could be explained by a cutaneous mosaicism due to postzygotic loss of heterozygosity ( $\mathrm{LOH}$ ) that occurred at an early stage in embryogenesis in an individual heterozygous for an $\mathrm{FH}$ germline mutation.

In $\mathbf{2 . 2}$ we report on two newly ascertained unrelated Dutch and British patients with cutaneous leiomyomatosis. Mutation analysis revealed two previously unreported $\mathrm{FH}$ missense mutations, designated p.S334R and p.M368T. We provide distinct lines of evidence to support that these missense mutations are pathogenic. Furthermore, we show by computational analysis that both mutations involve functionally important regions of the encoded FH protein. 
In $\mathbf{2 . 3}$ we present a patient with a histologically confirmed cutaneous leiomyosarcoma whose brother died of metastatic renal cancer at young age. The familial occurrence of cutaneous leiomyosarcoma and renal cancer was suggestive of HLRCC. Mutation analysis did not reveal a mutation in the $F H$ gene, making HLRCC highly improbable. However, we cannot rule out that another yet unrecognized gene could give rise to both leiomyosarcoma and kidney cancer.

In chapter 3 we studied two patients with the clinical characteristics of a type 2 segmental manifestation of hereditary cutaneous leiomyomatosis. As said before, for this phenotype the theoretic molecular model proposed by Happle involves a heterozygous germline mutation in combination with postzygotic LOH. This theory, however, had not yet been investigated in hereditary cutaneous leiomyomatosis. By direct DNA sequencing and subsequent microsatellite analysis we detected two distinct heterozygous $\mathrm{FH}$ germline mutations and LOH in all segmentally arranged leiomyomas from both patients, which is in perfect concordance with Happle's theory. In one of the patients, we had the chance to study two segmentally arranged leiomyomas and found an identical region of $\mathrm{LOH}$ in both tumors. These findings for the first time provide molecular genetic support for the type 2 segmental manifestation in hereditary cutaneous leiomyomatosis.

In chapter 4 we present the first nationwide study on hereditary cutaneous leiomyomatosis in the Netherlands. We evaluated clinical and genetic data from all Dutch families suspected of HLRCC. We performed FH sequence analysis and multiplex ligation-dependent probe amplification. Families with similar $\mathrm{FH}$ mutations were examined for haplotype sharing. In 14 out of 33 families we identified 11 different pathogenic $F H$ germline mutations, including 4 novel mutations and 1 wholegene deletion. Clinical data from 35 mutation carriers revealed that cutaneous leiomyomas were present in all carriers older than 40 years. 11 out of 21 female mutation carriers underwent surgical treatment for symptomatic uterine leiomyomas at an average age of 35 years. Two $\mathrm{FH}$ mutation carriers had a medical history of renal cancer. Based on these findings we propose clinical diagnostic criteria, define the indications for $\mathrm{FH}$ mutation analysis and provide recommendations for patient management.

In chapter 5 we describe a 31-year-old female with progressive cutaneous and uterine leiomyomas since the age of 25 years. Her family history revealed both cutaneous and uterine leiomyomas. Interestingly, she had been diagnosed with a metastatic Wilms tumor (WT) at the age of two years. Mutation analysis in the $F H$ gene showed a heterozygous mutation, designated p.G397R, thereby confirming the diagnosis of hereditary cutaneous leiomyomatosis. At present, it is well known that patients with hereditary cutaneous leiomyomatosis have an increased risk of devel- 
oping renal cancer, most likely the papillary type 2 renal cell cancer. A WT, however, had not yet been reported in association with HLRCC. We hypothesize that in this patient the development of WT is closely related to FH dysfunction. Further, we propose that WT constitutes a hitherto unrecognized type of kidney malignancy in HLRCC and provide a hypothetic model that links FH mutations with the development of this renal tumor. 



\section{Samenvatting}

Erfelijke leiomyomatosis is een zeldzame autosomaal dominant overervende genodermatose, die wordt gekenmerkt door cutane leiomyomen, uterusleiomyomen en een verhoogde kans op het ontwikkelen van nierkanker. Dit tumorsydroom staat in de literatuur bekend als 'multiple cutaneous and uterine leiomyomatosis syndrome' (MCUL; OMIM 150800) en 'hereditary leiomyomatosis and renal cell cancer' (HLRCC; OMIM 605839). Erfelijke leiomyomatosis wordt veroorzaakt door heterozygote mutaties in het fumaraat hydratase $(F H)$ gen. Dit gen codeert voor het gelijknamige enzym fumaraat hydratase (FH), dat een belangrijke rol speelt in de citroenzuurcyclus.

In hoofdstuk 1 wordt een algemene introductie over erfelijke leiomyomatosis gegeven met een uiteenzetting van de beschikbare literatuur. Dit hoofdstuk geeft een overzicht van de klinische en genetische aspecten van dit tumorsyndroom met een bespreking van de therapeutische opties en adviezen ten aanzien van nacontrole en screenend onderzoek.

In hoofdstuk 2 worden de resultaten weergegeven van mutatieanalyse van het $F H$ gen bij patiënten en families met een klinische verdenking op erfelijke leiomyomatosis.

In $\mathbf{2 . 1}$ worden zes onverwante Nederlandse en Spaanse patiënten en hun families met klinische kenmerken van erfelijke leiomyomatosis beschreven. Mutatie-analyse toonde een zestal verschillende, nooit eerder gepubliceerde, pathogene mutaties in het $F H$ gen in deze families. Deze mutaties bestonden uit een missense en een nonsense mutatie, twee deleties en twee splice-site mutaties, respectievelijk p.Q142K, p.E404X, c.233delA, c.1238delA, c.378+1delG and c.555+1G>A. Opvallend was dat er zowel diffuse als segmentale fenotypes werden gezien bij deze patiënten en families. Deze studie toonde dat het segmentale fenotype opvallend vaak wordt gezien in erfelijke leiomyomatosis. In elke familie was minimaal 1 individu aanwezig met een segmentaal fenotype. Zoals ook beschreven door andere groepen, doet dit segmentale fenotype in deze autosomaal dominant overervende genodermatose denken aan de theorie van de type 2 segmentale manifestatie volgens Happle. Dit fenotype kan verklaard worden door een cutaan mozaïek dat ontstaat door een heterozygote kiembaan mutatie in combinatie met een postzygotisch verlies van heterozygotie (LOH) in een vroege embryonale fase.

In 2.2 worden twee onverwante Nederlandse en Britse patiënten met erfelijke leiomyomatosis beschreven. Mutatie-analyse toonde een tweetal nieuwe missense mutaties in het $F H$ gen, te weten p.S334R en p.M368T. Er wordt op verschillende 
manieren bewijs gegeven dat deze mutaties pathogeen zijn. Daarnaast wordt middels een computergestuurde analyse van het $\mathrm{FH}$ homologiemodel aangetoond dat beide mutaties betrekking hebben op belangrijke functionele gebieden van het enzym FH.

In $\mathbf{2 . 3}$ wordt een patiënt gepresenteerd met een cutaan leiomyosarcoom in de voorgeschiedenis, wiens broer overleden is aan een gemetastaseerd niercarcinoom op vroege leeftijd. De co-existentie van een cutaan leiomyosarcoom en nierkanker in één familie deed de diagnose HLRCC vermoeden. Mutatieanalyse toonde echter geen mutatie in het $\mathrm{FH}$ gen, hetgeen de diagnose HLRCC in deze familie minder waarschijnlijk maakt. De resultaten van dit onderzoek suggereren dat het familiair voorkomen van deze twee zeldzame tumoren op jonge leeftijd toeval zou kunnen zijn. Daarnaast zou het mogelijk kunnen zijn dat een ander nog onbekend gen een belangrijke rol speelt bij de ontwikkeling van het cutane leiomyosarcoom en nierkanker.

In hoofdstuk 3 wordt een studie gepresenteerd van twee patiënten met de klinische kenmerken van een type 2 segmentale manifestatie van erfelijke leiomyomatosis. Zoals eerder besproken zou de type 2 segmentale manifestatie, volgens de theorie van Happle, een combinatie van een heterozygote kiembaan mutatie met een postzygotische LOH zijn. Deze theorie is tot op heden bewezen voor een andere autosomaal dominante genodermatose; de ziekte van Hailey-Hailey. Echter bij erfelijke leiomyomatosis is deze theorie nooit eerder moleculair genetisch onderzocht. Middels mutatieanalyse detecteerden wij twee verschillende pathogene heterozygote kiembaan mutaties in het $\mathrm{FH}$ gen. Aanvullende microsattelietanalyse toonde LOH in alle segmentale leiomyomen van beide patiënten, hetgeen perfect aansluit bij de theorie van Happle. Daarnaast bestond bij één van beide patiënten de mogelijkheid om een tweetal segmentale leiomyomen te onderzoeken en in deze leiomyomen werd het identieke gebied van $\mathrm{LOH}$ gevonden. Deze bevindingen tezamen leveren het eerste bewijs voor de type 2 segmentale manifestatie volgens Happle in erfelijke leiomyomatosis.

In hoofdstuk 4 wordt de eerste nationale studie naar erfelijke leiomyomatosis in Nederland gepresenteerd. In deze studie werden de klinische en genetische data van alle Nederlandse patiënten met de klinische verdenking op erfelijke leiomyomatosis geëvalueerd. $F H$ mutatie-analyse werd verricht middels sequentie-analyse en multiplex ligatie-afhankelijke probe amplificatie (MLPA). Families met dezelfde $F H$ mutatie werden onderzocht op verwantschap middels haplotype-analyse. In 14 van de 33 families werden 11 verschillende mutaties in $F H$ gevonden, waaronder 4 nieuwe mutaties en één deletie van het gehele gen. Klinische data van $35 \mathrm{FH}$ mutatiedragers toonde dat cutane leiomyomen aanwezig waren in alle $\mathrm{FH}$ mutatiedragers boven de leeftijd van 40 jaar. Elf van de 21 vrouwen hadden een chirurgische 
interventie ondergaan voor symptomatische uterusleiomyomen op een gemiddelde leeftijd van 35 jaar. Twee $\mathrm{FH}$ mutatiedragers hadden nierkanker in hun voorgeschiedenis. Op basis van deze klinische en genetische data werden klinisch diagnostische criteria opgesteld, indicaties voor het verrichten van $\mathrm{FH}$ mutatie-analyse en aanbevelingen voor screening en nacontrole.

In hoofdstuk 5 wordt een 31-jarige vrouw beschreven met progressieve cutane en uterusleiomyomen vanaf de leeftijd van 25 jaar. Haar familieanamnese was positief voor cutane en uterusleiomyomen. Opmerkelijk was dat zij op 2-jarige leeftijd was behandeld aan een gemetastaseerde Wilms tumor (WT) van de nier. Mutatieanalyse van het $\mathrm{FH}$ gen toonde een heterozygote missense mutatie G397R, waardoor de diagnose erfelijke leiomyomatosis bevestigd kon worden. Het is bekend dat erfelijke leiomyomatosis een verhoogde kans geeft op het ontwikkelen van nierkanker, in het bijzonder het papillaire type 2 niercelcarcinoom. Echter een WT was nooit eerder beschreven in het kader van erfelijke leiomyomatosis. In dit hoofdstuk wordt gehypothetiseerd dat bij deze patiënt de ontwikkeling van de WT zeer nauw gerelateerd is aan de disfunctie van FH. Daarnaast wordt gepostuleerd dat de WT een nog onbekende vorm van nierkanker betreft in het klinische spectrum van erfelijke leiomyomatosis en dat $F H$ mutaties ook geassocieerd kunnen zijn bij de ontwikkeling van (sporadische) Wilms tumoren. Dit laatste wordt weergegeven in een theoretisch model. 



\section{List of abbreviations}

$\begin{array}{ll}\text { BTX-A } & \text { Botulinum toxin A } \\ \text { CK7 } & \text { Cytokeratin 7 } \\ \text { CRC } & \text { Collecting duct carcinoma } \\ \text { EGFR } & \text { Endothelial growth factor receptor } \\ \text { FH } & \text { Fumarate hydratase } \\ \text { FHD } & \text { Fumarate hydratase deficiency } \\ \text { Glut-1 } & \text { Glucose transporter protein 1 } \\ \text { HIF } & \text { Hypoxia inducible factor } \\ \text { HLRCC } & \text { Hereditary leiomyomatosis and renal cell cancer } \\ \text { HPH } & \text { HIF prolyl hydroxylase } \\ \text { LOH } & \text { Loss of heterozygosity } \\ \text { MCUL } & \text { Multiple cutaneous and uterine leiomyomatosis syndrome } \\ \text { MLPA } & \text { Multiplex ligation dependent probe amplification } \\ \text { PCR } & \text { Polymerase chain reaction } \\ \text { PDGF } & \text { Platelet derived growth factor } \\ \text { RCC } & \text { Renal cell cancer } \\ \text { SNP } & \text { Single nucleotide polymorphisms } \\ \text { TCA } & \text { Tricarboxylic acid } \\ \text { TGF- } \alpha & \text { Transforming growth factor- } \alpha \\ \text { TSC } & \text { Tuberous sclerosis complex } \\ \text { UEA-1 } & \text { Ulex europeaus agglutinin } \\ \text { VEGF } & \text { Vascular endothelial growth factor } \\ \text { VHL } & \text { Von Hippel-Lindau } \\ \text { WT } & \text { Wilms tumor } \\ & \end{array}$





\section{Curriculum vitae}

Sadhanna Badeloe werd op 2 juni 1980 geboren in Delfzijl. Zij groeide op in Gouda als oudste van drie dochters en behaalde daar in 1998 haar VWO diploma aan het Sint Anthoniuscollege. In 1998 startte zij haar studie geneeskunde aan de Universiteit van Utrecht. Tijdens de co-schappen dermatologie in het Sint Franciscus Gasthuis en het Erasmus Medisch Centrum in Rotterdam ontstond een grote interesse voor de dermatologie. Na het behalen van haar artsexamen in 2004 werkte zij gedurende 8 maanden als AGNIO interne geneeskunde in het Langeland ziekenhuis in Zoetermeer. Op 1 september 2005 startte zij de opleiding tot dermatoloog in het Academisch Ziekenhuis Maastricht. Na enkele maanden opleiding werd zij, onder andere door haar co-promotor Jorge Frank, geënthousiasmeerd voor wetenschappelijk onderzoek binnen de genodermatologie. Dit resulteerde in een combinatie van wetenschap en opleiding gedurende haar assistententijd in Maastricht. In 2006 werd zij door de co-assistenten van de Universiteit Maastricht uitgeroepen tot "Clinicus van het Jaar" in de categorie arts-assistent binnen het Academisch Ziekenhuis Maastricht. In 2010 ontving zij een mentorstipendium voor een stage kinderdermatologie in het Wilhelmina Kinderziekenhuis in Utrecht, onder leiding van kinderdermatoloog Suzanne Pasmans. Op 1 september 2010 rondde zij haar opleiding tot dermatoloog af, waarna zij toetrad tot de maatschap dermatologie in het Medisch Centrum Haaglanden te Den Haag. 


\section{List of publications}

Smit DL, Mensenkamp AR, Badeloe S, et al. Hereditary leiomyomatosis and renal cell cancer in families referred for fumarate hydratase germline mutation analysis. Clin Genet. 2011 Jan;79(1):49-59.

Smit DL, Badeloe S, Mensenkamp AR, et al. Erfelijke leiomyomatosis (deel 2): diagnostiek, beleid en onderzoek. Ned Tijdschr Dermatol Venereol. 2010;20:333-4

Smit DL, Badeloe S, Mensenkamp AR, et al. Erfelijke leiomyomatosis (deel 1): moleculaire en klinische achtergrond. Ned Tijdschr Dermatol Venereol. 2010;20:114-119

Badeloe S, Frank J. Clinical and molecular genetic aspects of hereditary multiple cutaneous leiomyomatosis. Eur J Dermatol. 2009 Nov-Dec;19(6):545-51

van Steensel M, van Geel M, Badeloe S, et al. Molecular pathways involved in hair follicle tumor formation: all about mammalian target of rapamycin? Exp Dermatol. 2009 Feb;18(2):185-91

S Badeloe, K van Spaendonck-Zwarts, M van Steensel, et al. Wilms tumour as an early manifestation of hereditary leiomyomatosis and renal cell cancer? $\mathrm{Br} J$ Dermatol. 2009 Mar, 160(3):707-9.

Badeloe S, Frank J. Hereditary multiple cutaneous leiomyomatosis. Atlas Genet Cytogenet Oncol Haematol. October2008. http://atlasgeneticsoncology.org/Kprones/HeredMultCutLeiomyolD10127.html

Badeloe S, van Geest AJ, van Marion AM, et al. Absence of fumarate hydratase mutation in a family with cutaneous leiomyosarcoma and renal cancer. Int J Dermatol. 2008 Nov;47 Suppl 1:18-20.

Badeloe S, Emans P, Jagtman B. Contactallergie bij orthopedische implantaten. Ned Tijdschr Dermatol Venereol 2008;18:226-229.

van Steensel MA, Badeloe S, Winnepenninckx V, et al. Granulomatous rosacea and Crohn's disease in a patient homozygous for the Crohn-associated NOD2/CARD15 polymorphism R702W. Exp Dermatol. 2008 Dec 1;17(12):1057-1058.

Badeloe S, Bladergroen RS, Jonkman MF, et al. Hereditary multiple cutaneous leiomyoma resulting from novel mutations in the fumarate hydratase gene. J Dermatol Sci. 2008 Aug;51(2):139-43. 
Badeloe S, van Geel M, Nagtzaam I, et al. Chanarin-Dorfman syndrome caused by a novel splice site mutation in ABHD5. Br J Dermatol. 2008 Jun;158(6):1378-80.

van Tuyll van Serooskerken AM, Habets JM, Badeloe S, et al. Porphyria cutanea tarda in pre-existent lupus erythematosus - is there an association? Int J Dermatol. 2007 Nov;46 Suppl 3:50-2.

Badeloe S, Henquet CJ, Nieuwhof CM, et al. Secondary erythromelalgia involving the ears probably preceding lupus erythematosus. Int J Dermatol. 2007 Nov;46 Suppl 3:6-8.

Badeloe S, van Geel M, van Steensel MA, et al. Van gen naar ziekte: leiomyomatosis cutis. Ned Tijdschr Geneeskd. 2007 Feb 3;151(5):300-4.

Poblete-Gutiérrez $\mathrm{P}$, Badeloe $\mathbf{S}$, Wiederholt $\mathrm{T}$, et al. Dual porphyrias revisited. Exp Dermatol. 2006 Sep;15(9):685-91.

Badeloe S, van Geel M, Poblete-Gutiérrez P, et al. Diffuse and segmental variants of cutaneous leiomyomatosis: novel mutations in the fumarate hydratase gene and review of the literature. Exp Dermatol. 2006 Sep;15(9):735-41.

Badeloe S, Verstraeten V, van Steensel MA. Twee broers met bultjes in het gelaat. Ned Tijdschr Dermatol Venereol 2006;16:216-18.

Badeloe S, Rübben A, van Marion A, et al. Molecular genetic support for type 2 segmental manifestation in hereditary cutaneous leiomyomatosis. (manuscript submitted)

\section{Oral presentations}

Winter ailments of the skin. Regional evening seminar for general practitioners, The Hague, January 2011.

Differential diagnosis of atopic eczema. Dutch Society for Pediatricians, Hilversum, September 2010.

Eosinophilc Fasciitis in a 10-year old girl. Regional evening seminar dermatology: southern Limburg, Maastricht, March 2010. 
Molecular genetic support for type 2 segmental manifestation in hereditary cutaneous leiomyomatosis. Annular meeting of the Dutch Society for Experimental Dermatology, Lunteren, February 2010.

Amyopathic dermatomyositis. Regional evening seminar dermatology: southern Limburg, Maastricht, May 2009.

Cutaneous leiomyosarcoma and renal cancer in one family. Regional evening seminar dermatology: southern Limburg, Maastricht, March 2008.

Genetic and metabolic studies in Chanarin-Dorfman syndrome. Annular meeting of the Dutch Society for Experimental Dermatology, Lunteren, February 2008.

Haem arginate therapy in acute intermittent porphyria. Lunch seminar Internal Medicine, Medical Centre Alkmaar, Alkmaar, August 2007.

Secondary erythromelalgia probably preceding lupus erythematosus. Regional evening seminar dermatology: southern Limburg, Maastricht, March 2007.

Molecualr genetic studies in diffuse and segmental manifestations of cutaneous leiomyomatosis. Annular meeting of the Dutch Society for Experimental Dermatology, Lunteren, February 2007.

Decubitus ulcers, Training seminar nurses, Academic Hospital Maastricht, Maastricht, September 2007.

Haem arginate therapy in acute intermittent porphyria. Regional evening seminar internal medicine: southern Limburg, Born, December 2006.

Novel mutations in the fumarate hydratase gene in diffuse and segmental forms of cutaneous leiomyomatosis, European Academy of Dermatology and Venereology, Rhodes, October 2006.

Two brothers with facial papules. Annual meeting of the Dutch Society of Dermatology and Venereology, Maastricht, June 2006.

Leiomyomatosis cutis associated with a Grawitz tumor. Regional evening seminar dermatology: southern Limburg, Maastricht, March 2006. 
Novel mutations in the fumarate hydratase gene in diffuse and segmental forms of cutaneous leiomyomatosis, Annular meeting of the German Society for Experimental Dermatology, March 2006. 



\section{Dankwoord}

Aan ontzettend veel mensen ben ik grote dank verschuldigd. Allereerst heel veel dank aan alle mensen die mij de laatste jaren gesteund hebben en een bijdrage hebben geleverd aan dit proefschrift in welke vorm dan ook.

Een aantal mensen wil ik graag persoonlijk bedanken.

Professor Steijlen, dank voor het in mij gestelde vertrouwen door mij aan te nemen voor de opleiding tot dermatoloog en mij daarnaast de ruimte te geven om mijn wetenschappelijke ambities te ontplooien. Ik waardeer het enorm dat u mij de kans heeft gegeven om dermatoloog te worden en te promoveren in Maastricht.

Jorge, vanaf het eerste begin heb jij me enthousiast gemaakt voor de wetenschap. Dank voor al je tijd, geduld, optimisme en enthousiasme. Ik heb van jou geleerd om gestructureerd te schrijven, mijn artikelen nauwgezet te herlezen en bij te schaven, met dit proefschrift als uiteindelijke resultaat. Ik kan je niet genoeg bedanken; je bent echt een fantastische begeleider en copromotor geweest.

Michel, ik ben ontzettend blij dat jij de afgelopen jaren met jouw nuchtere, kundige en kritische blik mee hebt gekeken naar de onderzoeken, resultaten en artikelen. Met elke vraag, hoe onnozel ook, kon ik bij jou terecht. Dank voor dit alles en dank dat je mijn copromotor wilde zijn.

Pamela, veel mensen weten niet dat het eigenlijk jouw oorspronkelijke idee was om onderzoek naar leiomyomen te doen in Maastricht en dat jij ook degene bent die mij 's avonds na het werk heeft leren "PCR'en" in het lab. Mijn eerste mutaties in FH heb ik met jou gevonden. Samen met Jorge heb jij de basis gelegd voor dit proefschrift, heel veel dank hiervoor.

Lieve Anne-Moon en Klara, de laatste jaren zijn jullie mijn Maastrichtse maatjes geweest. Ik kan jullie niet zeggen hoeveel jullie vriendschap voor mij betekent. Zoveel leuke momenten hebben we samen beleefd en mede dankzij jullie heb ik het 5 jaar "alleen" volgehouden in Maastricht. Dank voor alle gezellige momenten, steun en inspiratie. Dank dat jullie er altijd voor mij geweest zijn. Ik ben ontzettend blij dat jullie op "de grote dag" als paranimfen aan mijn zijde staan.

Toen ik als assistent dermatologie begon in Maastricht, hadden we de leukste en gezelligste assistentengroep van Nederland. En het mooie is dat dit alle jaren zo is 
gebleven. Ik wil alle collega-arts-assistenten met wie ik heb samengewerkt ontzettend bedanken voor de geweldige tijd in Maastricht. Nadia, veel dank voor alle inspirerende gesprekken. Jaap, dank voor alle mooie figuren en de zeer welkome "coffee breaks".

In het lab kon ik altijd rekenen op hulp en gezelligheid. Reno, heel veel dank voor alles. Met alle projecten kon ik rekenen op jouw steun. Als ik weer eens wat kwijt was, of stress had omdat mijn DNA bijna op was, jij was er altijd om mijn probleem weer op te lossen. Mirjam en Tijs, jullie ook veel dank voor al jullie hulp op het lab.

Alle stafleden in Maastricht, zeer veel dank voor jullie interesse, steun en het opleiden.

Alle dames van het secretariaat, dank voor jullie hulp, vriendelijke woorden en ondersteuning. Kim, dank voor het regelen van alle afspraken met Jorge en alles daar omheen. Annelies, dank voor alle formulieren, promotierompslomp en Jommekes. En Nicole, dank voor alle andere 100.000 dingen.

Collega's van de pathologie, in het bijzonder Arienne van Marion, dank dat ik altijd binnen mocht lopen om samen coupes te bekijken en histologische foto's te maken.

Collega's uit andere centra en coauteurs, dank voor het verwijzen van patiënten en dank voor het meewerken aan onderzoeken en artikelen.

Alle patiënten die hebben meegewerkt aan het onderzoek, dank voor uw interesse, geduld en vertrouwen.

Daarnaast dank aan alle vrienden en familie voor wie ik de afgelopen jaren niet altijd voldoende tijd had. Ik heb nu eindelijk tijd om het weer in te halen!

Lieve pap en mam, ik heb dit boekje opgedragen aan jullie, omdat jullie het verdienen. Dank dat jullie de meest geweldige ouders zijn die ik me maar kon wensen. Jullie hebben me altijd gesteund, gestimuleerd het beste uit mezelf te halen en bovenal altijd zoveel liefde gegeven. Dank. Ik hou van jullie.

Sunita en Priya, mijn zusjes en maatjes. Ik ben zo ontzettend blij dat ik weer bij jullie in de buurt woon. De kilometers tussen Maastricht en de Randstad hebben onze band gelukkig alleen nog maar sterker gemaakt. Dank dat ik altijd op jullie kan rekenen. Ik ben blij dat ik alle belangrijke momenten in mijn leven met jullie kan delen. Matties for life! 
Nel en Siew, 11 jaar geleden kreeg ik er een extra paar ouders bij. Dank voor al jullie interesse, steun en hulp en natuurlijk dank voor jullie geweldige jongste zoon!

Lieve Lucien, ik ben zo ontzettend blij met jou. De afgelopen 5 jaar was het niet altijd makkelijk om zo ver van jou te wonen. Jouw geduld, vertrouwen en liefde hebben er voor gezorgd dat we de tijd en afstand hebben overwonnen. Nu weer eindelijk samen in Den Haag. Zoals Floris op onze trouwdag heeft gesproken: "Laat het feest van ons leven maar beginnen en nooit meer op houden." Love you. 